2013-07-17

\title{
Injury Rates, Mechanisms, and Risk Factors For Injury in Youth Rock Climbers
}

Woollings, Kaikanani

Woollings, K. (2013). Injury Rates, Mechanisms, and Risk Factors For Injury in Youth Rock Climbers (Unpublished master's thesis). University of Calgary, Calgary, AB. doi:10.11575/PRISM/26534 http://hdl.handle.net/11023/839

Downloaded from PRISM Repository, University of Calgary 


\title{
UNIVERSITY OF CALGARY
}

Injury Rates, Mechanisms, and Risk Factors

For Injury in Youth Rock Climbers

by

Kaikanani Woollings

\begin{abstract}
A THESIS
SUBMITTED TO THE FACULTY OF GRADUATE STUDIES

IN PARTIAL FULFILMENT OF THE REQUIREMENTS FOR THE

DEGREE OF MASTER OF SCIENCE
\end{abstract}

FACULTY OF KINESIOLOGY

CALGARY, ALBERTA

JULY, 2013

C KAIKANANI WOOLLINGS 2013 


\begin{abstract}
Objective: To examine the incidence, mechanisms, and risk factors for injury in 11- to 19-year-old recreational and elite sport climbers and boulderers.

Methods: Cross-sectional study design. Participants were recruited from climbing facilities across Alberta, Canada, and 116 youths completed an anonymous questionnaire. Primary Outcome Measure: Climbing injury

Results: The incidence rate of climbing injury was 4.44 injuries/1000 climbing hours (95\% CI; 3.74, 5.23). Sprains and strains were the predominant injury type, and the primary mechanism of injury was repetitive overuse. Hands and fingers were the most commonly injured locations. Older age (15-19-year-olds), injury in a sport other than climbing, and preventive taping were shown to be risk factors for injury.

Conclusions: Climbing injury incidence rates are high in youth climbers. Findings are consistent with reported rates and details surrounding injury in adults. Modifiable potential risk factors warrant further investigation in order to inform development of future injury prevention strategies.
\end{abstract}




\section{Acknowledgements}

I would like to acknowledge all the members of the climbing community who made this project possible. I owe a debt of gratitude to the coaches, parents, young climbers, and gym owners who supported and helped facilitate this research. It has been a pleasure to share a mutual passion for climbing, and to discuss the exciting directions where this sport is headed.

There are many people who have helped to teach, encourage, and support me throughout this degree. I am especially grateful to Dr. Carolyn Emery for her guidance, patience, and for supporting me in carrying out a project of which I am passionate. I would also like to thank my thesis committee members Dr. Carly McKay, Dr. Jane Kang, and Dr. Winne Meeuwisse. I am eternally grateful for all of your direction and help. I have learned a great deal from every one of you, and this thesis would not have been possible without you.

I owe gratitude to everyone in the Sport Injury Prevention Research Centre. Thank you to my office mates for sharing your knowledge, advice, and positive energy. Your friendship and good humour has made this degree memorable, enjoyable, and rewarding.

Thank you to my family and friends who have supported to me through both the challenges that I have faced, as well as the successes. I appreciate the advice and encouragement, as well as the smiles and laughs that relieved my stress throughout this degree. You have kept me grounded, and made this research all the more meaningful for me. 
Finally, I would like to acknowledge that funding support for this research was provided by Alberta Innovates Health Solutions, and the Alberta Children's Hospital Research Institute for Child \& Maternal Health through the Talisman Energy Research Fund in Healthy Living and Optimizing Health Outcomes. 


\section{Dedication}

This thesis is dedicated to my wonderful family, Tina Fong, Don, and Fa-Linn Woollings. I am truly grateful for the unconditional love and support that you have always shown me, and I will always be thankful for your unwavering encouragement, reassurance, and guidance in all parts of my life. 


\section{Table of Contents}

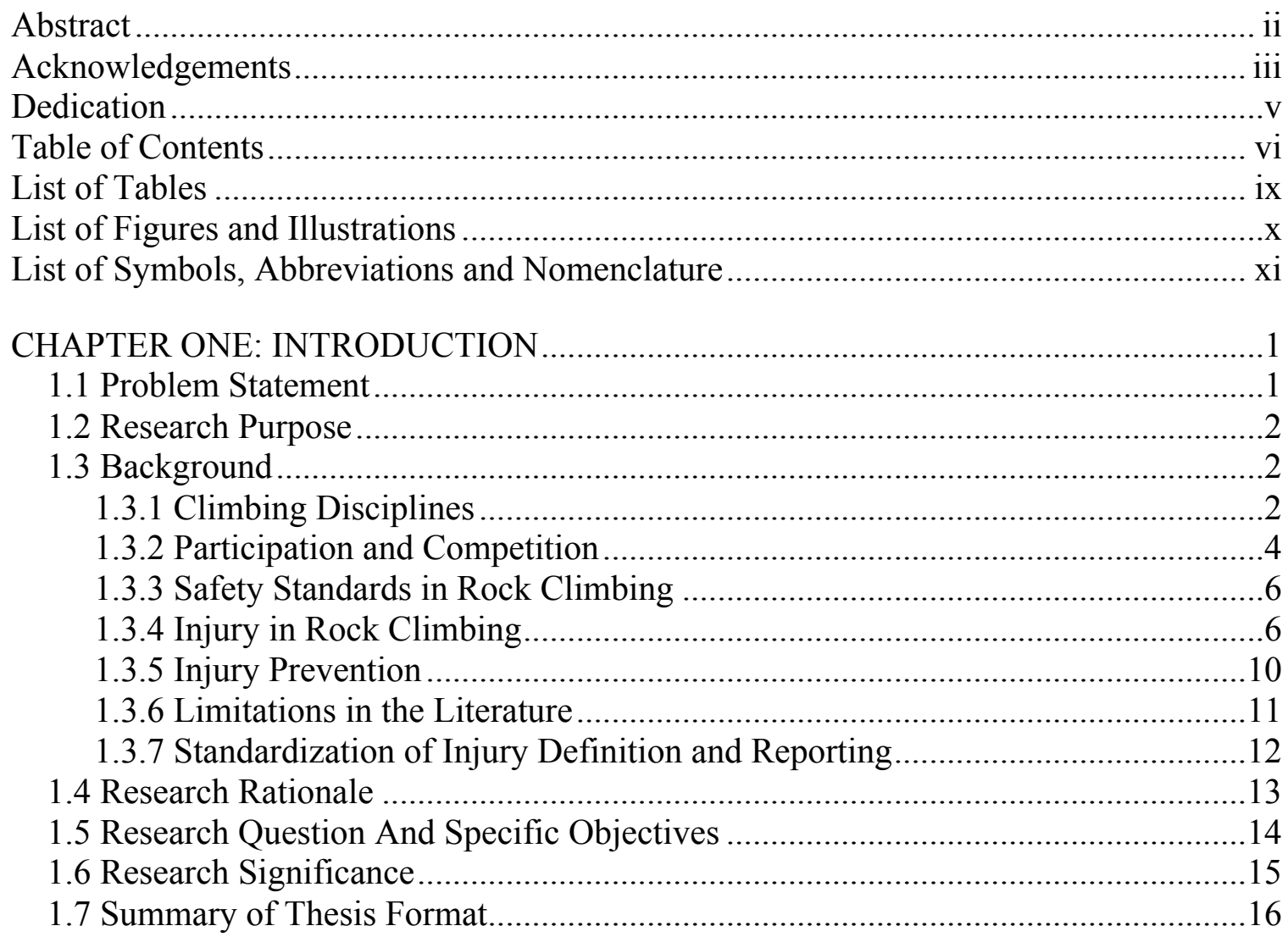

\section{CHAPTER TWO: RISK FACTORS FOR INJURY IN SPORT CLIMBING AND} BOULDERING: A SYSTEMATIC REVIEW OF THE LITERATURE ................18

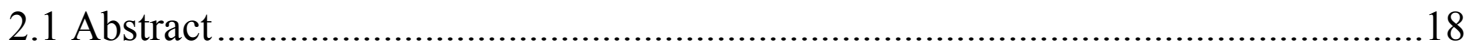

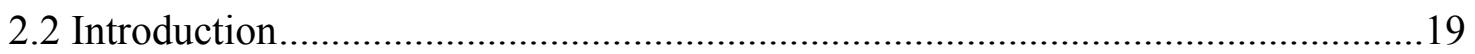

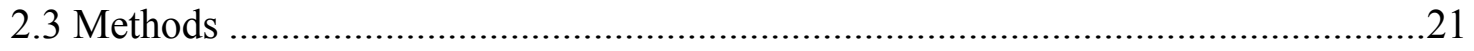

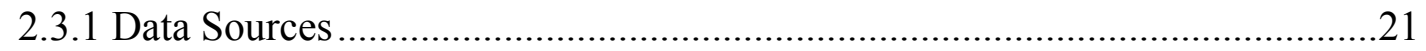

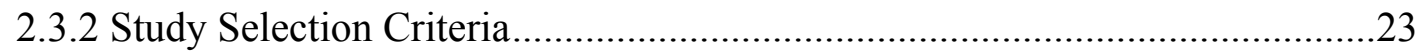

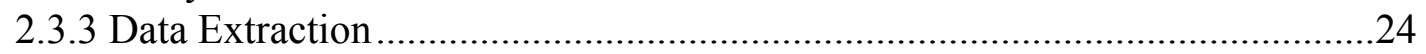

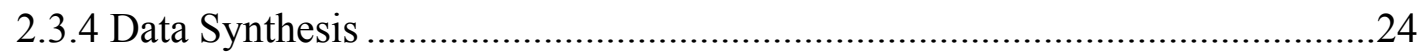

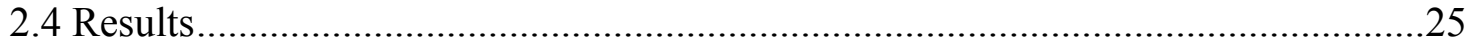

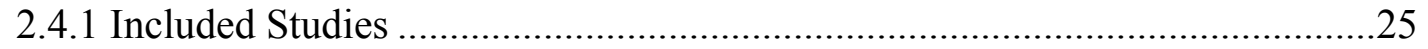

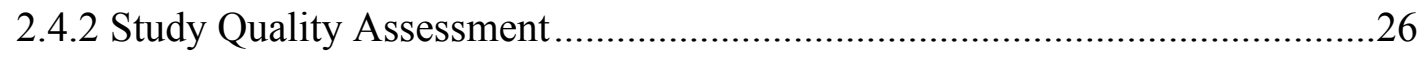

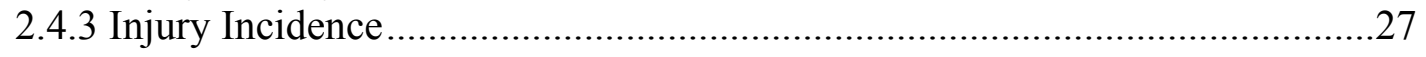

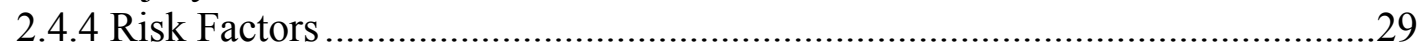

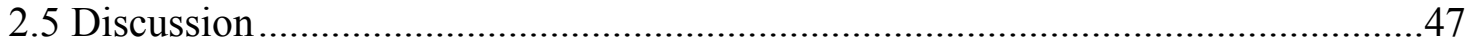

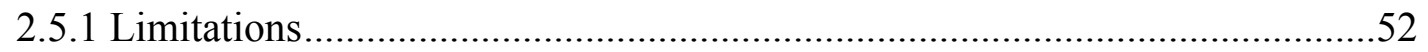

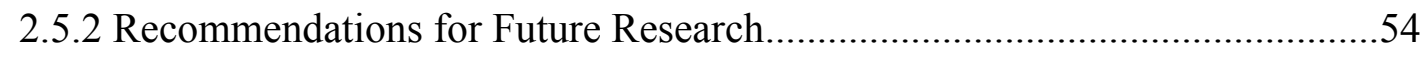

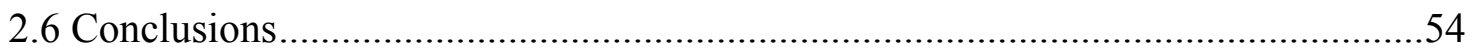




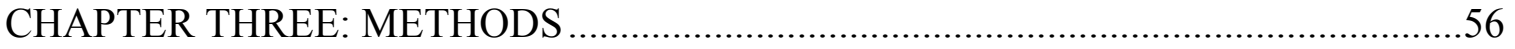

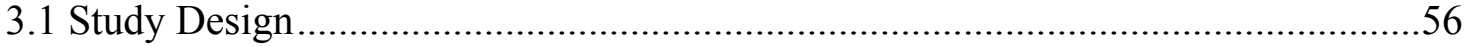

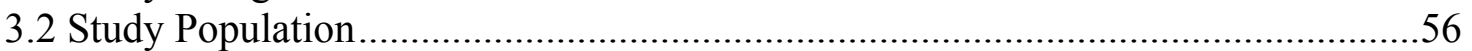

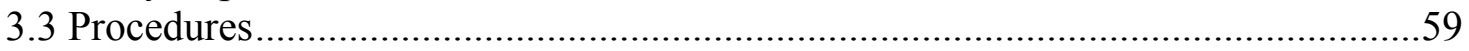

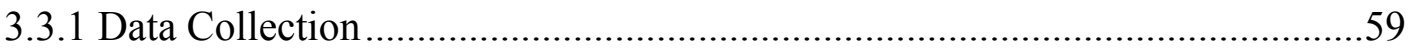

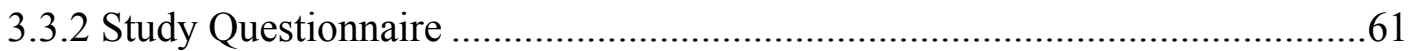

3.3.3 Outcome measures...............................................................................62

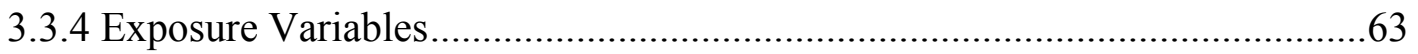

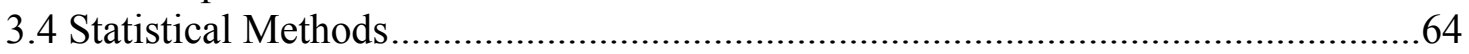

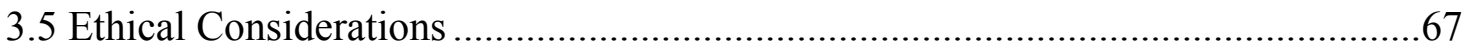

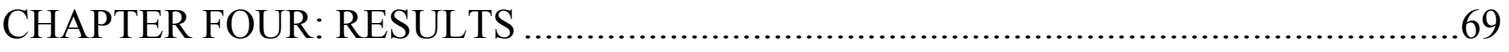

4.1 Study Participants ..........................................................................................69

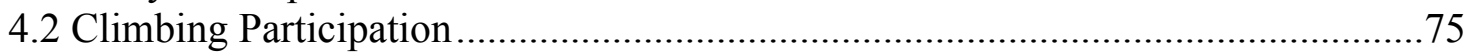

4.3 Physical Education (PE) and Other Sport Participation .......................................76

4.4 Climbing Injury Incidence Rates and Incidence Proportions ...................................77

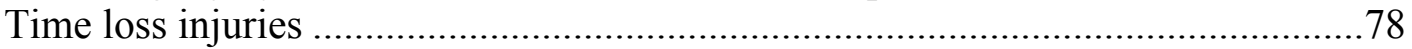

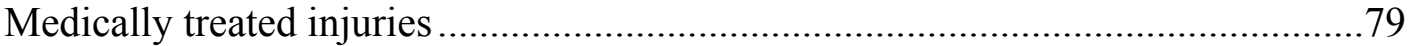

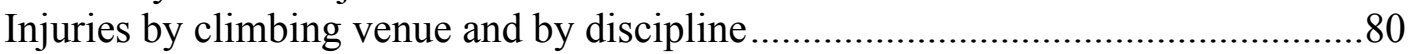

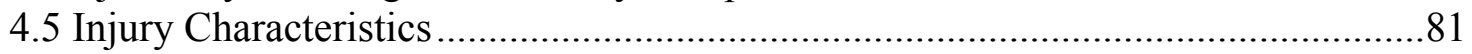

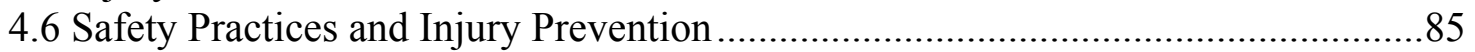

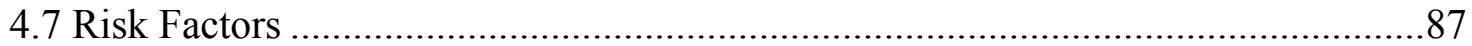

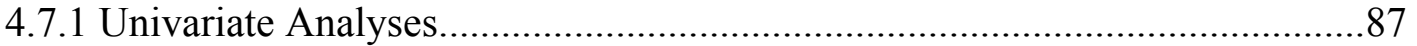

4.7.2 Multivariate Logistic Regression Analysis .....................................................92

4.8 Other Sport Injury ………………...................................................................

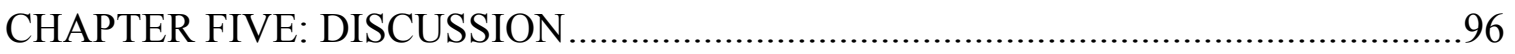

5.1 Participant Characteristics and Participation .........................................................96

5.2 Climbing Injury Incidence Rates and Incidence Proportions …………………......99

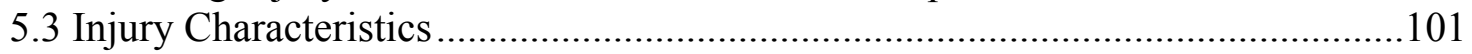

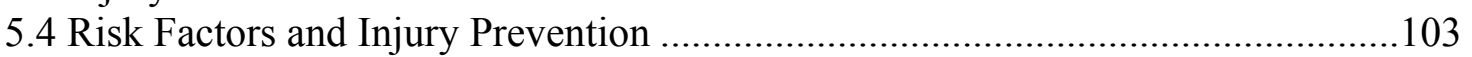

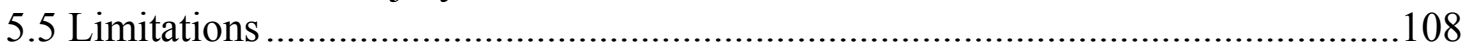

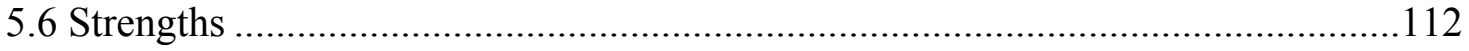

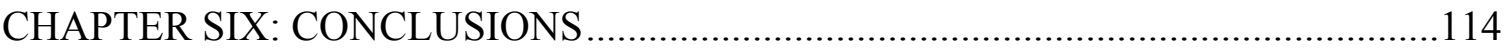

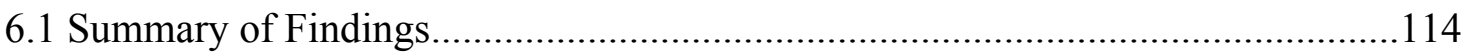

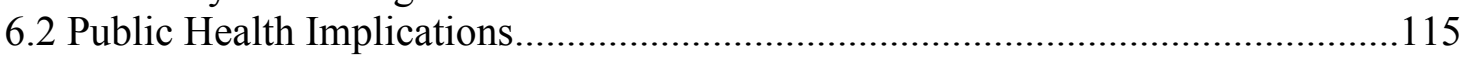

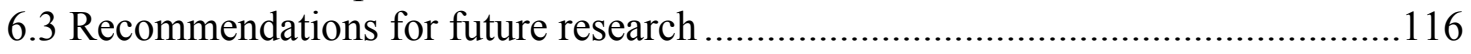

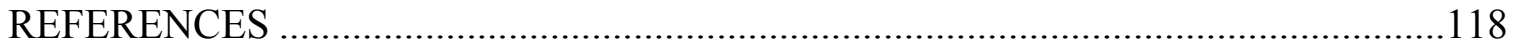

APPENDIX A: UIAA MEDICAL COMMISSION INJURY CLASSIFICATION FOR MOUNTAINEERING AND CLIMBING SPORTS …………………........126

APPENDIX B: UIAA MEDICAL COMMISSION COMPARISON OF THE RECOMMENDED CLIMBING GRADE METRIC SCALE FOR SCIENTIFIC STUDIES TO THE UIAA, FRENCH, AND AMERICAN GRADES ..................128 
APPENDIX C - SAMPLE SIZE CALCULATIONS. 130

APPENDIX D: PARENTAL CONSENT FORM ……………………………...........133

APPENDIX E: CHILD ASSENT FORM (UNDER 18-YEAR-OLDS) …………...........137

APPENDIX F: ADULT CONSENT FORM (18- \& 19-YEAR-OLDS) ...........................141

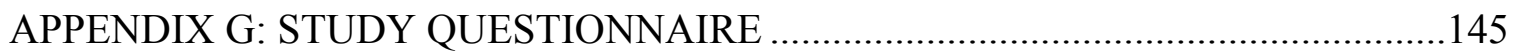




\section{List of Tables}

Table 2.1 Medical subject headings and text words used for article extraction 22

Table 2.2 Reported injury incidence proportions or incidence rates for all reviewed studies

Table 2.3 Studies examining risk factors for injury in sport climbing and bouldering

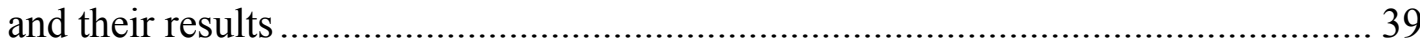

Table 4.1 Recruitment numbers at climbing facilities in each city............................... 70

Table 4.2 Baseline characteristics for elite and recreational climbers........................... 73

Table 4.3 Participation hours per week by venue for elite and recreational climbers ...... 76

Table 4.4 Other leisure time sport participation .................................................. 77

Table 4.5 Distribution of medical practitioner visits for all climbing injuries receiving

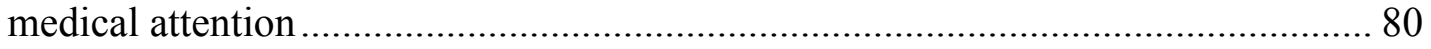

Table 4.6 Injury incidence proportion (IP) and incidence rate (IR) by venue ................. 80

Table 4.7 Injury incidence proportion (IP) by discipline........................................... 81

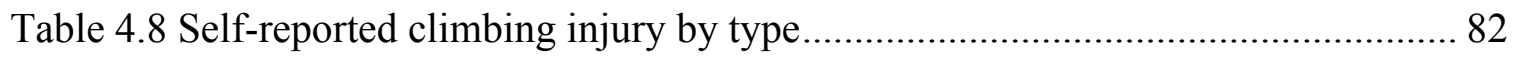

Table 4.9 Self-reported mechanism of climbing injury ........................................... 84

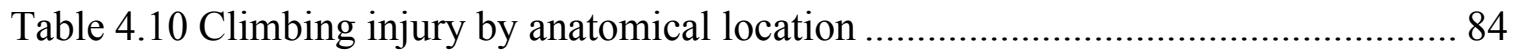

Table 4.11 Frequencies of reported sources of safety instruction ............................... 86

Table 4.12 Helmet use by proportion of outings for participants who wore helmets....... 86

Table 4.13 Crude and adjusted odds ratios from univariate models predicting

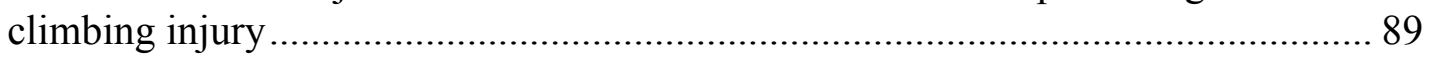

Table 4.14 Exploratory multivariate logistic regression predicting climbing injury ....... 93

Table 4.15. Distribution of medical practitioner visits for all non-climbing injuries receiving medical attention 


\section{List of Figures and Illustrations}

Figure 2.1 Study selection process based on inclusion and exclusion criteria ............... 26

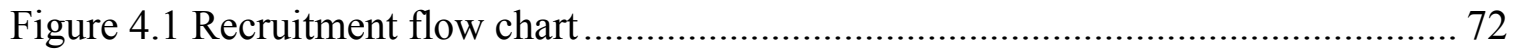

Figure 4.2 Distribution of participant scores on the Family Affluence Scale II.............. 74

Figure 4.3 Proportion of injuries incurring time loss from climbing in days ................. 79

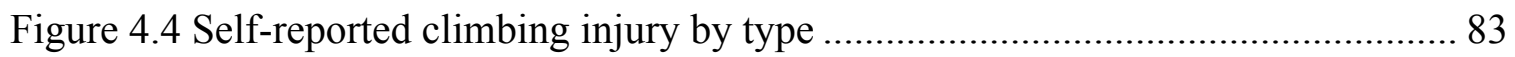

Figure 4.5 Climbing injury by mechanism of injury and anatomical location ................ 85 


\section{List of Symbols, Abbreviations and Nomenclature}

Symbol

BMI

CEC

CIS

CHREB

CI

EMT

FAS

IFSC

IP

IR

LTAD

$\mathrm{MeSH}$

OR

SES

UIAA

tw

YDS
Definition

Body mass index

Competition Climbing Canada / Competition d'Escalade

Canada

Climbing intensity score

Conjoint Health Research Ethics Board

Confidence interval

Emergency medical technician

Family affluence scale

International Federation of Sport Climbing

Incidence proportion

Incidence rate

Long-term athlete development

Medical subject headings

Odds ratio

Socioeconomic status

International Mountaineering and Climbing Federation / Union Internationale de Associations d'Alpinisme Text words

Yosemite decimal system 


\section{CHAPTER ONE: INTRODUCTION}

\subsection{Problem Statement}

Rock climbing is a sport that has been steadily gaining popularity worldwide in recent years, both as a recreational activity, and also as a competitive sport. Climbing includes a variety of different disciplines that utilize unique movement forms resulting in distinct injury patterns. Previous research has focused on injuries sustained in traditional rock climbing, ice climbing, mountaineering, and alpine settings in adult participants. ${ }^{1-5}$ Injuries sustained in these activities consist largely of trauma resulting from falls and overhead rock fall, injuries from weather (such as frostbite), and negative altitude effects. $^{6}$

There has been a paucity of research examining injuries and risk factors in young climbers specifically. ${ }^{7-10}$ The studies that exist are either case reports, or are focused on one single type of injury, such as epiphyseal fractures and finger injuries. ${ }^{7-11}$ Large epidemiological survey studies have included youth in their cross-sectional samples, but there is an obvious lack of information regarding injuries and incidence specific to youth and how they might differ from adults. ${ }^{512} 13$ Nevertheless, knowledge gained from research involving adult climbers may be relevant for youth and can help inform studies examining young climbers. Injury incidence rates and incidence proportions in adults are high (Chapter 2), and as climbing is a growing recreational and competitive sport, further research is needed involving youth climbers. It is important to build this knowledge in order to inform future injury prevention strategies. 


\subsection{Research Purpose}

The purpose of this study was to examine injury risk in youth who participate in sport climbing and bouldering, and additionally, to compare those youth who climb at the elite level to those who climb recreationally. Specifically, the injury incidence, primary injury types, locations, mechanisms, and risk factors for injury were evaluated.

\subsection{Background}

\subsubsection{Climbing Disciplines}

Alpinism, Mountaineering, and Traditional Climbing

Rock climbing was officially established as a sport in 1932, when the International Mountaineering and Climbing Federation / Union Internationale de Associations d'Alpinisme (UIAA) was founded. ${ }^{14}$ Since that time, this sport has evolved significantly. The first disciplines to develop were alpine climbing and mountaineering, which involve climbing to the summit of mountains over rocky and icy terrain. When the modern Olympic Games were re-established in 1896, alpinism was included as one of the original sports, though it was removed in $1946 .{ }^{15}$ Traditional climbing is a third style where protective gear, such as camming devices, are placed into naturally occurring features or cracks in the rock. This equipment is designed to arrest an individual in the event of a fall. Traditional climbs are often many pitches long, where each "climbing 
pitch" is approximately 30 metres in length. As such, alpine climbing, mountaineering, and traditional climbing have long been considered high-risk activities.

\section{Sport Climbing}

Sport climbing, established in the 1970s, is a safer sub-discipline of rock climbing that is different from the historical styles and can be performed both indoors and outdoors. ${ }^{16}$ This discipline involves a large number of gymnastic movements requiring a high degree of muscle memory, strength, and power. ${ }^{5}$ Sport climbing primarily involves single pitch climbs, where the goal is usually to achieve the greatest difficulty or grade of climb. Climbers attempt challenging routes that often involve steep, overhanging walls on small handholds and footholds. Indoor climbing has been developed in most gyms to simulate outdoor sport routes. In sport climbing, climbers protect themselves by clipping their rope through quick-draws, which they attach to permanent bolts in the rock or wall. They will either "lead," clipping the rope in from the bottom up, or "top-rope," where the climber's rope is pre-threaded through anchoring bolts at the top of the climb. ${ }^{12}$ Sport climbing grew and gained popularity throughout the 1980s, and in the late part of that decade as well as in the1990s, international sport climbing competitions began.

\section{Bouldering}

Bouldering, another evolved sub-discipline, was originally conceived as a way to practice movement skills and techniques for longer routes. It did not garner widespread participation until the 1990s. ${ }^{16}$ Bouldering concentrates the powerful movements of sport climbing into shorter routes, called "boulder problems," which are usually no more than 
four to five metres above the ground. It often involves dynamic movements performed on handholds and footholds as narrow as five to 10 millimetres. ${ }^{17}$ Since boulder problems are short and low to the ground, climbers will practice extremely strenuous and technically difficult moves repeatedly, falling after each attempt. ${ }^{18}$ Rather than using a rope and permanent bolts, thick crash mats are used to cushion falls, and spotters help ensure that the "boulderer" falls in the right place and position. This discipline was officially recognized by the UIAA in 1998, and has since grown into a sport with World Cup competitions and international circuits. ${ }^{16}$ Most indoor climbing walls offer bouldering areas as well as sport climbing routes. Sport climbing and bouldering are the most easily accessible disciplines of climbing as they are offered in these indoor facilities and tend to be the easiest and safest for beginners.

\subsubsection{Participation and Competition}

The first artificially built rock climbing wall was designed by Clark Schurman, built at Camp Long in Seattle in the late 1930s. ${ }^{19}$ Since that time, the growing number of artificial climbing facilities, improved safety standards, and increased media exposure has made rock climbing an easily accessible recreational activity for all demographics, resulting in an explosion in its popularity. In the United States, it was estimated that 4,119,000 Americans participated in bouldering, sport climbing, and indoor climbing during $2011 .{ }^{20}$ As there have been no Canadian research studies on climbing, the only existing relevant information regarding Canadian participation is a survey that was carried out by the Canadian Tourism Commission in 2000. It was found that during 1998 
and 1999, Canadians engaged in several "high energy" outdoor trip activities with the goal of experiencing "adventure and excitement." Rock climbing was found to have the second highest participation rate after mountain biking, at $34 \% .{ }^{21}$ Although there is no information specifically regarding Canadian youth participation, a United States survey in 2010 found that $3 \%$ of all youth had participated in bouldering, sport, or indoor climbing the previous year, and that $50 \%$ of all American participants in these activities were between the ages of six and 24 years. $^{22}$

Rising participation has resulted in an increase in organized competition. ${ }^{18}$ Adult competition includes sport climbing, bouldering, and ice climbing, while youth climbing competitions presently involve only sport climbing and bouldering (youth can also participate in open/adult competitions if they wish). The first World Championship in sport climbing was held in 1991, followed by the first Youth World Championship in 1992. ${ }^{16}$ By 2001, climbing had World and Continental Championship circuits. ${ }^{16}$ In 2007, 48 nations came together to form the International Federation of Sport Climbing (IFSC) to standardize regulations, which until that time had differed among countries. ${ }^{16}$ In February 2010, the IFSC was officially recognized by the International Olympic Committee as a member of the Olympic Family and is pursuing the addition of climbing as an Olympic sport for the 2020 Summer Games. ${ }^{16}$ Many of today's participants will be youth taking up climbing with the hopes of one day representing their sport in the Olympics. 


\subsubsection{Safety Standards in Rock Climbing}

Safety equipment for rock climbing is continually evolving, and safety standards for climbing gear have been mandated by the UIAA. ${ }^{23}$ In sport climbing, athletes wear harnesses to which ropes are tied. The rope is then clipped into pre-drilled bolts in the rock or wall using quick-draws. A partner uses a belay device attached to the opposite end of the rope to aid in catching the climber in the event of a fall. In bouldering, specially designed crash pads serve to cushion climbers' falls. Helmets are frequently worn and widely accepted as a means of injury prevention (especially from overhead rock fall outdoors), though there are no policies or laws requiring their use during climbing activities. Indeed, there are presently no policies or laws regarding the use of any safety equipment in climbing.

\subsubsection{Injury in Rock Climbing}

\section{Injury Incidence Rates}

Reported injury incidence rates (IR) in general climbing populations range from 0.027 to 4.2 injuries per 1000 climbing hours. ${ }^{24} 25$ It is difficult to compare these rates however, as the types of climbing examined, the injury definitions, and the methodology vary greatly between studies. For example, the study by Limb (1995) was a postal survey sent to 90 climbing gyms in England, Scotland, and Wales, which examined only significant injuries sustained in the previous two years requiring transport to the

emergency department. ${ }^{24}$ In contrast, the survey by Backe et al. (2008) was also a postal 
survey but was completed by 355 individuals. It examined not only those injuries requiring medical attention but also those that simply required rest and cessation from climbing over the previous year and a half. ${ }^{25}$ Josephsen et al. (2007) examined bouldering injuries specifically, in a two-phase cross-sectional and cohort study. ${ }^{26}$ According to Schöffl and Küpper (2006), injury incidence is likely lower in bouldering than in traditional and alpine climbing due to the safety equipment that has been developed to cushion falls. These authors also found a higher rate of injury for adults in bouldering than in sport climbing overall, and suggest that this is likely due to the more dynamic and powerful nature of this discipline. ${ }^{18}$ Injury incidence specific to youth participants in bouldering and sport climbing has yet to be examined in detail.

\section{Injury Types}

Several cross-sectional studies involving primarily adult populations suggest that chronic upper extremity injuries and acute flexor tendon pulley injuries of the fingers are the most common injuries sustained by rock climbers in varying disciplines, across ages and abilities. ${ }^{612}$ 27-31 However, Schlegel et al. (2002) performed a cross-sectional study examining finger injury in 29 elite, nationally ranked youth climbers and found that, although finger pain was common, there were only three flexor tendon pulley injuries in these adolescents. ${ }^{8}$ Carmeli et al. (2002) also found that there were fewer finger and hand injuries in adolescent climbers than in young adults. ${ }^{32}$ As such, when comparing these youth studies to similar adult studies, it appears that the types and incidence of injury may be different in younger athletes than in adults. ${ }^{832}$ 
Holchholzer and Schöffl (2005) found 24 non-traumatic cases of epiphyseal plate fractures in youth climbers, four of which were found to have epiphysiolysis (separation of the epiphysis from the rest of the bone), suggesting that epiphyseal fractures of the middle phalanx of the finger may be an injury likely to occur instead of pulley injuries in the younger age groups. ${ }^{7}$ The only other study examining epiphyseal plate fracture injury in a young climber was a case-report conducted by Chell et al. (1999). ${ }^{11}$ Based on this research, the UIAA has recently set the minimum age for international bouldering competition participation to 16 years old. This guideline was set to minimize the risk of epiphyseal fractures, as bouldering training often involves dynamic and maximal power movements that should be avoided in children whose bones have not yet matured sufficiently. $^{7}$

\section{Mechanisms of Injury}

Although the types of injuries sustained by youth and adult climbers may differ, the mechanism of injury reported by Holchholzer and Schöffl (2005) does appear to be consistent with adult studies examining general climbing injury. In the above study, all stress fractures resulted from repeated pressure on the bone, similar to research suggesting that performing repeated strenuous movements is the most common mechanism of climbing injury in adults. ${ }^{57}$ Chell et al. (1999) suggested the same mechanism of injury for epiphyseal fractures in young climbers. ${ }^{11}$ 


\section{Risk Factors for Injury}

Previous studies involving predominantly adult populations have examined numerous potential risk factors for injury in rock climbing; however, results are unclear, highly conflicting, and often limited by the poor methodological quality of these studies. It therefore remains unclear which of these variables are, in fact, risk factors for injury (Chapter 2). The different disciplines examined, the differing injury definitions, and the heterogeneous nature of the study populations across studies all contribute to inconsistent results. The scarcity of studies examining risk factors for injury in samples of youth climbers exclusively is also evident. Schöffl et al. performed a cross-sectional study (2004) and a subsequent cohort study (2007) examining radiographic changes in young elite and recreational climbers, including climbers from the German Junior National Climbing Team and recreational climbers of similar age. It was found that climbing led to adaptations such as cortical hypertrophy and broadened joint bases in the fingers, but that osteoarthritic changes were rare in both elite (aged 21.0 \pm 1.6 years) and recreational (aged $19.9 \pm 1.9$ years) young climbers. ${ }^{1033}$ Although radiographic changes are not in themselves injuries and it is arguably irrelevant to examine osteoarthritis in this young age group, the results suggest that years of climbing experience, competition participation, hours per week of climbing, number of training units per week and climbing level may be statistically significant predictors for adaptive bone changes (significance level $\alpha=0.05$ ). ${ }^{1033}$ Many studies examining sport injury in general have identified age, sex, body mass index (BMI), and socioeconomic status (SES) as potential risk factors in youth; however, at the present time, there is no existing research examining SES in rock climbers, and results are conflicting with regards to whether sex, age, or BMI 
affect injury risk in general climbing populations. ${ }^{12} 25{ }^{264-37}$ BMI has never been examined as a risk factor in youth climbers specifically, but three studies examining the anthropometrics (i.e., body composition and other physiological adaptations) of youth rock climbers have been published. ${ }^{38-40}$ In general, youth climbers were found to be of a small stature with low body mass and a lower fat mass than non-climbers, similar to findings for adults. ${ }^{39} 40$

\subsubsection{Injury Prevention}

Few studies have examined interventions for injury prevention in climbing. The use of a warm-up as a prevention strategy was examined in three separate studies. None of these found that the use of, or length of a warm-up was significantly associated with injury. Josephsen et al. (2007) examined stretching and yoga as preventive measures, but found no significant difference between those climbers who stretched versus those who did not, nor those who did or did not participate in yoga. ${ }^{26}$ However, stretching prior to climbing was actually reported to be associated with overuse injury by Tomczak et al. (1989). The data were interpreted incorrectly in this study however, and as such the validity of the authors' claims are questionable (Chapter 2$).{ }^{41}$ Imposing strict regulations regarding equipment use and instructor presence were not found to significantly decrease the risk of injury, nor were the presence or number of safety mats used during bouldering, or the number of spotters. ${ }^{24} 26$ Josephsen et al. (2007) also investigated the taping of fingers and wrists, taking glucosamine and other supplements, heating hands prior to climbing, taking time off to prevent injuries, the use of corticosteroid injections, and 
weight training as potential prevention strategies. The authors found that wrist taping and weight training each had a protective effect against injury, though none of the other measures demonstrated a significant effect on injury. ${ }^{26}$ Schöffl et al. (2007) examined prophylactic taping of the fingers to prevent flexor tendon pulley strains, an injury common among climbers. They found that although finger strength was significantly higher in injured fingers when tape was used, for uninjured fingers there was no significant difference in injury risk with and without prophylactic taping, similar to the findings of Josephsen et al. (2007). ${ }^{42}$

\subsubsection{Limitations in the Literature}

There has been a great deal of inconsistency in the literature involving rock climbing injury to date. Many articles do not discriminate between types of climbing, climbing environments (i.e., indoor versus outdoor) or level of performance (i.e., recreational versus elite). Additionally, most research studies have relied on the reporting of injuries to medical centres or to national park authorities, likely biasing their results to only reflect the most serious acute injuries. ${ }^{23}$ Prior to 2011 , there was no standardization with regards to the reporting of injury rates (i.e., inconsistent denominators) and the definition of injury, making it difficult to compare results between studies. ${ }^{27}$ These issues make it challenging to accurately assess the injury burden within the climbing community due to a lack of generalizability.

The majority of studies investigating climbing injury have been underpowered cross-sectional surveys focused predominantly on adult male climbers. ${ }^{6262943}$ Inherent in 
all cross-sectional studies is the susceptibility to selection bias, misclassification bias, and temporality issues, which affect the generalizability of the research. Furthermore, none of these studies have examined effect modification, and confounding was rarely controlled for. Selection bias is likely to occur in the data collection phase, especially when data are collected by convenience sampling. For example, in the study by Jones et al. (2008), where the sample was recruited from an indoor climbing facility, they may not have included climbers that were absent from the gym due to injury. ${ }^{12}$ This would necessarily result in the underestimation of injury rates and severity of injuries. Recall bias is also a concern if climbers are asked to report non-recent injuries and potential risk factors of which they no longer remember the details. There is also potential bias when collecting self-reported data for both exposure time and injury, rather than objectively measuring each subject. This is an issue related to the validity of the survey instrument. Finally, there is difficulty in determining temporal cause-and-effect relationships between risk factors and injury when data are collected at a single point in time.

\subsubsection{Standardization of Injury Definition and Reporting}

In 2011, Schöffl et al. (2011) authored The UIAA Medical Commission Injury Classification for Mountaineering and Climbing Sports. ${ }^{44}$ This document outlines recommendations for injury reporting in climbing research with the goal of creating objective standards so as to make future studies more easily comparable. Injury is defined as "any physical complaint sustained by a participant during trekking, mountaineering or climbing. This includes belaying, ascent and descent to the climb and camp time for 
expeditions." Time loss and medical attention injuries are not distinguished. The authors propose that injuries should be recorded by location, injury and illness classification, and fatality risk (see Appendix A). Location is reported with regards to body part, injury classification is rated numerically from zero (no injury) to six (immediate death) and case fatality from one (fatalities very rare) to four (extremely dangerous) depending on objective descriptions. Indoor climbing is given a rating of one for case fatality, as "fatalities [are] technically possible but very rare, [and there is] no objective danger," while sport climbing outdoors is given a rating of two, with "few objective dangers, fatalities [are] rare, falls are not very dangerous, [and] risk is mostly calculable." 44 Among other stipulations, the authors also suggest that injuries be reported per 1000 climbing hours in scientific studies. ${ }^{44}$

There are many different grading systems that exist for rating the difficulty of

climbs. ${ }^{44}$ Operationalizing the rating system is important, especially since attempting difficult routes with high grades has been suggested as a risk factor for injury. ${ }^{12}$ The UIAA has developed a metric grading system for sport climbing that allows easier comparison between many countries' scales (Appendix B). ${ }^{44}$ This will create a more standardized means of quantifying the difficulty of climbs and the ability level of climbers.

\subsection{Research Rationale}

There is a paucity of research examining rock climbing injuries in youth. With rock climbing having one of the highest recreational participation rates among outdoor 
trip activities that Canadians engage in, as well as an increase in organized competition, it is natural that an increase in the number of climbing injuries will follow. ${ }^{1821}$ This will increase the need for healthcare providers to be familiar with the injury types and mechanisms associated with this sport. Injury prevention in youth climbing will also become a more relevant issue.

With the 2011 UIAA protocol standardizing the reporting and recording of climbing injury, benchmark research can be conducted that will deepen the understanding of the injury burden in youth climbing that will both inform and allow for comparisons with future studies.

\subsection{Research Question And Specific Objectives}

\section{Research Question}

What are the injury incidence rates, the main injury types, injury mechanisms, and risk factors for injury in 11- to 19-year-old recreational and elite climbers?

\section{Primary Objectives}

1. To estimate injury incidence proportion and injury incidence rate (number of injuries per 1000 participation hours) in young climbers that climb at artificial indoor facilities in Alberta.

2. To compare the injury incidence proportion and the injury incidence rate between elite youth climbers and recreational youth climbers. 
3. To describe the most frequent injury types and their mechanisms in elite and recreational youth climbers.

Secondary Objectives

1. To examine intrinsic (i.e., age, sex, BMI, and the difficulty at which subjects climb) extrinsic [i.e., exposure hours, SES, the specific disciplines of climbing (sport climbing or bouldering), and climbing environment (indoors or outdoors)] risk factors for climbing injury.

Exploratory Objectives

1. To examine potential effect modifiers and confounders affecting the relationship between climbing level (recreational versus elite) and injury risk in youth climbers.

2. To examine the use of safety/injury prevention measures by youth climbers, and their effect on injury rates.

\subsection{Research Significance}

As rock climbing continues to grow in global popularity, the expected increase in participation will inevitably result in a greater number of injuries and consequent time loss from activity. This will increase the public health burden of climbing injuries, and healthcare providers will require familiarity with climbing injuries in order to recognize and manage these injuries specific to a pediatric population. Research examining the injuries and risk factors associated with sport climbing and bouldering is becoming more 
relevant as the number of youth participants increases, and especially as climbing moves toward becoming an Olympic sport. Indeed, some the youth rock climbing participants of today will aspire to one day represent this sport in the Olympics. By increasing knowledge about climbing injury types, mechanisms, and risk factors, injury in this sport may become more predictable and prevention strategies can be developed and evaluated accordingly in the future.

\subsection{Summary of Thesis Format}

This thesis contains six chapters, including an introduction, a systematic review, methods, results, discussion, and conclusions. Chapter one, the introduction, contains the background, the purpose of this research, the research rationale, the research questions and objectives, the significance of this research, and a summary of thesis formatting. Chapter two is a systematic review of the literature on risk factors for injury in sport climbing and bouldering. Chapter three describes the methods used in this research study. It includes the study design, study population, procedures, statistical methods, and a statement of ethical considerations. Chapter four reports the results of this study, describing the study participants, climbing participation, injury incidence rates and incidence proportions, injury characteristics, safety practices and injury prevention strategies of participants, physical education received and other sport participation, injury in sports other than sport climbing and bouldering, and finally the results of the risk factor analysis. Chapter five includes a discussion of these results, and compares them to previous literature, including both climbing research as well as other sport research 
involving youth. This chapter also presents study limitations and strengths. Chapter six provides conclusions to the thesis, and discusses future directions for research in this area. Several appendices serve to supplement the chapters, and include background documents, sample size calculations, the questionnaire used in this study, and informed consent forms. 


\section{CHAPTER TWO: RISK FACTORS FOR INJURY IN SPORT CLIMBING AND BOULDERING: A SYSTEMATIC REVIEW OF THE LITERATURE}

\subsection{Abstract}

Objective: To identify risk factors for injury in sport climbing and bouldering. Study Design: Systematic review of the literature.

Methods: Twelve electronic databases and several other non-academic sources (i.e., websites, conferences, the Canadian Alpine Journal) were searched systematically using predetermined inclusion and exclusion criteria.

Results: A total of 16 studies met the inclusion criteria for this review, and introduced 35 possible risk factors for injury in climbing. Current literature suggests that years of climbing experience, highest climbing grade achieved (skill level), climbing volume, and participating in lead climbing may be risk factors for injury in climbers. Results are conflicting with regards to sex, age, body mass index (BMI), and several injury prevention strategies.

Conclusions: This review highlights the need for further study into risk factors for injury in sport climbing and bouldering. Many potential risk factors require further investigation, namely those that are modifiable. Further research is also warranted with regards to injury prevention strategies, especially focusing on taping, weight training, BMI, and the use of stretching. With this valuable information, injury prevention strategies can be implemented in the future. 


\subsection{Introduction}

Rock climbing is becoming an increasingly popular sport worldwide, both as a recreational activity and also as a competitive sport. In the United States, it was estimated that 4,119,000 Americans participated in bouldering, sport climbing, and indoor climbing during $2011 .^{45}$ There are no such data for Canada, reflecting a general paucity of research conducted on rock climbing, despite its increasing popularity.

As rock climbing has developed, several disciplines of the sport have been established. The newest disciplines include sport climbing and bouldering, and are arguably the safer disciplines of climbing, though more gymnastic in nature than the traditional forms of the sport where the goal is to summit mountains. ${ }^{526}$ Sport climbing and bouldering are performed on either artificial surfaces or on natural rock. In sport climbing, routes are normally a maximum of 30 metres in height. The climber is attached to a rope that is clipped into permanent bolts using "quickdraws," spaced intermittently from the bottom up (lead climbing), or it will be anchored at the top of the climb (top roping). This allows the climbers to incur frequent falls safely. Bouldering uses large crash mats instead of ropes to protect climbers from falls, as "boulder problems" are usually short and low to the ground. This discipline allows climbers to practice much more difficult and powerful moves repeatedly, close to the ground.

Each discipline has rating scales to grade the difficulty of each climb. The United States and Canada use the Yosemite Decimal System (YDS) to rate sport and traditional climbs, a scale originally developed to rate hiking, scrambling, and climbing. ${ }^{46}$ Sport climbing grades range from 5.0 to 5.15. Europe predominantly uses the French system 
(grades 1 to 9b), though the United Kingdom uses the British Adjectival system ("Easy" to "Extremely Severe 1, 2, etc."). ${ }^{46}$ Australia, New Zealand, and South Africa use the Australian system (grades 1 to 38 ). ${ }^{46}$ Several scales also exist for bouldering, the most common being the Hueco Scale, also known as the Sherman V-scale (grades V0 to V16), used across North America. ${ }^{46}$ The International Mountaineering and Climbing Federation (UIAA) has its own scale, and the UIAA Medical Commission has also recently established a metric rating system into which all of these scales can be converted, standardizing reporting for research purposes in particular. ${ }^{446}$ However, as it is a relatively new instalment, few previous studies use the UIAA or metric scales.

With the continued development of each climbing discipline, unique injuries specific to climbers have become apparent. Previous research involving primarily adult populations suggests that chronic upper extremity injuries and acute flexor tendon pulley strains of the fingers are the most common injuries sustained by rock climbers in varying disciplines. ${ }^{6}{ }^{127-31}$ However, there has been little research into the specific risk factors for these injuries. Risk factors are defined as either an intrinsic or extrinsic factor that increase the potential for injury. ${ }^{47}$ Intrinsic risk factors are internal and unique to the individual (e.g., sex, age, strength). Extrinsic factors are external to the individual (e.g., equipment, intensity of training).

Existing studies that examine risk factors for injury in climbing are difficult to compare due to the diversity of study populations (e.g. age groups, competitive level, climbing discipline), injury definitions, methodology, and reporting. The objective of this systematic review is to examine injury rates and identify intrinsic and extrinsic risk factors for injury in sport climbing and bouldering. In addition, prevention strategies 
evaluated in sport climbing or bouldering will be examined. By identifying potentially modifiable risk factors for injury, it may be possible to develop and evaluate effective prevention strategies for injury in this sport.

\subsection{Methods}

\subsubsection{Data Sources}

Twelve electronic databases were searched systematically for relevant documents and articles during October and November 2012: PubMed (1960-present), MEDLINE (OVID) (1946-present), SPORTDiscus (1960-present), BIOSOS Previews (1980present), CINAHL Plus (1960-present), Academic Search Complete (EBSCO) (1960present), PsychInfo (1967-present), ScienceDirect (Elsevier) (1960-present), Health STAR (1980-present), EMBASE (1974-present), SafetyLit (www.safetylit.org), and Statistics Canada (http://statcan.summon.serialssolutions.com). Four websites were searched to find additional relevant publications: the International Mountaineering and Climbing Federation / Union Internationale de Associations d'Alpinisme (UIAA) (www.theuiaa.org), the International Federation of Sport Climbing (IFSC) (www.ifscclimbing.org), the Alpine Club of Canada (http://www.alpineclubofcanada.ca) and The Alpine Journal (a flagship publication of the Alpine Club of Canada). Articles were also obtained from a comprehensive collection provided at the annual 2012 Banff Climbing Conference. Bibliographies of selected articles were also searched to find further additional relevant publications. 
Search Terms

Table 2.1 Medical subject headings and text words used for article extraction

\begin{tabular}{|l|l|}
\hline $\begin{array}{c}\text { Medical subject headings (MeSH) } \\
\text { (also used as text words in each search) }\end{array}$ & \multicolumn{1}{|c|}{ Text words (tw) } \\
\hline 1. "Mountaineering" & 5. "Climb" [Boolean climb*] \\
2. "Wounds and injuries" & 6. "Boulder" [Boolean boulder*] \\
3. "Athletic injuries" & $\begin{array}{l}\text { 7. "Injury" } \\
\text { 4. "Risk factors" }\end{array}$ \\
& $\begin{array}{l}\text { 8. "Sport injury" } \\
\text { 9. "Prevention" }\end{array}$ \\
& 10. "Intervention" \\
& 11. "Safety" \\
\hline
\end{tabular}

Search Strategy
A. climbing: 1 OR 5 OR 6
B. injuries: 2 OR 3 OR 7 OR 8
C. risk factors: 4
D. injury prevention: 9 OR 10 OR 11
E. climbing and injury: A AND B
F. climbing and risk factors for injury: E AND C
G. climbing and injury prevention: E AND D
H. climbing, risk factors for injury, and prevention: F AND D

If fewer than 300 articles were obtained for strategies $\mathrm{E}$ to $\mathrm{H}$, titles and abstracts were reviewed to retrieve relevant articles. If over 300 results were returned, the search was narrowed further using the subsequent step in the search strategy. Articles were organized using EndNote 5. 


\subsubsection{Study Selection Criteria}

Study selection was based on several inclusion criteria for all articles:

- The article was based on primary research using original data.

- The outcome measure included injury, morbidity or mortality associated with rock climbing (indoor or outdoor).

- $\quad$ The study included one or more potential injury risk factor(s) or an injury prevention strategy.

- $\quad$ Study designs included randomized controlled trials, quasi-experimental designs, cohort, cross-sectional, case-control, longitudinal, and case series studies.

- The article was peer reviewed.

- The article was published in English.

Research articles were excluded based on the following criteria:

- Review articles (systematic reviews and others) or case studies. (However, review articles found in the search were included at first in order to review their reference lists for additional relevant articles.)

Two independent reviewers completed the review of all selected articles during December 2012. Each reviewer screened the full text of each manuscript to determine whether all inclusion criteria were met. Any disagreements were resolved by discussion and subsequent consensus. 


\subsubsection{Data Extraction}

Data were extracted from the 16 studies that met all inclusion criteria. Study design, study population, the definition of injury, risk factor(s) examined, and the results of each study were extracted. Risk factors for sport climbing were considered separately from those risk factors examined for bouldering, though some articles did not specify the discipline of climbing studied.

Two independent reviewers assessed the methodological quality of the research in each study using the Downs and Black criteria for methodological quality. The Downs and Black method is a 27-question checklist for both randomized and non-randomized study designs. It aids in evaluating the quality of reporting, external validity, internal validity (the presence or absence of selection bias, measurement bias, and potential

confounders), and the power. ${ }^{48}$ The reviewers met following this stage, and consensus was reached for each article.

\subsubsection{Data Synthesis}

Due to the diversity of objectives, methodology, and statistical analyses in these studies, meta-analyses of risk factors were not appropriate to carry out for this review. The data extracted is summarized, and appraisals of the articles are presented with respect to the quality of evidence presented. 


\subsection{Results}

\subsubsection{Included Studies}

One hundred and forty-nine manuscripts were identified from electronic databases after title and abstract review, and 51 were identified from other sources. One hundred and fifty-four of these 200 articles were duplicate records of each other and were therefore removed, leaving 46 unique articles of which both reviewers had assessed the full text for eligibility based on the inclusion and exclusion criteria. Thirty articles were excluded at this stage. A total of 16 studies met the inclusion criteria for this review. Figure 2.1 summarizes the study selection process. 
Figure 2.1 Study selection process based on inclusion and exclusion criteria

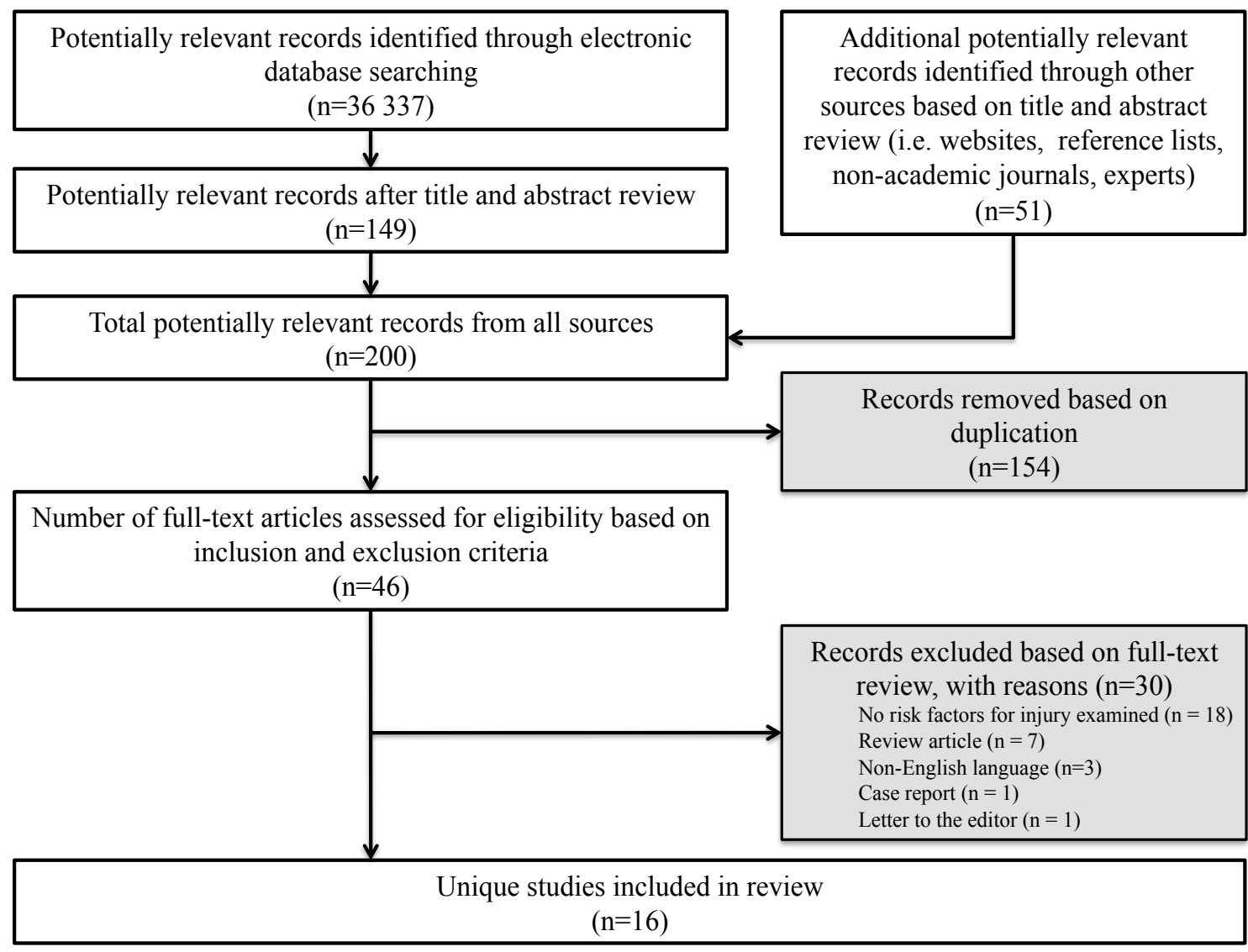

\subsubsection{Study Quality Assessment}

Though the disciplines of sport climbing and bouldering were the focus of this review, results were included from studies that did not specify the type of climbing examined. Often, all "rock climbers" willing to participate were included in a study. As such, samples were frequently unrepresentative of the population being examined. Age ranges were also often quite large, though some studies focused specifically on youth or young adults. There was a large sex disparity in most studies, with samples composed 
predominantly of males, from approximately $60 \%$ to $100 \%$ of the sample. ${ }^{26} 49$ Two studies did not specify sex. ${ }^{24}{ }^{30}$ Several studies failed to adjust for confounding, introducing bias in the results. The methodological quality, based on the Downs and Black criteria, produced scores as low as six out of 32 , and up to 15 out of 32 . Study quality score based on the Downs and Black criteria is summarized in Table 2.3.

\subsubsection{Injury Incidence}

Several studies have attempted to determine the incidence of injury in rock climbing. However, these proportions and rates are not easily compared due to the context and focus of each study, injury definitions, the manner in which they have been reported, and the varying methodologies used. The study by Limb (1995), for example, consisted of a postal survey sent to 56 climbing gyms in England, Scotland, and Wales, and examined only acute injuries sustained over two years that required transport to an emergency department. This author reported an incidence of 55 such injuries in 1.021 million visits. ${ }^{24}$ The survey by Backe et al. (2008) was also a postal survey, but in contrast it was completed by 355 individuals, and examined injuries incurred in the previous 18 months that required either rest from climbing or medical attention. These authors estimated the injury incidence rate to be 4.2 injuries per 1000 participation hours in climbing. For those studies that included all injuries (as opposed to studies examining only specific areas of the body or specific injuries), these authors were the only ones to report an injury incidence rate. ${ }^{25}$ However, most of the reviewed studies reported the frequency of injuries and sample size, thus it was possible to calculate the mean number 
of injuries sustained per subject. The career incidence of injury ranges from 1.52 injuries per subject to 4.24 injuries per subject for a general population of rock climbers. ${ }^{41}{ }^{50} \mathrm{See}$

Table 2.2 for reported injury incidence proportions and incidence rates.

Table 2.2 Reported injury incidence proportions or incidence rates for all reviewed studies

\begin{tabular}{|c|c|}
\hline Study (year) & $\begin{array}{l}\text { Injury incidence proportion (IP) or incidence rate (IR) } \\
\text { (95\% Confidence Interval) }\end{array}$ \\
\hline Tomczak et al. (1989) & $\begin{array}{l}\text { Career incidence proportion (IP): } \\
428 \text { injuries/100 participants }(409,447)\end{array}$ \\
\hline Limb (1995) & $\begin{array}{l}\text { Injury incidence rate (IR): } \\
53.87 \text { injuries/1 million visits }(40.58,70.12)\end{array}$ \\
\hline Paige et al. (1998) & Not examined. \\
\hline $\begin{array}{l}\text { Rorhbough et al. } \\
(2000)\end{array}$ & Career IP: 300 injuries/100 participants $(250,357)$ \\
\hline Wright et al. (2001) & Not examined. \\
\hline Carmeli et al. (2002) & Not examined. \\
\hline Schlegel et al. (2002) & Not examined. \\
\hline Logan et al. (2004) & Career IP: 152 injuries/100 participants $(133,172)$ \\
\hline Gerdes et al. (2006) & $\begin{array}{l}\text { Career IP: } 131 \text { injuries/ } 100 \text { participants }(126,136) \\
\text { (Authors allowed } 3 \text { injury reports maximum) }\end{array}$ \\
\hline $\begin{array}{l}\text { Josephsen et al. } \\
(2007)\end{array}$ & $\begin{array}{l}\text { IP of outdoor bouldering injuries: } \\
103 \text { injuries/ } 100 \text { participants/year }(71,146) \\
\text { IP of indoor bouldering injuries: } \\
127 \text { injuries/ } 100 \text { participants/year }(85,184)\end{array}$ \\
\hline Shahram et al. (2007) & Not examined. \\
\hline Backe et al. (2008) & $\begin{array}{l}\text { IR: } 4.2 \text { injuries/1000 climbing hours }(3.61,4.77) \\
\text { (14 traumatic and } 194 \text { overuse injuries in } 49986 \text { climbing hours) }\end{array}$ \\
\hline Jones et al. (2008) & IP: 137 injuries/100 participants/year $(121,154)$ \\
\hline Neuhof et al. (2011) & IR: 0.2 injuries/ 1000 climbing hours (acute injury only) $(0.02,0.72)$ \\
\hline Hasler et al. (2012) & Not examined. \\
\hline Pieber et al. (2012) & Career IP: 194 injuries/100 participants $(175,214)$ \\
\hline
\end{tabular}




\subsubsection{Risk Factors}

The 16 studies reviewed introduced 35 possible risk factors; however, 19 of these were examined uniquely by only one study. As well, throughout the literature, there were varying study designs, different objectives, types of climbing, and age ranges examined.

\section{Intrinsic Risk Factors}

$\operatorname{Sex}$

Nine of the reviewed studies examined sex as a potential risk factor for injury in sport climbing, bouldering, or both. The results were highly conflicting. Five of these studies found no difference in injury risk between sexes, while four found that males were at greater risk than females. ${ }^{61225-2730325152}$ Backe et al. (2008) found that males had a higher risk not only of injury, but also of reinjury. ${ }^{25}$ However, the majority of these studies examined samples of climbers that were predominantly male. Wright et al. (2001), who found a significantly higher risk of injury in males, failed to report any sex distribution. ${ }^{30}$ The studies that reported no difference between sexes had samples ranging from $59.9 \%$ to as high as $83.3 \%$ male. ${ }^{612262751}$ Rorhbough et al. (2000) made their conclusions based on a sample consisting of 35 male and only seven female subjects, and did not report any adjustment for effect modification or confounding. ${ }^{6}$ Conversely, Josephsen et al. (2007), who also found no difference, had the highest proportion of female subjects at $40.1 \%$ of 152 subjects, though they also did not report any adjustments for possible effect modification or confounding. ${ }^{26}$ In general, most of these studies had 
study samples that were not representative of the population from which they were recruited, thus lowering the Downs and Black score.

Age

Age was investigated as a possible risk factor in eight of the reviewed studies. Five articles reported that the risk of injury was not associated with age. ${ }^{8122751}$ Most of these studies covered a broad age range, from adolescents to seniors. However, Schlegel et al. (2002) examined elite youth climbers exclusively, between the ages of 10 to 17 years. The authors found no association between age and injury $(\alpha=0.05, \mathrm{p}>0.05)$. Carmeli et al. (2002) reported finding significantly more hand and finger injuries $(\alpha=0.05, p<0.05)$ and a higher incidence of tendonitis in the long flexor tendons of the second and third fingers for young adults (19-34 years old) versus adolescents (9-18 years old). ${ }^{15}$ Similarly, Pieber et al. (2012) found that their two older age groups $(29.5 \pm 1.7$ years and $39.7 \pm 5.6$ years) sustained significantly more injuries $(\alpha=0.05, p=0.021)$ than the younger climbers $(23 \pm 2.4$ years $) .{ }^{52}$ Conversely, Backe et al. (2008) found that the risk of injury increased for the adolescent age group, as opposed to older climbers $(\alpha=0.05, p=0.003$ for $20-45$ year-olds, and $\mathrm{p}<0.001$ for +46 -year-olds compared with $<20$-year-olds $).{ }^{25}$ However, only 73 of the 355 total participants in this study (21\%) were under the age of 21 , and the sample was predominantly between 22 and 45 years. $^{25}$

\section{Body Mass Index (BMI)}

BMI was examined in three of the reviewed studies. Backe et al. (2008) were the only authors that found a higher BMI to be significantly associated with a higher risk of 


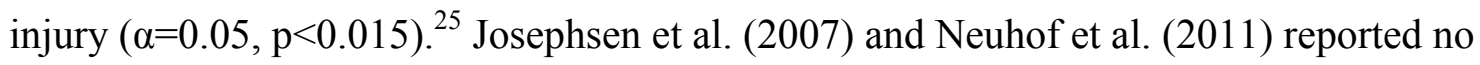
significant difference in injury risk associated with this factor. ${ }^{26}{ }^{27}$ However, Backe et al. (2008) scored higher on methodological quality than either of the other studies. Both Josephsen et al. (2007) and Neuhof et al. (2011) failed to adequately adjust for any possible confounders, and in both studies the subjects may not have been representative of the population from which they were recruited. ${ }^{2627}$

\section{Body Weight}

Directly related to BMI is body weight. Only two studies examined weight as a risk factor, and neither found any significant association with injury. ${ }^{826}$ However, one of these studies included only young, elite rock climbers, and the other, active boulderers. Because these studies examined different populations, it is difficult to hypothesize the effect of body weight on injury. Furthermore, Josephsen et al. (2007) also examined BMI, but did not account for multicollinearity between body weight and BMI. Therefore, further research is needed to determine if body weight truly has no impact on injury in a more diverse population of climbers of different levels and age groups.

\section{Years of Experience}

Years of climbing experience was examined as a risk factor in seven studies. Three found the number of years a person had been climbing to have no significant impact on the risk of injury. ${ }^{122526}$ Of these studies, Jones et al. (2008) adjusted this factor for sex and age, and Josephsen et al. (2007) stratified by location and only examined this factor in bouldering. ${ }^{126}$ Overall, these three studies did not contain biases that would invalidate 
these results. Conversely, four studies found years of experience to be a significant predictor of injury. ${ }^{627} 3051$ Wright et al. (2001) found higher injury rates for climbers with over 10 years of experience $(\alpha=0.05, p=0.006)$, as did Hasler et al. (2012) $(\alpha=0.05$, $\mathrm{p}=0.006$ ), though both of these studies analyzed prevalence only; injury incidence was not reported. ${ }^{3051}$ Neuhof et al. (2011) found higher injury incidence rates for climbers with over five years of experience $(\alpha=0.05, \mathrm{p}<0.01) .{ }^{27}$ Finally, Rorhbough et al. (2000) found that history of medial epicondylitis increased with increasing experience $(\alpha=0.05$, $\mathrm{p}<0.0005)$, though these authors found no impact by experience on any other injuries. ${ }^{6}$ As observed previously, the methodological quality of these seven studies was low overall, the most common potential bias being the failure of their samples to reasonably represent the source population.

\section{Difficulty (Skill) Level}

Eight studies investigated the highest difficulty level at which the subject could climb as a risk factor for injury. Three studies found that this measure of general skill had no significant impact on injury, while five found a difference in injury for climbers of differing levels. ${ }^{68122627304953}$ Though the studies differed in their study populations, all found that in general, participants that climbed at higher grades sustained more injuries. Discretion needs to be used when including the article by Gerdes et al. (2006) with this group, as the authors did not use statistics to analyze this factor. Results were simply listed as proportions of total injuries incurred by beginner to expert climbers, though the number of subjects was not evenly distributed by climbing grade. ${ }^{53}$ Though it is only 
possible to make conservative inferences from these results, it does appear that expert climbers sustained a significantly higher proportion of injuries than other levels.

A multitude of different rating scales were used in each of the seven papers to grade the technical difficulty of climbs, as different countries and different disciplines often use different scales. Josephsen et al. (2007) used the Hueco Scale for bouldering, Rohrbough et al. (2000), Sharam et al. (2007) and Gerdes et al. (2006) used the American Yosemite Decimal System, Schlegel et al. (2002) and Neuhof et al. (2011) used the standardized metric UIAA grading system, Jones et al. (2008) and Wright et al. (2001) used the British Adjectival scale, and the latter also used the Fontainebleau bouldering scale.

\section{Extrinsic Risk Factors}

\section{Lead Climbing and Top Roping}

Lead climbing was investigated as a risk factor in five separate studies. Most of these articles compared it to top roping, though two also compared it to bouldering, and a third included bouldering, traditional climbing, and free soloing (free soloing is a type of climbing where no ropes, harnesses or any other protective gear are used, and falls are often fatal). Four of these studies suggested that lead climbing was a risk factor for injury. 5273053 Shahram et al. (2007) were the only authors who found that lead climbing was not associated with injury, though this conclusion was based on prevalence proportions, as incidence and risk were not captured in their study. ${ }^{49}$ 


\section{Climbing Volume}

The amount of time spent climbing (per week or per year) was examined in three studies. Backe et al. (2008) found that the total climbing time each year did not have a significant effect on injury, though the authors did control for exposure hours in their injury incidence rate (IR). ${ }^{25}$ Schlegel et al. (2002) found the same results with hours per week spent climbing. ${ }^{8}$ Conversely, in the study by Neuhof et al. (2011) the authors found that greater climbing volume per week did significantly increase the risk of injury during both summer $(\alpha=0.05, \mathrm{p}<0.01)$ and winter months $(\alpha=0.05, \mathrm{p}<0.01)$, though they did not indicate whether indoor climbing, outdoor climbing, or both were examined. ${ }^{27}$ Similarly, a fourth study by Jones et al. (2008) investigated the frequency of climbing (times per year) for each subject, though not the number of hours, and also found that as the frequency per year of outdoor sport climbing (leading), indoor sport climbing (leading), and bouldering increased, so did the incidence of overuse injury. ${ }^{12}$

\section{Climbing Intensity Score (CIS)}

A climbing intensity score (CIS) was used in two studies to examine degree of exposure to climbing stress as a risk factor. CIS scores, proposed by Logan et al. (2003), and used again by Pieber et al. (2012), indicate both climbing intensity and volume by multiplying the average grade of climbing by the mean number of climbing days in a year. ${ }^{31} 52$ Both of these studies found participants who scored higher in climbing intensity to be at a higher risk of injury. Logan et al. (2003) compared an injury group to a noninjury group and found the mean CIS scores in the injury group to be significantly higher $(\alpha=0.05, p=0.01) .{ }^{31}$ Pieber et al. (2012) split CIS into terciles (CIS 1: $398 \pm 232$ points; 
CIS 2: $1526 \pm 461$ points; CIS 3: $5088 \pm 2701$ points) with 56 subjects in each group, and found groups two and three to be significantly different in injury risk from group one, which scored lower on the CIS $(\alpha=0.05, \mathrm{p}<0.001){ }^{52}$

\section{Indoor Versus Outdoor Climbing}

Two articles investigated outdoor climbing as compared to indoor climbing as a predictor for injury. Josephsen et al. (2007) examined whether there was a higher potential for injury while participating in indoor or outdoor bouldering specifically. The results from their study suggest a significantly higher risk of finger injuries and fallingrelated injuries outdoors. The authors found no significantly higher risk of injury for any other body part or mechanism of injury. Gerdes et al. (2006) observed that an approximately even distribution of injuries occurred indoors and outdoors, though this study included sport climbing, bouldering, traditional climbing, and free soloing. ${ }^{53}$ Traditional climbing is rarely performed indoors and free soloing is performed exclusively outdoors, thus introducing a potential bias.

\section{Influence of Drugs/Alcohol}

Only two articles studied the influence of drugs or alcohol on climbing injury, with opposing results. Gerdes et al. (2006) found that substance use significantly increased the potential for injury, while Hasler et al. (2012) found no significant increase in risk. ${ }^{53}$ 


\section{Other Risk Factors}

A number of different risk factors were examined uniquely in only one study. Further research is therefore necessary to improve the body of knowledge regarding the following risk factors. Josephsen et al. (2007) found that a previous history of injury to the fingers was a significant predictor of reinjury. Wall height for sport climbing routes, boulder maximum height, and boulder average height were also examined, and did not significantly affect injury rate. ${ }^{26}$ Gerdes et al. (2006) observed that a high proportion of injuries occurred at familiar locations $(79.2 \%)$ as opposed to new areas that the climber was unfamiliar with (i.e., a new gym or crag) $(20.8 \%) .{ }^{53}$ No other studies examined this variable. Hasler et al. (2012) were the only authors to study "on-sighting" at the time of injury (climbing a specific route for the first time) as a risk factor. They found that onsighting was significantly associated with injury. These authors also investigated the difficulty of the specific climbing route at the time of injury (as opposed to the highest grade at which participants can climb overall) and found no increased risk of injury. Moreover, participants' self-reported "readiness for risk" was not found to be significantly associated with injury. ${ }^{51}$ The number of years climbing at the elite level for those climbers categorized as elite by Rohrbough et al. (2000) was also unrelated to injury. ${ }^{6}$ Handedness was not found to be a risk factor for injury to either the dominant nor the non-dominant hand. ${ }^{49}$ Schlegel et al. (2002) examined a number of potential risk factors in 10- to 17-year-old elite climbers, including lean body mass, Beighton (hypermobility) score, the age at which climbers began training regularly, increase in climbing difficulties (grade, and increase in grade per year), performing regular onefinger climbing, capsular thickening in the fingers, and radio-ulnar instability of the 
finger joints. None of these factors were found by the authors to be associated with injury. ${ }^{8}$ Finally, both Schlegel et al. (2002) and Carmeli et al. (2002) suggested that low grip strength may be a potential risk factor for climbing injury, though it was not statistically analyzed in either study. ${ }^{832}$

\section{Prevention Measures}

A number of prevention strategies were evaluated in the reviewed studies. The selfreported use of a warm-up was examined by Schlegel et al. (2002), who found no difference in injury between those climbers who reported having warmed up, and those

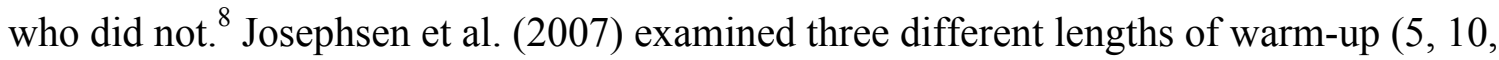
and $>10$ minutes ${ }^{26}$ while Hasler et al. (2012) examined two $\left(<10\right.$ and $>10$ minutes). ${ }^{51}$ Neither study found any difference between warm-up groups. Stretching prior to climbing was actually reported to be significantly associated with overuse injury by Tomczak et al. (1989). However, their claim that their "'P' value of 0.9763 [meant] that $97 \%$ of all people who reported stretching prior to climbing reported an overuse injury of some type" is incorrect. ${ }^{41}$ It is possible that a value of 0.9763 is instead a correlation coefficient, in which case this would suggest a strong association between stretching and overuse injuries. Conversely, Josephsen et al. (2007) found no significant difference in injury risk between those climbers who stretched versus those who did not. These authors also examined regular participation in yoga as a preventative measure and found the same results. $^{26}$

Imposing strict regulations regarding equipment use and instructor presence were not found to significantly decrease the risk of injury in sport climbing or bouldering, nor 
were the presence or number of safety mats used. ${ }^{24} 26$ The number of spotters was not found to decrease this risk either. ${ }^{26}$ Josephsen et al. (2007) also investigated the taping of fingers and wrists, taking glucosamine and other supplements, heating hands prior to climbing, taking time off to prevent injuries, the use of corticosteroid injections, and weight training as potential preventive measures. Of these strategies, only taping wrists and weight training were found to be significantly associated with a decreased rate of injury. $^{26}$ 
Table 2.3 Studies examining risk factors for injury in sport climbing and bouldering and their results

\begin{tabular}{|c|c|c|c|c|c|c|}
\hline $\begin{array}{l}\text { Study } \\
\text { (year) }\end{array}$ & $\begin{array}{l}\text { Study } \\
\text { design }\end{array}$ & $\begin{array}{c}\text { Study } \\
\text { population }\end{array}$ & $\begin{array}{l}\text { Downs } \\
\& \\
\text { Black } \\
\text { score } \\
(/ 32)\end{array}$ & $\begin{array}{l}\text { Type of } \\
\text { climbing }\end{array}$ & Injury definition & Results of risk factor examination \\
\hline $\begin{array}{l}\text { Backe et } \\
\text { al. }(2008)\end{array}$ & $\begin{array}{c}\text { Cross- } \\
\text { sectional }\end{array}$ & $\begin{array}{l}\text { Swedish } \\
\text { Climbing } \\
\text { Association } \\
\text { members } \\
(\mathrm{n}=355)\end{array}$ & 15 & $\begin{array}{c}\text { Sport } \\
\text { climbing } \\
\text { and } \\
\text { bouldering }\end{array}$ & $\begin{array}{l}\text { "Injuries that occurred while } \\
\text { participating in a climbing } \\
\text { activity indoors or outdoors and } \\
\text { that resulted in an injury } \\
\text { treatment intervention (medical } \\
\text { treatment, hospitalization } \\
\text { and/or discontinuation and rest } \\
\text { from climbing)." Traumatic } \\
\text { injuries defined as acute onset, } \\
\text { overuse injuries defined as } \\
\text { repeated microtrauma without a } \\
\text { single identifiable event. }\end{array}$ & $\begin{array}{l}\text { - Time climbing per year: } \mathrm{p}=0.439 \\
\text { - Body mass index (BMI): } \mathrm{p}=0.121 \\
\text { - Sex (male): } \mathrm{p}=0.019 \\
\text { - Age group }(20-45 \text { vs. }<20 \text { yrs. }): \mathrm{p}=0.003 \\
\text { - Age group ( } 46+\text { vs. }<20 \text { yrs. }): \mathrm{p}=0.000 \\
\text { - Bouldering: } \mathrm{p}=0.122 \\
\text { - Sport climbing: } \mathrm{p}=0.719 \\
\text { - Years climbing experience }(5-9 \text { vs. } 0-4 \text { yrs. }) \text { : } \\
\mathrm{p}=0.775 \\
\text { - Years climbing experience }(10+\text { vs. } 0-4 \text { yrs. }) \text { : } \\
\mathrm{p}=0.060)\end{array}$ \\
\hline $\begin{array}{l}\text { Carmeli et } \\
\text { al. (2002) }\end{array}$ & $\begin{array}{c}\text { Cross- } \\
\text { sectional }\end{array}$ & $\begin{array}{c}\text { Sport } \\
\text { climbing } \\
\text { club in Tel } \\
\text { Aviv, Israel } \\
(\mathrm{n}=19)\end{array}$ & 11 & $\begin{array}{c}\text { Sport } \\
\text { climbing }\end{array}$ & $\begin{array}{l}\text { Injuries sustained during sport } \\
\text { climbing were self-reported soft } \\
\text { tissue injury to the hands and } \\
\text { fingers, classified by functional } \\
\text { diagnoses (tendons and } \\
\text { ligaments), and medical } \\
\text { diagnoses }\end{array}$ & $\begin{array}{l}\text { - Sex (male): } \mathrm{p}<0.05 \\
\text { - Age }(19-34 \text { vs. } 9-18 \text { yrs.): significant }(\mathrm{p}<0.05) \\
\text { - Frequency: } \mathrm{p}<0.05 \text { (practicing } 4-5 \mathrm{x} \text { per week } \\
\text { reported more diverse wrist and finger injuries) } \\
\text { - Grip strength: } \mathrm{p}<0.05 \text { "mild to moderate correlation: } \\
\mathrm{r}=0.26 \text { and } \mathrm{r}=0.41 \text { " }\end{array}$ \\
\hline
\end{tabular}




\begin{tabular}{|c|c|c|c|c|c|c|}
\hline $\begin{array}{l}\text { Study } \\
\text { (year) }\end{array}$ & $\begin{array}{l}\text { Study } \\
\text { design }\end{array}$ & $\begin{array}{c}\text { Study } \\
\text { population }\end{array}$ & $\begin{array}{l}\text { Downs } \\
\& \\
\text { Black } \\
\text { score } \\
(/ 32)\end{array}$ & $\begin{array}{c}\text { Type of } \\
\text { climbing }\end{array}$ & Injury definition & Results of risk factor examination \\
\hline $\begin{array}{l}\text { Gerdes et } \\
\text { al. }(2006)\end{array}$ & $\begin{array}{c}\text { Cross- } \\
\text { sectional }\end{array}$ & $\begin{array}{l}\text { Rock } \\
\text { climbers of } \\
\text { any age, } \\
\text { ability, or } \\
\text { experience, } \\
\text { primarily } \\
\text { male, } \\
\text { advanced or } \\
\text { intermediate } \\
(\mathrm{n}=1887)\end{array}$ & 9 & $\begin{array}{c}\text { All types of } \\
\text { "rock } \\
\text { climbing" }\end{array}$ & $\begin{array}{l}\text { Subjects identified three most } \\
\text { significant injuries. Data was } \\
\text { collected on injured body part, } \\
\text { type of injury, type of climbing, } \\
\text { medical care sought, and } \\
\text { recovery time. }\end{array}$ & 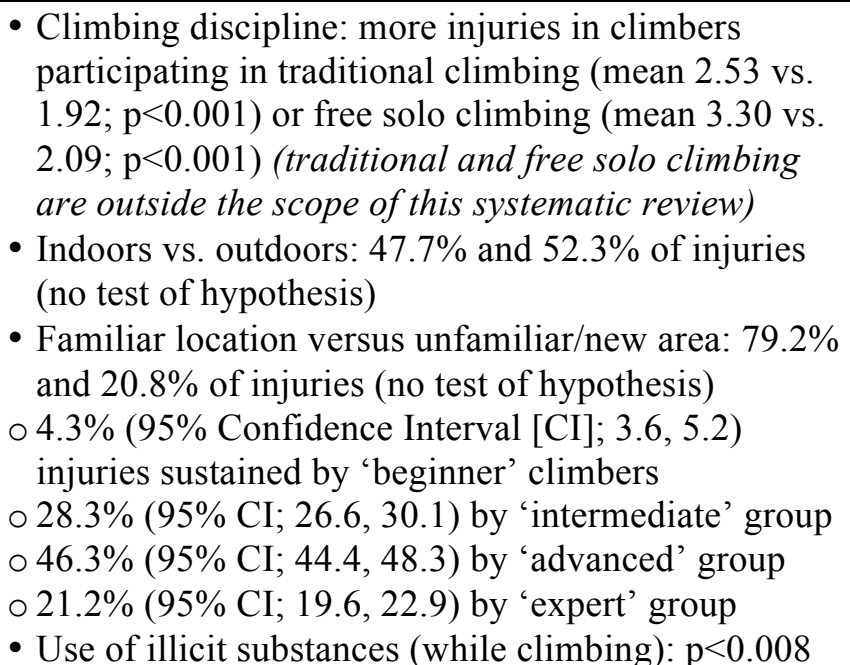 \\
\hline $\begin{array}{l}\text { Hasler et } \\
\text { al. (2012) }\end{array}$ & $\begin{array}{l}\text { Case- } \\
\text { control }\end{array}$ & $\begin{array}{l}\text { Indoor and } \\
\text { outdoor } \\
\text { climbers in } \\
\text { Switzerland } \\
(\mathrm{n}=113)\end{array}$ & 13 & $\begin{array}{c}\text { All types of } \\
\text { "rock } \\
\text { climbing" }\end{array}$ & $\begin{array}{l}\text { Acute injury from indoor or } \\
\text { outdoor climbing where the } \\
\text { climber was admitted to an } \\
\text { emergency department. } \\
\text { (Chronic overuse syndromes, } \\
\text { intracranial bleeding, skull } \\
\text { fractures, Glasgow Coma Score } \\
\text { [GCS] of greater than } 14 \text { or } \\
\text { persistent retrograde amnesia } \\
\text { were excluded.) }\end{array}$ & $\begin{array}{l}\text { - Sex: } p>0.05 \\
\text { - Age: } p>0.05 \\
\text { - Level of difficulty of the climbing route: } \mathrm{p}>0.05 \\
\text { - } \text { Duration of warm-up: } \mathrm{p}>0.05 \\
\text { - Readiness for risk: } \mathrm{p}>0.05 \\
\text { - Abstinence from alcohol and drugs: } \mathrm{p}>0.05 \\
\text { - }>10 \text { yrs. climbing experience (vs. }<1 \text { yr.): } \mathrm{p}>0.05 \\
\text { - } 1-10 \text { yrs. climbing experience (vs. }<1 \text { yr.): } \mathrm{p}=0.006 \text {, } \\
\text { Odds ratio (OR) }=5.34,(95 \% \mathrm{CI} ; 1.61 ; 17.76) \\
\text { - No previous experiences on the climbing route: } \\
\mathrm{p}=0.022, \mathrm{OR}=2.72(95 \% \mathrm{CI} ; 1.15,6.39)\end{array}$ \\
\hline
\end{tabular}




\begin{tabular}{|c|c|c|c|c|c|c|}
\hline $\begin{array}{l}\text { Study } \\
\text { (year) }\end{array}$ & $\begin{array}{l}\text { Study } \\
\text { design }\end{array}$ & $\begin{array}{c}\text { Study } \\
\text { population }\end{array}$ & $\begin{array}{l}\text { Downs } \\
\quad \& \\
\text { Black } \\
\text { score } \\
(/ 32)\end{array}$ & $\begin{array}{l}\text { Type of } \\
\text { climbing }\end{array}$ & Injury definition & Results of risk factor examination \\
\hline $\begin{array}{l}\text { Jones et al. } \\
(2008)\end{array}$ & $\begin{array}{c}\text { Cross- } \\
\text { sectional }\end{array}$ & $\begin{array}{l}\text { Rock } \\
\text { climbers in } \\
\text { Britain } \\
(\mathrm{n}=201)\end{array}$ & 11 & $\begin{array}{l}\text { All types of } \\
\text { "rock } \\
\text { climbing" }\end{array}$ & $\begin{array}{l}\text { Injuries requiring medical } \\
\text { attention or withdrawal from } \\
\text { sport participation for more } \\
\text { than one day }\end{array}$ & 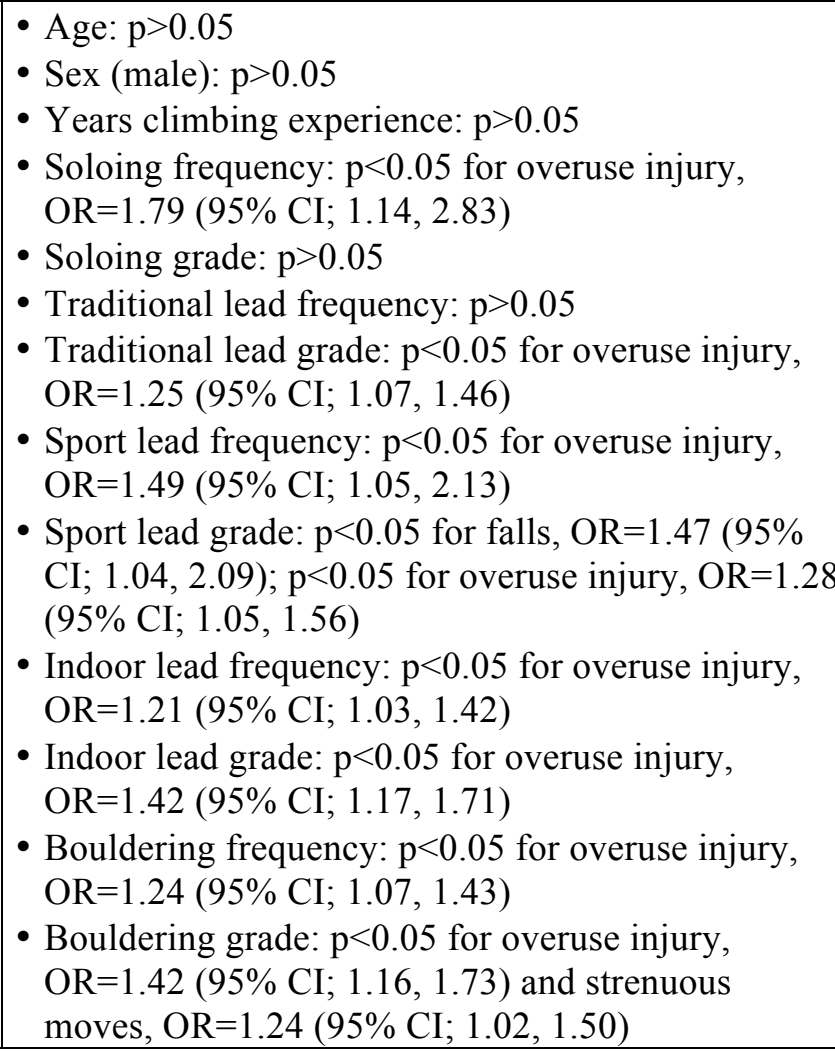 \\
\hline
\end{tabular}




\begin{tabular}{|c|c|c|c|c|c|c|}
\hline $\begin{array}{l}\text { Study } \\
\text { (year) }\end{array}$ & $\begin{array}{l}\text { Study } \\
\text { design }\end{array}$ & $\begin{array}{c}\text { Study } \\
\text { population }\end{array}$ & $\begin{array}{c}\text { Downs } \\
\& \\
\text { Black } \\
\text { score } \\
(/ 32)\end{array}$ & $\begin{array}{l}\text { Type of } \\
\text { climbing }\end{array}$ & Injury definition & Results of risk factor examination \\
\hline $\begin{array}{l}\text { Josephsen } \\
\text { et al. } \\
(2007)\end{array}$ & $\begin{array}{c}\text { Cross- } \\
\text { sectional } \\
\text { with a } \\
\text { prospective } \\
\text { cohort } \\
\text { component }\end{array}$ & $\begin{array}{l}\text { Boulderers in } \\
\text { two cohorts: } \\
\text { primarily } \\
\text { indoor } \\
\text { climbers and } \\
\text { primarily } \\
\text { outdoor } \\
\text { climbers } \\
(n=152)\end{array}$ & 12 & Bouldering & $\begin{array}{l}\text { Not defined, divided by } \\
\text { anatomical location and } \\
\text { mechanism of injury }\end{array}$ & $\begin{array}{l}\text { For finger injuries (analyzed since it was the most } \\
\text { common climbing injury, as opposed to falling): } \\
\text { - Outdoor vs. indoor bouldering: higher outdoor }(19 \\
(61 \%) \text { vs. } 6(27 \%) ; 95 \% \text { CI for risk difference: }-10 \text {, } \\
\text {-3) } \\
\text { - Previous history of finger injury: } p=0.03 \text {, OR }=4.0 \\
\text { (95\% CI; } 1.2,13.6) \\
\text { - Sex: } p>0.05 \\
\text { - Years climbing experience: } p>0.05 \\
\text { - Body mass index (BMI): } p>0.05 \\
\text { - Weight: } p>0.05 \\
\text { - Climbing ability: } p>0.05 \\
\text { For fall injuries: } \\
\text { - Outdoor vs. indoor bouldering: higher indoor }(7 \\
\text { (23\%) vs. } 11 \text { ( } 50 \%) ; 95 \% \text { CI for risk difference: } 2,- \\
\text { 53) } \\
\text { - Presence of spotters: } p>0.05 \\
\text { - Number of spotters: } p>0.05 \\
\text { - Height of average boulder: } p>0.05 \\
\text { - Height of tallest boulder climbed: } p>0.05 \\
\text { - Use of pads: } p>0.05 \\
\text { - Years climbing experience: } p>0.05 \\
\text { - BMI: } p>0.05 \\
\text { - Weight: } p>0.05 \\
\text { - Ability level: } p>0.05\end{array}$ \\
\hline
\end{tabular}




\begin{tabular}{|c|c|c|c|c|c|c|}
\hline $\begin{array}{l}\text { Study } \\
\text { (year) }\end{array}$ & $\begin{array}{l}\text { Study } \\
\text { design }\end{array}$ & $\begin{array}{c}\text { Study } \\
\text { population }\end{array}$ & $\begin{array}{c}\text { Downs } \\
\& \\
\text { Black } \\
\text { score } \\
(/ 32)\end{array}$ & $\begin{array}{l}\text { Type of } \\
\text { climbing }\end{array}$ & Injury definition & Results of risk factor examination \\
\hline $\begin{array}{l}\text { Logan et } \\
\text { al. (2004) }\end{array}$ & $\begin{array}{c}\text { Cross- } \\
\text { sectional }\end{array}$ & $\begin{array}{l}\text { Members of } \\
\text { the } \\
\text { Climber's } \\
\text { Club of } \\
\text { Great Britain } \\
(\mathrm{n}=545)\end{array}$ & 10 & $\begin{array}{l}\text { All types of } \\
\text { "rock } \\
\text { climbing" }\end{array}$ & $\begin{array}{l}\text { Wrist or hand injury by type } \\
\text { and severity }\end{array}$ & - Climbing intensity scale (CIS): $\mathrm{p}=0.01$ \\
\hline
\end{tabular}




\begin{tabular}{|c|c|c|c|c|c|c|}
\hline $\begin{array}{l}\text { Study } \\
\text { (year) }\end{array}$ & $\begin{array}{l}\text { Study } \\
\text { design }\end{array}$ & $\begin{array}{c}\text { Study } \\
\text { population }\end{array}$ & $\begin{array}{l}\text { Downs } \\
\quad \& \\
\text { Black } \\
\text { score } \\
(/ 32) \\
\end{array}$ & $\begin{array}{l}\text { Type of } \\
\text { climbing }\end{array}$ & Injury definition & Results of risk factor examination \\
\hline $\begin{array}{l}\text { Paige et al. } \\
\text { (1998) }\end{array}$ & $\begin{array}{c}\text { Cross- } \\
\text { sectional }\end{array}$ & $\begin{array}{l}\text { Traditional } \\
\text { and sport } \\
\text { climbers } \\
(\mathrm{n}=398)\end{array}$ & 7 & $\begin{array}{l}\text { Traditional } \\
\text { and sport } \\
\text { climbing }\end{array}$ & $\begin{array}{l}\text { Injuries occurring outdoors } \\
\text { during either traditional or sport } \\
\text { rock climbing }\end{array}$ & $\begin{array}{l}\text { Out of } 48 \text { injuries: } \\
\text { - } 38(79 \%) \text { were leading, } \\
\text { - } 8(17 \%) \text { were top roping, } \\
\text { - } 2(4 \%) \text { were belaying }\end{array}$ \\
\hline $\begin{array}{l}\text { Pieber et } \\
\text { al. (2012) }\end{array}$ & $\begin{array}{c}\text { Cross- } \\
\text { sectional }\end{array}$ & $\begin{array}{c}\text { Sport } \\
\text { climbers and } \\
\text { boulderers in } \\
\text { Austria } \\
(n=193)\end{array}$ & 12 & $\begin{array}{l}\text { Sport } \\
\text { climbing } \\
\text { and } \\
\text { bouldering }\end{array}$ & $\begin{array}{l}\text { Injuries and overuse } \\
\text { syndromes, classified by } \\
\text { anatomical location, cause, } \\
\text { diagnosis if known. Minor } \\
\text { abrasions were excluded. }\end{array}$ & $\begin{array}{l}\text { - } \text { Sex (male): } \mathrm{p}=0.032 \\
\text { - } \text { Age group }(\sim 29.5 \text { yrs. vs. } \sim 23 \text { yrs.): } \mathrm{p}=0.000 \text { (injury } \\
\text { higher in older group) } \\
\text { - } \text { Age group ( } \sim 39.7 \text { yrs. vs. } \sim 29.5 \text { yrs.): non- } \\
\text { significant (authors did not report a test statistic) } \\
\text { - Climbing intensity score (CIS) groups: } p=0.000 \\
\text { (injury higher in higher intensity groups) }\end{array}$ \\
\hline $\begin{array}{l}\text { Rohrbough } \\
\text { et al. } \\
(2000)\end{array}$ & $\begin{array}{c}\text { Cross- } \\
\text { sectional }\end{array}$ & $\begin{array}{l}\text { Elite } \\
\text { competitive } \\
\text { climbers in } \\
\text { the U.S. } \\
(\mathrm{n}=42)\end{array}$ & 12 & $\begin{array}{c}\text { Elite } \\
\text { competitive } \\
\text { climbing } \\
\text { (likely } \\
\text { sport } \\
\text { climbing) }\end{array}$ & $\begin{array}{l}\text { Upper extremity injuries only. } \\
\text { Recorded by location of pain, } \\
\text { type and difficulty of move that } \\
\text { caused injury, duration and } \\
\text { intensity of pain. Injuries } \\
\text { sustained in a fall were not } \\
\text { included. }\end{array}$ & $\begin{array}{l}\text { - Age: significant for A2 pulley pain only }(\mathrm{p}=0.004) \\
\text { - Years of climbing experience: significant for history } \\
\text { of medial epicondylitis only }(\mathrm{p}<0.0005) \\
\text { - Difficulty level climbing: non-significant (authors } \\
\text { did not report a test statistic) } \\
\text { - Years climbing at an elite level: non-significant } \\
\text { - Gender: non-significant }\end{array}$ \\
\hline $\begin{array}{l}\text { Schlegel et } \\
\text { al. (2002) }\end{array}$ & $\begin{array}{c}\text { Cross- } \\
\text { sectional }\end{array}$ & $\begin{array}{l}\text { Adolescent, } \\
\text { nationally- } \\
\text { ranked sport } \\
\text { climbers } \\
(\mathrm{n}=29)\end{array}$ & 13 & $\begin{array}{c}\text { Sport } \\
\text { climbing } \\
\text { (elite level) }\end{array}$ & $\begin{array}{l}\text { Climbers were divided into two } \\
\text { groups: one with current finger } \\
\text { pain, one asymptomatic. }\end{array}$ & $\begin{array}{l}- \text { Age: } \mathrm{p}>0.05 \\
\text { - Height: } \mathrm{p}>0.05 \\
- \text { Body weight: } \mathrm{p}>0.05 \\
- \text { Percentage of body fat: } \mathrm{p}>0.05 \\
- \text { Laxity score }(0-9): \mathrm{p}>0.05 \\
\text { - Start of regular climbing training (age): } \mathrm{p}>0.05 \\
\text { - Increase in climbing difficulties (highest grade and } \\
\text { increase in grade per year): } \mathrm{p}>0.05\end{array}$ \\
\hline
\end{tabular}




\begin{tabular}{|c|c|c|c|c|c|c|}
\hline $\begin{array}{l}\text { Study } \\
\text { (year) }\end{array}$ & $\begin{array}{l}\text { Study } \\
\text { design }\end{array}$ & $\begin{array}{c}\text { Study } \\
\text { population }\end{array}$ & $\begin{array}{c}\text { Downs } \\
\& \\
\text { Black } \\
\text { score } \\
(/ 32)\end{array}$ & $\begin{array}{l}\text { Type of } \\
\text { climbing }\end{array}$ & Injury definition & Results of risk factor examination \\
\hline $\begin{array}{l}\text { Schlegel et } \\
\text { al. (2002) } \\
\text { continued }\end{array}$ & & & & & & $\begin{array}{l}\text { - Climbing training volume during the last season } \\
\text { (hours/week): } p>0.05 \\
\text { - General physical training volume during the last } \\
\text { season (hours/week): } p>0.05 \\
\text { - Climbing techniques such as position of the fingers } \\
\text { while climbing on small grips: } p>0.05 \\
\text { - One finger climbing: } p>0.05 \\
\text { - Grip strength: } p>0.05 \\
\text { - Use of initial warm-up: } p>0.05\end{array}$ \\
\hline $\begin{array}{l}\text { Shahram et } \\
\text { al. (2007) }\end{array}$ & $\begin{array}{c}\text { Cross- } \\
\text { sectional }\end{array}$ & $\begin{array}{c}\text { Male } \\
\text { climbers } \\
\text { from the } \\
\text { western } \\
\text { provinces of } \\
\text { Iran } \\
(n=50)\end{array}$ & 7 & $\begin{array}{c}\text { Sport } \\
\text { climbing }\end{array}$ & $\begin{array}{l}\text { Injury determined by clinical } \\
\text { examination, and based on } \\
\text { clinical signs such as topical } \\
\text { pain, weakness and tenderness } \\
\text { (especially with palpation), } \\
\text { decrease in range of motion, } \\
\text { topical deformity, and physical } \\
\text { tests }\end{array}$ & $\begin{array}{l}\text { - Maximum climbing grade: } \mathrm{p}=0.000 \\
\text { - Type of climbing: non-significant (authors did not } \\
\text { report a test statistic) }\end{array}$ \\
\hline $\begin{array}{l}\text { Tomczak } \\
\text { et al. } \\
(1989)\end{array}$ & $\begin{array}{c}\text { Cross- } \\
\text { sectional }\end{array}$ & $\begin{array}{l}\text { Rock } \\
\text { climbers (all } \\
\text { disciplines) } \\
\text { in the U.S., } \\
\text { England, } \\
\text { Canada, } \\
\text { Australia, } \\
\text { Peru } \\
(\mathrm{n}=460)\end{array}$ & 7 & $\begin{array}{l}\text { All types of } \\
\text { "rock } \\
\text { climbing", }\end{array}$ & $\begin{array}{l}\text { Injuries were classified as either } \\
\text { fall injuries or overuse injuries. } \\
\text { Location of each injury was } \\
\text { determined. }\end{array}$ & - Stretching prior to climbing: 'P' value of 0.9763 \\
\hline
\end{tabular}




\begin{tabular}{|c|c|c|c|c|c|c|}
\hline $\begin{array}{l}\text { Study } \\
\text { (year) }\end{array}$ & $\begin{array}{l}\text { Study } \\
\text { design }\end{array}$ & $\begin{array}{c}\text { Study } \\
\text { population }\end{array}$ & $\begin{array}{l}\text { Downs } \\
\& \\
\text { Black } \\
\text { score } \\
(/ 32)\end{array}$ & $\begin{array}{l}\text { Type of } \\
\text { climbing }\end{array}$ & Injury definition & Results of risk factor examination \\
\hline $\begin{array}{l}\text { Wright et } \\
\text { al. (2001) }\end{array}$ & $\begin{array}{c}\text { Cross- } \\
\text { sectional }\end{array}$ & $\begin{array}{c}\text { Climbers } \\
\text { participating } \\
\text { at indoor } \\
\text { facilities } \\
(\mathrm{n}=295)\end{array}$ & 11 & $\begin{array}{l}\text { Indoor } \\
\text { climbing } \\
\text { (likely } \\
\text { sport } \\
\text { climbing } \\
\text { and } \\
\text { bouldering) }\end{array}$ & $\begin{array}{l}\text { Overuse injury sustained } \\
\text { indoors, defined in an } \\
\text { introductory paragraph and } \\
\text { reiterated verbally. }\end{array}$ & $\begin{array}{l}\text { - Sex: } \mathrm{p}=0.009 \\
\text { - } \text { Preferred activity } \\
\text { - } \quad \text { Bouldering vs. top roping: } \mathrm{p}=0.001 \\
\text { - } \quad \text { Leading vs. top roping: } \mathrm{p}>0.05 \\
\text { - } \quad \text { Bouldering AND leading (together) vs. top } \\
\text { - } \text { roping: significant } \mathrm{p}<0.0005 \\
\text { - } \text { Bouldering: } \mathrm{p}<0.0005 \\
\text { - } \text { Age groupificant } \mathrm{p}<0.0005 \\
\text { - Years experience: } \mathrm{p}=0.006 \\
\text { - Visits per annum: } \mathrm{p}=0.016\end{array}$ \\
\hline
\end{tabular}




\subsection{Discussion}

Though a multitude of potential risk factors for injury in rock climbing have been examined in previous research, it remains unclear which of these are true predictors. The different disciplines of climbing, the differing injury definitions, and the heterogeneous nature of the study populations across the reviewed studies all contribute to the conflicting results. Furthermore, methodological quality is an important consideration when making conclusions based on the reviewed studies. For the same reasons, the true incidence of rock climbing injury is impossible to estimate.

Many studies examining sport injury in general have identified sex, age, and BMI as potential risk factors for injury in youth, but so far there are conflicting results in the literature as to whether these factors affect injury risk in rock climbers in this, or any

other, age group. ${ }^{12526353654}$ Age and sex are both non-modifiable, but BMI is a potentially modifiable risk factor, and may be relevant for future interventions.

None of the reviewed studies that evaluated sex as a risk factor found that females had a higher risk of injury in climbing than males, suggesting that either no difference exists, or that males are more likely to be injured than females. However, it is difficult to know the validity of these conclusions, as the overall results were conflicting. Furthermore, the studies that included sex in their analysis were of varying methodological quality and there was a systematic bias in the studies reviewed here; they generally employed, but did not control for, samples composed predominantly of male subjects. Further research is needed to evaluate sex as a risk factor for climbing injury, to 
conclude if males are truly at a higher risk of injury than females as concluded by other non-climbing studies. ${ }^{54}$

More research is also needed in order to confidently draw conclusions about age as a risk factor for injury in sport climbing and bouldering, as results have been conflicting in the literature. This is not surprising as previous research has used samples of convenience, and therefore no two studies have examined the same age groups. The methodological quality of research again makes conclusions difficult to draw in this area. For example, the participants in the study by Schlegel et al. (2002) did not well represent the source population, and the authors failed to numerically report the results. ${ }^{8}$ Carmeli et al. (2002) had a small sample size $(n=19)$ and failed to report actual probability values or confidence intervals. The low number of younger participants $(<21$ years old $)$ in the study by Backe et al. (2008) makes it difficult to draw conclusions confidently about this study's younger age group. Previous research has suggested that there are differences in the types of injury sustained by younger and older climbers, such as epiphyseal fractures of the fingers from repeated stress on the bone in children and adolescents. ${ }^{7}$ Based on this research, the UIAA has set the minimum age for international bouldering competition participation to 16 years old. This guideline was established to minimize the risk of epiphyseal fractures, as bouldering training often involves dynamic and maximal power movements that should be avoided in children whose bones have not yet matured sufficiently. ${ }^{7}$ In light of this information, it would follow that since the types of injury differ between adults and children, the risk of injury may differ as well. Similar conclusions have been made previously with regards to resistance training in young children and adolescents, though past claims that such training is unsafe and poses a risk 
of injury are now being refuted. Current research indicates that age-appropriate resistance training can be safe. ${ }^{55}$ Future studies will be needed to explore this possibility in young climbers.

An additional consideration is that multicollinearity may exist with age when it is examined as a risk factor for injury in multivariate analyses. Factors such as years of experience and difficulty level may covary with age, making analyses involving these individual factors invalid if they are not adjusted for.

Though there is a paucity of valid research about BMI as a risk factor for injury in climbing, the results reported by Backe et al. (2008) that a higher BMI was significantly associated with a higher risk of injury appear to have more validity than the other studies reviewed here. Backe et al. (2008) scored higher on methodological quality, and their study sample approached a normal population distribution for BMI, thus potentially making their results more generalizable and valid for a recreational population than those of the former two studies. Previous research has also indicated that BMI is a potentially modifiable risk factor in other sports. ${ }^{36}$ As such, it may gain attention for future injury prevention strategies in climbing. Similarly, body weight merits further investigation as a potentially modifiable risk factor and should be considered for injury prevention, though care must be taken when analyzing BMI and body weight together, considering multicollinearity between these two measures.

The literature suggests that the number of years of experience that a climber has increases his or her risk of injury. More research is needed to confirm current findings for this factor and to explore whether it covaries with other factors, such as age. The same is true for the highest difficulty or skill level at which individuals can climb. It is, as yet, 
challenging to make conclusions about this factor due to the many methods of rating climbs and the conflicting results in previous studies. Rating sport climbing routes and boulder problems is inherently subjective, and converting between scales is therefore challenging and somewhat arbitrary. Though this will continue to be a difficulty, as the UIAA grading system becomes more common in the research community it will become easier to compare studies and to therefore make conclusions about the difficulty level at which participants climb.

When compared to top roping (and in two cases bouldering), the examination of lead climbing as a risk factor suggests that it presents a higher potential for injury. The only study to find no significant difference was by Shahram et al. (2007), wherein their methodology was of low quality, and thus of low validity. ${ }^{49}$ Further research is needed to confirm these findings. This is a potentially modifiable risk factor, in that if lead climbing is shown to have a higher risk of injury, it may be advisable to limit the amount of "leading" that a climber participates in, wherever possible.

Results are conflicting with regards to volume as a modifiable predictor for injury in climbing. Though it seems logical to conservatively conclude from the studies by Backe et al. (2008) and Schlegel et al. (2002) that higher climbing volume increases the risk of injury, especially overtraining and overuse injury, it is certain that additional studies are needed to confirm this finding. ${ }^{825}$ This will be important information for future injury prevention measures, as knowing the healthy climbing volume limit will help reduce future injuries.

Two studies combined the volume of climbing with the grade being climbed to give the CIS. Both showed a significant correlation between higher climbing intensity scores 
and injury. However, neither study sample was representative of their population, and neither reported adjusting for any possible confounders. It is therefore unknown whether factors such as previous climbing experience, age, sex, or other demographic or anthropometric characteristics may have distorted the measure of effect. ${ }^{31}{ }^{52}$ Certainly, further research on climbing volume and intensity is required, but the CIS may be a measure to continue using in future studies. As stated with regards to climbing volume, CIS is a potentially modifiable risk factor and knowing the healthy limit may aid in future injury prevention.

Only two studies reviewed here examined indoor climbing compared with outdoor climbing, and with the differences in objectives and the errors in methodological quality, conclusions are uncertain. Josephsen et al. (2007) examined bouldering only, and Gerdes et al. (2006), who examined all "rock climbers," failed to adjust for any potential modification or confounding. ${ }^{2653}$ Further research is necessary to make valid conclusions about whether either environment poses a higher risk for injury.

The influence of drugs and alcohol on climbing injury is also difficult to make conclusions about, though this is perhaps the most easily modifiable risk factor examined in this review. Research involving general youth populations have shown that behaviours such as alcohol consumption and smoking tobacco are risk factors for sport injury in youth. ${ }^{37}$ Although findings by Gerdes et al. (2006) and by Hasler et al. (2012) are conflicting, it follows that these risk behaviours would also increase the risk of injury in young climbers. ${ }^{51} 53$

Finally, muscular strength has been suggested as a possible factor influencing musculoskeletal injury. ${ }^{56}$ Grip strength was commented on in two studies, though not 
statistically analyzed. ${ }^{32}$ Low grip strength may be a modifiable risk factor, and research is certainly warranted in this area.

Few studies have investigated prevention strategies for climbing. It is therefore imprudent to make conclusions based on the available data. Stretching is often used as an injury prevention measure, though Josephsen et al. (2007) found no association, and Tomczak et al. (1989) actually suggested a strong relationship between climbing injury and the use of stretching. However, a high proportion of the subjects in this study reported stretching prior to climbing (73\%), and the association found by the authors does not necessarily imply causation. It is likely that this is a spurious correlation.

Though the presently available studies do not show that warming up causes any difference in the risk of injury, and the use of stretching remains inconclusive, this may yet be an avenue for future research as organized warm-up and dynamic flexibility training routines have been shown to decrease injury in other sports such as soccer. ${ }^{57}$

Further research is necessary regarding this topic, especially focusing on taping, weight training, BMI, and the use of stretching, so that as the knowledge of modifiable risk factors for injury in climbing grows, future prospective, longitudinal, and intervention studies will aid in validating and establishing successful injury prevention measures.

\subsubsection{Limitations}

Several factors limit the ability to make valid conclusions based on the data available for this systematic review, including the multi-disciplinary nature of climbing, 
the multitude of injury definitions, the methodology with which data was collected, and the heterogeneous nature of the study populations.

Non-differential misclassification bias may be introduced because studies have not often differentiated between different types of climbing, though each discipline has unique characteristics and likely distinctive risk factors. Thus, other types of climbers that do not participate in sport climbing or bouldering may be included in the sample. Injury definitions pose a second possible measurement bias as they range from including only acute injury to chronic injuries only, and may include or exclude the approach to the climb, belaying, certain anatomical locations, and mechanisms of injury (Table 2.3). With the standardization of injury reporting by the UIAA Medical Commission it is likely that this will become less of a problem in the future. ${ }^{44}$ Study populations have also been highly heterogeneous and therefore difficult to compare between studies.

Systematic reviews inherently contain the limitations of each study included. The majority of the reviewed studies were retrospective surveys and were therefore subject to all the bias associated with cross-sectional studies. Recall bias and an overestimation of the most traumatic injuries may result, as well as uncertainty of temporal relationships and causation. Selection bias is also a limitation of the convenience samples, since the most acutely injured climbers may not be included in the sample if they were not present at the locations from which the sample was selected.

Finally, because significant results may be more likely to be submitted and accepted for publication, publication bias must be considered as a possibility in systematic reviews. However, many results from this review were conflicting since the 
studies included yielded both significant and non-significant results, suggesting a lower likelihood of this bias.

\subsubsection{Recommendations for Future Research}

There is a paucity of methodologically rigorous studies examining risk factors for injury in sport climbing and bouldering. The literature will benefit from prospective cohort studies from which interpretations based on incidence, risk, and temporality can be made. Examining youth climbing specifically will be important, as there is an even greater paucity of literature involving children and adolescents, especially with regards to injury. Analyzing the disciplines separately will also be important, as each is unique and there is evidence to suggest that bouldering and sport climbing have different rates and possibly types of injury. ${ }^{25} 30$

\subsection{Conclusions}

Further research examining risk factors for injury in climbing is warranted, as it is difficult to make valid conclusions due to the nature of the study designs and methodology in the studies examined in this systematic review. Many of the potential risk factors examined are worth further investigation, namely those that are modifiable. With this valuable information, injury prevention strategies can be implemented in the future. It will also be important for future research to involve youth, so that young climbers and their coaches will be able to learn safe development and training for climbing. As sport 
climbing and bouldering continue to grow, rising participation will intensify the need for injury prevention measures. 


\section{CHAPTER THREE: METHODS}

\subsection{Study Design}

A cross-sectional study design was used. Data on injury incidence rates and proportions, mechanisms, main types, and potential risk factors for injury were collected in the form of a questionnaire that was distributed to both elite and recreational climbers, aged 11 to 19 years.

\subsection{Study Population}

Nineteen indoor climbing facilities across Alberta were targeted for participant recruitment in this study. These facilities were in Calgary, Edmonton, Lethbridge, Canmore, Banff, Fort McMurray, Hinton, Grande Prairie, Medicine Hat, Sylvan Lake, Jasper, and Red Deer. The study population included males and females, aged 11 to 19 years. Climbers were recruited from competitive junior teams and from recreational programs, lessons, or workshops at each gym, as well as by convenience sampling at two local youth competitions. The research coordinator directly recruited participants at nine of these facilities, by introducing and describing the research to climbing teams and groups, while a research representative carried out this responsibility at the other nine participating gyms. Research representatives also aided the research coordinator with further recruitment at each facility by contacting potential participants not present at these brief presentations, and by distributing and gathering consent forms. 
The age range of 11 to 19 years encompasses all competitive age groups for youth in climbing. The youngest age category includes climbers aged 11 years and under, while the eldest category includes 18 - and 19-year-olds. ${ }^{14}$ To help ensure that each subject could read and write proficiently (at a grade 5 minimum level) and thus be able to competently complete the questionnaire, 11 years was chosen as the youngest age for participants. It was communicated that parents or coaches could help the participant if they had difficulty in understanding questions.

The sample size calculations, located in Appendix C, were based on a two-sided comparison of proportions with a significance level of $5 \%$ and a power of $80 \%(\alpha=0.05$, $\beta=0.20$ ). Injury incidence proportions (IPs) were used to determine sample size, as no similar studies have reported climbing injury incidence rates (IRs) (per 1000 participation hours). Based on an a-priori hypothesis that elite youth climbers sustain a higher rate of injury than recreational youth climbers, the required sample size for this study was calculated to be 206 subjects in total, comprised of 103 recreational and 103 elite climbers. This was a conservative estimate containing a continuity correction, based on calculations done in STATA 12.0. The sample size was calculated to detect a $20 \%$ difference between exposure groups. An injury IP of 0.30 was used as an estimate for recreational climbers, as this number was reported by Backe et al. (2008) from their cross-sectional study involving a general climbing population. ${ }^{25}$ An IP of 0.50 was used as the conservative estimate of injury incidence in elite athletes, as there are no studies reporting the overall IP of injury in this population, though some research suggests a higher IP in elite climbers than for recreational climbers. ${ }^{658} 12$ Thus, the sample size of 
206 subjects would detect a difference of $20 \%$ injury proportions or larger between elite athletes and recreational climbers.

Potential clustering effects were not accounted for in this sample size calculation, as there were so few clusters (10 different climbing gyms), and in the original proposal for this study, only eight gyms were expected to participate. See the Research Limitations section (5.5) for more details.

Inclusion criteria for elite climbers were:

1. Participation in competition climbing at the time of the study (for the 2012-2013 competition season) and for at least two years prior, or participation in an international competition during the past year.

2. Membership in Competition Climbing Canada/Competition d'Escalade Canada (CEC).

3. Completion of informed consent form signed by the climber and at least one parent or guardian if the participant was less than 18 years of age.

4. Being between the ages of 11 and 19 years at the time of the questionnaire. Exclusion criteria for elite climbers were:

1. Refusal to participate.

Inclusion criteria for recreational climbers were:

1. Participation in sport climbing or bouldering at a climbing facility in Alberta.

2. Participation in sport climbing or bouldering during the previous year, at least once a month. 
3. Completion of informed consent form signed by the climber and at least one parent or guardian if the participant was less than 18 years of age.

4. Being between the ages of 11 and 19 years at the time of the questionnaire. Exclusion criteria for recreational climbers were:

1. Refusal to participate.

\subsection{Procedures}

\subsubsection{Data Collection}

Eight climbing facilities in Calgary $(n=3)$, Edmonton $(n=3)$, Canmore $(n=1)$, and Banff ( $n=1)$, Alberta were initially asked to participate in this study. One facility in Calgary declined to be part of the study. From the seven participating facilities, too few participants were recruited to meet the required sample size. In order to enhance participant numbers, three additional smaller facilities in Calgary that offer youth climbing classes were recruited (University of Calgary Outdoor Centre, Mount Royal University climbing wall, Shawnessy YMCA), and an amendment to the original ethics application was sent to the Children's Hospital Research Ethics Board (CHREB) to extend recruitment to additional climbing facilities in Alberta. Other towns with facilities included Grande Prairie, Fort McMurray, Hinton, Jasper, Lethbridge, Medicine Hat, Red Deer, and Sylvan Lake. Each of these locations possesses one climbing gym. The amendment also proposed distributing paper copies of the questionnaire as an alternative option to completing the survey online, as a way to expedite data collection. In February 
2013, this amendment was approved. It should be noted that all the facilities above offered youth climbing programs except for the Jasper Fitness and Aquatics Centre and the Hinton Dr. Duncan Murray Recreation Centre. Sylvan Lake did offer programs, but at the time of recruitment did not have any youth above the age of 10 years participating in their programs. At these three facilities, posters were put up advertising the study, but no other recruitment took place.

Each subject was provided with information and details regarding the study and its purpose. They were required to give written assent/consent, and an additional consent form signed by a legal guardian was required for those subjects under 18 years of age (Appendices D, E, F). Once consent forms were received, participants were given a unique study identification number and password, which they used to log in and complete an anonymous on-line questionnaire. Beginning in February 2013, following approval of the above-mentioned ethics amendment, paper copies were also distributed to consenting subjects (Appendix G). Unique study identification numbers were used to maintain the anonymity of each of these subjects as much as possible. In order to prevent coercion, coaches were not involved in this process. To reduce selection bias, gym managers were asked to send out a mass email to participants in their programs, in order to contact those youth that may not have been present at the climbing facility due to injury. Five facilities agreed to do this [Calgary Climbing Centre (CCC) Chinook, CCC Stronghold, The Cave Bouldering Gym, The Banff Centre, and Vertically Inclined Rock Gym], while others did not keep contact information for youth and parents on file, and some declined due to privacy concerns. 
A study poster was also advertised in climbing facilities beginning in February 2013 in a further attempt to increase recruitment.

\subsubsection{Study Questionnaire}

The questionnaire used for this study can be found in Appendix G. Information on demographics and climbing experience were collected, including date of birth, sex, height, weight, maximum climbing grade achieved red-point (without falls), safety instruction received, safety and prophylactic practices, and injury. Maximum climbing grade achieved "red-point" is the hardest grade attained without falls on a route and was used as a general measure of climbing ability and skill. The number of years of experience climbing at the level each climber had specified (recreational versus competitive) was also queried. This aided in objectively determining whether a subject was classified as "elite" or "recreational," as some competitive junior teams require very little prior climbing experience, while conversely, some top athletes are not members of junior teams.

The questionnaire contained items relating to the socioeconomic status (SES) of each child's family, taken from the Family Affluence Scale II (FAS II), originally developed by Williams et al. (1997), and amended in the World Health Organization Health Behaviour in School-aged Children study. ${ }^{59-61}$ The FAS II is a four-item measure of family wealth and is used as a valid alternative for SES when surveying children and adolescents. ${ }^{60}$ Data on exposure time (daily, weekly, and monthly frequency and hours) was also collected, as well as descriptions of injury types, anatomical locations, and 
mechanisms of injury incurred in the previous 12 months. Whether there were any subsequent visits to practitioners including doctors, physiotherapists, chiropractors, athletic therapists, massage therapists, or others was collected. Information on the type of climbing being performed at the time of any injuries was asked (i.e., bouldering or sport climbing), as well as whether the injury took place outdoors or indoors.

The questionnaire itself was face validated through interviews with four each of selected researchers, climbers, and parents, as well as three coaches, two physicians, two physiotherapists, and one occupational therapist ( $n=20$ total). One parent was also an athletic therapist. As a validation measure for exposure hours, coaches were asked to complete a brief questionnaire to aid in estimating the number of hours per week and months per year that their youth groups climbed, indoors and outdoors separately.

\subsubsection{Outcome measures}

The primary outcome measure of interest was climbing injury. The definition of “climbing injury" as defined by the International Mountaineering and Climbing Federation (UIAA) Medical Commission Injury Classification for Mountaineering and Climbing Sports, is "Any physical complaint sustained by a participant during trekking, mountaineering or climbing. This includes belaying, and ascent and descent to the climb." ${ }^{44}$ This definition includes, though is not limited to, sport climbing and bouldering. The consensus statement on injury definitions and data collection procedures in studies of football (soccer) injuries by Fuller et al. (2006) can also be adapted to climbing, and provides a similar but more detailed definition. ${ }^{62}$ This definition, modified 
specifically for the present study and combined with the above UIAA definition, would read, "Any physical complaint sustained by a climber that results from sport climbing or bouldering either indoors or outdoors, irrespective of the need for medical attention or time loss from climbing activities." An injury that results in a climber receiving medical attention (i.e., first aid, doctor, physiotherapist, chiropractor, athletic therapist, massage therapist, or other) is referred to as a "medical attention" injury, and an injury that results in a climber being unable to take full part in future sport climbing or bouldering participation as a "time loss" injury. Time loss injury is further categorized according to severity using groups defined by Fuller et al. (2006): Slight injury (no time loss), minimal (1-3 days), mild ( $4-7$ days), moderate ( $8-28$ days), severe ( $>28$ days), and career ending. ${ }^{62}$ Injury has also been recorded by anatomical location. Main groupings and categories for injury classification defined by the UIAA Medical Commission are summarized in Appendix A. ${ }^{44}$

\subsubsection{Exposure Variables}

Secondary and exploratory exposure variables involved potential risk factors for injury, both intrinsic and extrinsic. Intrinsic risk factors are those that are internal and unique to the individual, while extrinsic factors are those that are external to the individual. ${ }^{47}$ Potential intrinsic risk factors included climbing level, age in years measured from date of birth, sex, height, weight, the difficulty at which subjects climbed using the Yosemite Decimal System (YDS) scale (and converted to the standardized metric scale), injury in a sport other than sport climbing and bouldering, and risk-taking 
behaviours (i.e., smoking tobacco, alcohol consumption, and seatbelt non-use) that have been shown to be related to youth injury in sport. ${ }^{37}$ Potential extrinsic risk factors included SES on the FAS II, the specific disciplines of climbing being performed, participation in sports other than sport climbing and bouldering, helmet use, preventive taping, use of a cool-down, and climbing exposure hours, collected in hours per week and months per year for indoors and outdoors separately. Exposure hours were also used to calculate incidence rates in the primary analysis.

\subsection{Statistical Methods}

Study Trax (ScienceTrax, Macon, GA) was used for data entry, management and storage. All statistical analyses were carried out using STATA version 12 (Statacorp, College Station, TX). Injury types, mechanisms, and anatomical locations were analyzed using descriptive statistics. The primary analysis examined the injury IP and IR in recreational and elite climbers. IP is presented as the number of injuries per 100 participants per year, and IR is presented as the number of injuries per 1000 climbing exposure hours. Potential risk factors associated with injury were assessed, including climbing level, sex, age group, height, weight, socioeconomic status, sport climbing grade, venue (i.e., indoor versus outdoor), participation in sports other than sport climbing and bouldering, injury in these other sports within the previous year, any helmet use, preventive taping (i.e., fingers, hands, wrists, ankles, shoulders, or skin), use of a cool-down after climbing, and alcohol consumption as a risk-taking behaviour. Continuous variables were dichotomized. Crude odds ratios (ORs) based on univariate 
analyses with $95 \%$ confidence intervals (CIs) were calculated for each variable, as well as ORs where participation hours were used as an offset for each. P-values were also presented, and the statistical significance level was set at $5 \%(\alpha=0.05)$. From this preliminary analysis, pertinent variables showing a 20\% difference in OR were considered clinically significant predictors of injury. Potential risk factors were also examined with regards to time loss injury (at least one day of time loss) in univariate analyses for comparison. Potential risk factors for injury were then analyzed using a multivariate logistic regression, and effect modification was examined between age group and climbing level, and between sport climbing grade and climbing level, as it was suspected that these variables might modify the relationship between climbing level and injury. No previous literature has suggested that effect modification is present by any other factors in this relationship, and was therefore not assessed. The model was examined for potential confounding by all of the above variables. Total participation hours were again used as an offset in the model. Adjusted ORs with 95\% CIs in the multivariate logistic regression model were reported for each risk factor.

Discipline (i.e., sport climbing or bouldering) could not be examined as a risk factor in the logistic regression. This was due to the nature of the questionnaire. Either sport climbing or bouldering was selected with regards to each individual injury sustained, as each subject could participate in both bouldering and sport climbing at different times. Therefore, discipline was only indicated in the event of an injury. Consequently, it was not possible to examine this variable in a model where the outcome was either injury or non-injury. 
Due to the low number of outdoor injuries (eight), it was also not feasible to examine venue as a risk factor in this analysis.

Body mass index (BMI) was originally calculated in order to examine overweightness and obesity as a potential risk factor. However, based on international guidelines for BMI cut-offs for overweight and obese children proposed by Cole et al. (2000), only two participants fell into the "overweight" category, and none into the obese category. ${ }^{63}$ Since there are presently no established cut-off points for underweight children, BMI cannot yet be further categorized in this population. As such, it was not meaningful to examine BMI as a risk factor. Height and weight were fitted individually to predict injury instead for the univariate analysis.

Sport climbing grade was examined as a risk factor rather than bouldering grade, as all but 15 participants were able to report on this variable. Those who neglected to do so either did not participate in sport climbing $(n=9)$, or else were unfamiliar with the grading system $(\mathrm{n}=6)$.

Three "risk-taking behaviours" were queried: alcohol consumption, tobacco use, and seatbelt non-use. These have previously been shown to relate to youth injury in other sports. ${ }^{37}$ Due to the lack of variability in responses however, only alcohol consumption could be examined.

\section{Dichotomizing of risk factor variables}

All variables examined in the risk factor analyses were dichotomized. As age was approximately uniformly distributed in this sample, 15 years was used as the cut point between groups (sample median $=14.42$ years, mean $=14.70$ years). Group one contained 
11 - to $<15$-year-olds $(\mathrm{n}=67)$, and group two, 15 - to $<20$-year-olds $(\mathrm{n}=49)$.

SES, based on the FAS II, showed a left-skewed distribution with a large number having "high affluence" overall. In order to dichotomize, the first group contained those with "high affluence," scoring eight to nine on the FAS II $(n=72)$. The second group then contained individuals in all other categories, ranging from "low" to "medium-high affluence," and scoring between zero and seven on the FAS II (n=44). ${ }^{60} 61$ It was less meaningful to dichotomize the SES groups this way than to group scores based on the established cut-offs, but few participants scored lower than seven on the FAS II, and the sample could not be categorized meaningfully in any other way.

Sport climbing grades were split into two categories: low to moderate skill level, grades 5.8-5.11a $(\mathrm{n}=47)$, and moderate to high skill level, grades $5.11 \mathrm{~b}-5.13 \mathrm{c}(\mathrm{n}=54)$. Height and weight were both dichotomized into groups by the upper $25^{\text {th }}$ percentile by age group in order to prevent multicollinearity with age.

\subsection{Ethical Considerations}

The proposal for this study was approved by the Office of Medical Bioethics, University of Calgary, CHREB July 23, 2012. Autonomy of the subjects in this study was respected by obtaining written assent/consent from all participants, and in the case of those youth who were under 18 years of age, consent from a parent or guardian was obtained as well. Coaches who agreed to fill out a brief questionnaire to aid in validating exposure hours also signed a consent form. All personal information was kept confidential and the privacy of the subjects participating in this study was maintained. 
The questionnaire was anonymous and did not require names. All data was entered directly into Study Trax and was identified only by an anonymous user identification number, and accessible only by authorized study personnel with a unique password. All data files with identifying information were stored on a secure server. The password for this server changed every 60 days, and was not stored on the computer or in the personal effects of the investigator. Data files were not sent electronically. All paper copies and files have been stored in a locked filing cabinet located in the Roger Jackson Sport Medicine Centre at the University of Calgary (KNB 3300A). 


\section{CHAPTER FOUR: RESULTS}

\subsection{Study Participants}

Eighteen facilities across Alberta agreed to participate in this study. These facilities included the Sally Borden at the Banff Centre, the Cave Bouldering Gym in Canmore, the Calgary Climbing Centre (two locations), the University of Calgary Outdoor Centre, Mount Royal University climbing wall, the Shawnessy YMCA in Calgary, Rock Jungle Fitness in Edmonton, the University of Alberta in Edmonton, the Edmonton Vertically Inclined Rock Gym, K-Rock Climbing Wall in Fort McMurray, the Grande Prairie Regional College climbing wall, Ascent Climbing Gym at the University of Lethbridge, the Medicine Hat Downtown Family YMCA, the Red Deer Collicutt Centre, Best Body Fitness in Sylvan Lake, the Hinton Dr. Duncan Murray Recreation Centre, and the Jasper Fitness and Aquatic Centre. Ten of these facilities yielded consenting participants, though only nine ran programs for youth aged 11 to 19 years. Participation at each facility is summarized in Table 4.1. Sixty-two competitive athletes and 223 recreational climbers were approached $(62+223=285)$, and a total of 126 climbers $(44 \%)$ consented to participate in this study. One hundred and sixteen individuals (41\% response rate) completed the questionnaire, $52(45 \%)$ of whom were competitive climbers, and 64 (55\%) recreational. Figure 4.1 summarizes recruitment. 
Table 4.1 Recruitment numbers at climbing facilities in each city

\begin{tabular}{|c|c|c|c|c|c|c|}
\hline \multirow{2}{*}{ Facility } & \multicolumn{2}{|c|}{$\begin{array}{l}\text { Number of } \\
\text { competitive climbers }\end{array}$} & \multicolumn{2}{|c|}{$\begin{array}{l}\text { Number of } \\
\text { recreational climbers }\end{array}$} & \multirow{2}{*}{$\begin{array}{l}\text { Total number } \\
\text { of climbers } \\
\text { approached }\end{array}$} & \multirow{2}{*}{$\begin{array}{l}\text { Total number of } \\
\text { questionnaires } \\
\text { returned }(\%)\end{array}$} \\
\hline & Approached & $\begin{array}{l}\text { Consenting } \\
(\%)\end{array}$ & Approached & $\begin{array}{l}\text { Consenting } \\
(\%)\end{array}$ & & \\
\hline $\begin{array}{l}\text { The Sally Borden } \\
\text { The Banff Centre }\end{array}$ & 9 & $9(100)$ & N/A & $\mathrm{N} / \mathrm{A}$ & 9 & $9(100)$ \\
\hline $\begin{array}{l}\text { The Calgary Climbing Centre } \\
\text { Chinook Location }\end{array}$ & 22 & $14(64)$ & 49 & $16(33)$ & 71 & $\begin{array}{l}28(39) \\
{[2 \text { surveys }} \\
\text { unreturned] }\end{array}$ \\
\hline $\begin{array}{l}\text { The Calgary Climbing Centre } \\
\text { Stronghold Location }\end{array}$ & N/A & N/A & 39 & $26(67)$ & 39 & $\begin{array}{l}24(62) \\
{[2 \text { surveys }} \\
\text { unreturned] }\end{array}$ \\
\hline $\begin{array}{l}\text { University of Calgary } \\
\text { Outdoor Centre }\end{array}$ & N/A & N/A & 23 & $1(4)$ & 23 & $1(4)$ \\
\hline $\begin{array}{l}\text { Mount Royal University } \\
\text { Climbing Wall (Calgary) }\end{array}$ & N/A & N/A & 12 & $3(25)$ & 12 & $3(25)$ \\
\hline $\begin{array}{l}\text { Shawnessy YMCA } \\
\text { (Calgary) }\end{array}$ & N/A & N/A & 15 & $0(0)$ & 15 & $0(0)$ \\
\hline $\begin{array}{l}\text { The Cave Bouldering Gym } \\
\text { (Canmore) }\end{array}$ & 18 & $18(100)$ & 4 & $4(100)$ & 22 & $22(100)$ \\
\hline $\begin{array}{l}\text { Rock Jungle Fitness } \\
\text { (Edmonton) }\end{array}$ & 6 & $6(100)$ & 40 & $8(20)$ & 46 & $\begin{array}{l}12(30) \\
\text { [2 surveys } \\
\text { unreturned] }\end{array}$ \\
\hline $\begin{array}{l}\text { University of Alberta } \\
\text { Climbing Wall (Edmonton) }\end{array}$ & N/A & N/A & 6 & $5(83)$ & 6 & $5(83)$ \\
\hline $\begin{array}{l}\text { Vertically Inclined Rock Gym } \\
\text { (Edmonton) }\end{array}$ & 7 & $5(71)$ & 41 & $7(17)$ & 48 & $\begin{array}{l}11(23) \\
{[1 \text { survey }} \\
\text { unreturned] }\end{array}$ \\
\hline
\end{tabular}




\begin{tabular}{|c|c|c|c|c|c|c|}
\hline \multirow{2}{*}{ Facility } & \multicolumn{2}{|c|}{$\begin{array}{l}\text { Number of } \\
\text { competitive climbers }\end{array}$} & \multicolumn{2}{|c|}{$\begin{array}{l}\text { Number of } \\
\text { recreational climbers }\end{array}$} & \multirow{2}{*}{$\begin{array}{l}\text { Total number } \\
\text { of climbers } \\
\text { approached }\end{array}$} & \multirow{2}{*}{$\begin{array}{l}\text { Total number of } \\
\text { questionnaires } \\
\text { returned }(\%)\end{array}$} \\
\hline & Approached & $\begin{array}{l}\text { Consenting } \\
(\%)\end{array}$ & Approached & $\begin{array}{l}\text { Consenting } \\
(\%)\end{array}$ & & \\
\hline $\begin{array}{l}\text { K-Rock Climbing Wall } \\
\text { (Fort McMurray) }\end{array}$ & $\mathrm{N} / \mathrm{A}$ & N/A & 40 & $0(0)$ & 40 & $0(0)$ \\
\hline $\begin{array}{l}\text { Grande Prairie Regional College } \\
\text { Climbing Wall }\end{array}$ & $\mathrm{N} / \mathrm{A}$ & N/A & 10 & $1(10)$ & 10 & $1(10)$ \\
\hline $\begin{array}{l}\text { Ascent Climbing Gym } \\
\text { (Lethbridge) }\end{array}$ & $\mathrm{N} / \mathrm{A}$ & N/A & 30 & $0(0)$ & 30 & $0(0)$ \\
\hline $\begin{array}{l}\text { Downtown Family YMCA } \\
\text { (Medicine Hat) }\end{array}$ & N/A & N/A & 6 & $0(0)$ & 6 & $0(0)$ \\
\hline $\begin{array}{l}\text { The Collicutt Centre } \\
\text { (Red Deer) }\end{array}$ & N/A & $\mathrm{N} / \mathrm{A}$ & 8 & $0(0)$ & 8 & $0(0)$ \\
\hline TOTAL & 62 & $52(84)$ & 223 & $74(33)$ & 285 & $\begin{array}{l}116(41) \\
{[10 \text { surveys }} \\
\text { unreturned] }\end{array}$ \\
\hline
\end{tabular}


Figure 4.1 Recruitment flow chart

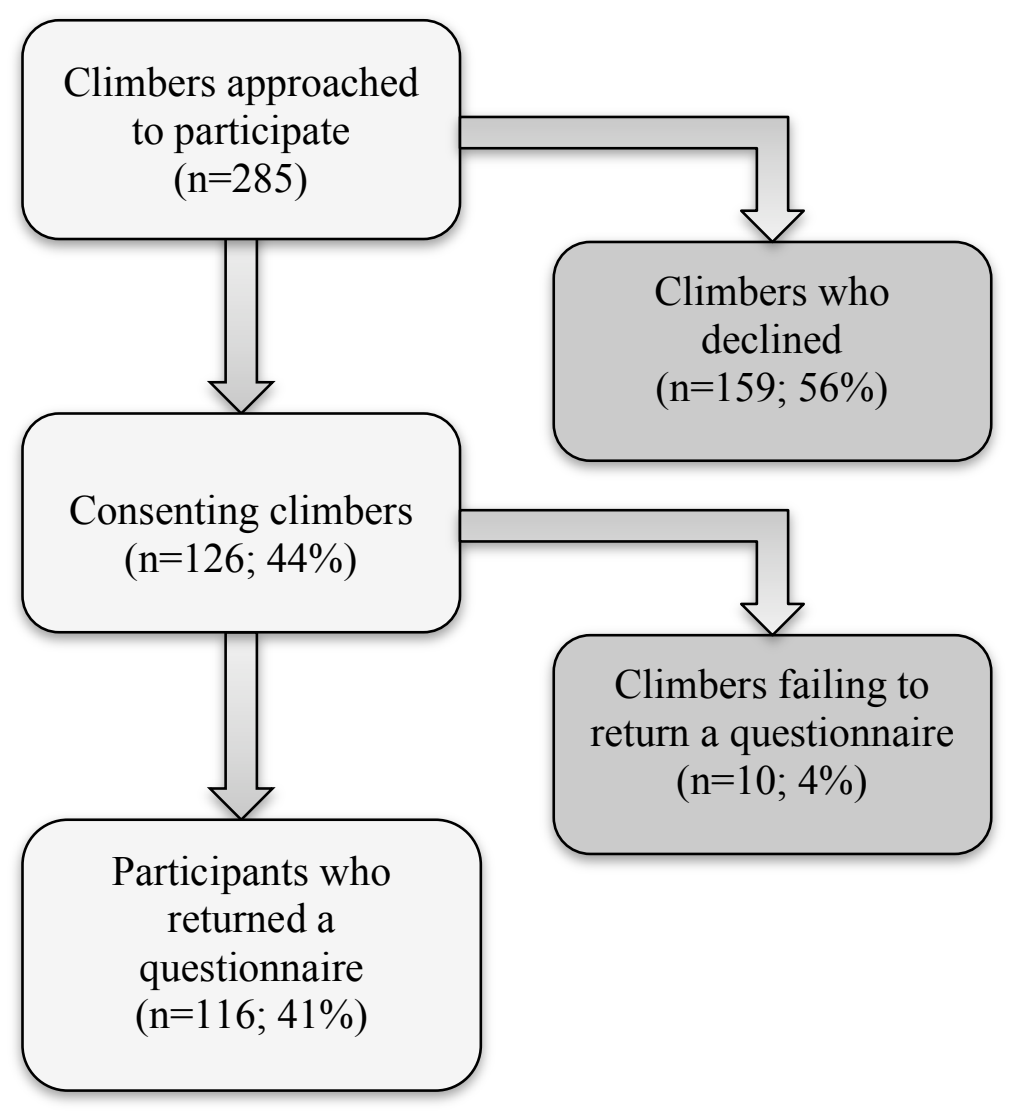

Participants were identified as "elite" $(n=50)$ or "recreational" $(n=66)$ based on inclusion and exclusion criteria for each group (Chapter 1), rather than on self-reported competitive or recreational participation. Participant characteristics are summarized in Table 4.2. 
Table 4.2 Baseline characteristics for elite and recreational climbers

\begin{tabular}{|l|l|l|}
\hline Characteristic & Elite $(\mathrm{n}=50)$ & Recreational $(\mathrm{n}=66)$ \\
\hline $\begin{array}{l}\text { Sex } \\
\text { (male, female) }\end{array}$ & $\begin{array}{l}31 \text { males } \\
19 \text { females }\end{array}$ & $\begin{array}{l}25 \text { males } \\
\text { 41 females }\end{array}$ \\
\hline & \multicolumn{2}{|c|}{ Mean $(95 \%$ Confidence Interval) } \\
\hline Age (years) & $15.46(14.84,16.08)$ & $14.12(13.53,14.71)$ \\
\hline Height (cm) & $166.95(163.40,170.49)$ & $158.90(155.36,162.43)^{*}$ \\
\hline Weight $(\mathrm{kg})$ & $53.63(50.29,56.96)$ & $47.23(44.25,50.22)$ \\
\hline Body mass index $\left(\mathrm{kg} / \mathrm{m}^{2}\right)$ & $19.00(18.31,19.69)$ & $18.30(17.67,18.94)^{*}$ \\
\hline $\begin{array}{l}\text { Climbing participation } \\
\text { (hours per week) }\end{array}$ & $13.40(11.87,14.93)$ & $6.91(5.71,8.11)$ \\
\hline $\begin{array}{l}\text { Socioeconomic status } \\
(0-9 \text { on affluence scale) }\end{array}$ & $8(4,9)$ & $8(2,9)$ \\
\hline $\begin{array}{l}\text { Sport climbing grade } \text { YYosemite } \\
\text { Decimal System (YDS)] }\end{array}$ & $5.12 \mathrm{a}(5.10 \mathrm{a}, 5.13 \mathrm{c})$ & $5.10 \mathrm{~d}(5.8,5.12 \mathrm{c})^{* *}$ \\
\hline Sport climbing grade (Metric) & $8.24(7.96,8.50)$ & $6.01(5.33,6.69)^{* *}$ \\
\hline Bouldering Grade (Hueco) & V5/6(V1, V10)*** & V3 (V1, V12)**** \\
\hline Participate in outdoor climbing & $36(72 \%)$ & $18(27 \%)$ \\
\hline Participate in indoor climbing & $50(100 \%)$ & $66(100 \%)$ \\
\hline Participate in sport climbing & $50(100 \%)$ & $57(86 \%)$ \\
\hline Participate in bouldering & $46(92 \%)$ & $66(100 \%)$ \\
\hline $\begin{array}{l}\text { Participate in school physical } \\
\text { education (PE) }\end{array}$ & $39(78 \%)$ & $57(86 \%)$ \\
\hline $\begin{array}{l}\text { Participate in other sports (apart } \\
\text { from climbing and PE) }\end{array}$ & $38(76 \%)$ & $51(77 \%)$ \\
\hline
\end{tabular}

*2 missing values excluded from mean

**6 participants unfamiliar with the YDS grading scale; excluded as missing values ***10 participants unfamiliar with the Hueco grading scale; excluded as missing values ****35 participants unfamiliar with the Hueco grading scale; excluded as missing values

Fifty-six (48\%) of the participants were male, and $60(52 \%)$ were female.

Participant ages ranged from 11 to 19 years, with a mean age of 14.70 years. Based on 95\% confidence intervals (CIs), elite climbers were typically taller and heavier than recreational climbers. They also tended to climb outdoors more than recreational 
climbers, and practiced more sport climbing than bouldering. Recreational climbers, conversely, favoured bouldering over sport climbing.

Frequencies of scores on the Family Affluence Scale II (FAS II) measuring socioeconomic status (SES) are shown in Figure 4.2. Scores for elite and recreational climbers were not significantly different. The scores of 0,1 , or 2 indicate low affluence; 3,4 , or 5 indicate moderate affluence; and 6, 7, 8, or 9 indicate high affluence. The mean score on the FAS II was 8, falling into the "high affluence" category, and translating into high family wealth and thus high SES. ${ }^{6061}$

\section{Figure 4.2 Distribution of participant scores on the Family Affluence Scale II}

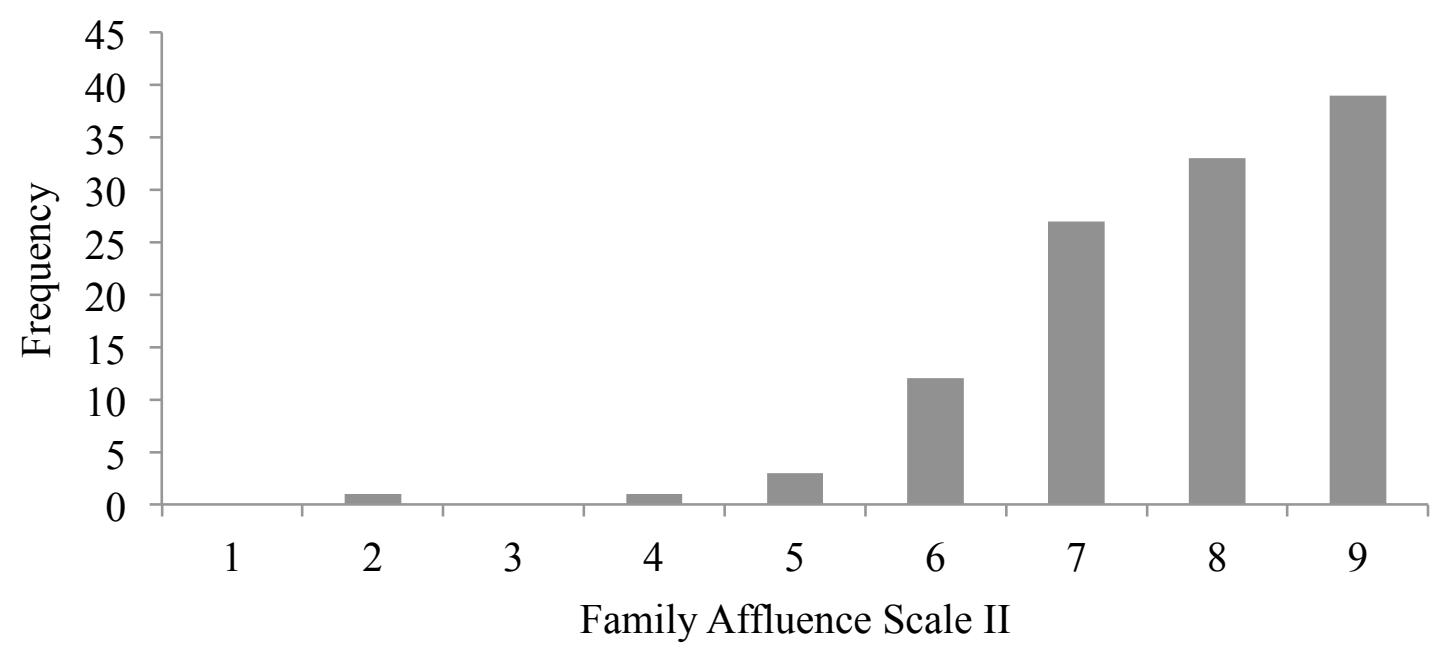

The occurrence and amount of seatbelt non-use, smoking tobacco, and alcohol consumption were captured in order to examine as potential risk factors in the analysis. All participants reported wearing seatbelts in vehicles, and all but two reported that they wore seatbelts at all times. Two reported wearing them "most of the time." Three 
participants reported smoking tobacco, two of whom smoked "less than once a month, but more than once a year," and one who smoked "less than once a week, but more than once a month.” More participants reported drinking alcohol $(\mathrm{n}=26), 11$ of whom reported drinking "less than once a month, but more than once a year," 12 who reported "less than once a week, but more than once a month," and three who reported drinking "less than once a day, but more than once a week." No participants reported smoking tobacco or consuming alcohol as often as "once a day" or "more than once a day."

\subsection{Climbing Participation}

The mean amount of time reported by participants in this study for indoor climbing was approximately seven hours per week and nine months per year. Less time overall was spent climbing outdoors, with an estimated mean of six hours per week, for three months per year. All participants had climbed indoors in the previous year, though $54(47 \%)$ had climbed exclusively indoors and $62(53 \%)$ had climbed in both venues. Based on 95\% CIs, elite climbers spent, on average, a greater amount of time participating in climbing than recreational climbers. Participation hours could not be validated by coach questionnaires as coaches reported that many participants in their programs often climbed outside of the organized course or team training. Participation hours are summarized in Table 4.3. 
Table 4.3 Participation hours per week by venue for elite and recreational climbers

\begin{tabular}{|l|l|l|l|l|}
\hline \multirow{2}{*}{ Climbing venue } & \multicolumn{2}{|l|}{ Elite } & Recreational \\
\cline { 2 - 5 } & $\begin{array}{l}\text { Mean hours/week } \\
(95 \% \text { Confidence } \\
\text { Interval [CI] })\end{array}$ & $\begin{array}{l}\text { Number of } \\
\text { participants }\end{array}$ & $\begin{array}{l}\text { Mean hours/week } \\
(95 \% \text { CI })\end{array}$ & $\begin{array}{l}\text { Number of } \\
\text { participants }\end{array}$ \\
\hline Indoors $(\mathrm{n}=116)$ & $8.46(7.75,9.17)$ & 50 & $5.38(4.68,6.08)$ & 66 \\
\hline Outdoors $(\mathrm{n}=54)$ & $6.68(5.56,7.79)$ & 36 & $5.61(3.89,7.33)$ & 18 \\
\hline
\end{tabular}

With regards to discipline, 103 (89\%) study participants participated in both sport climbing and bouldering, while nine (8\%) participated exclusively in bouldering, and four $(3 \%)$ participated exclusively in sport climbing. Those who participated only in bouldering and did not sport climb were all recreational climbers, while those who were exclusively sport climbers and did not participate in bouldering were all elite climbers.

\subsection{Physical Education (PE) and Other Sport Participation}

Ninety-six $(83 \%)$ of the participants in this study were enrolled in physical education $(\mathrm{PE})$ in school at the time of questionnaire completion. For these participants, the mean number of hours participating in school PE classes was approximately four hours per week, four weeks per month, and eight months per year. This resulted in a yearly mean of approximately 135 hours $(95 \% \mathrm{CI} ; 121,150)$.

Data were also collected on "other" regular leisure time sport participation, not including sport climbing or bouldering. Of the 116 participants, 89 (77\%) also participated in other sports. The top 10 activities by participation are summarized in Table 4.4. 
Table 4.4 Other leisure time sport participation

\begin{tabular}{|l|l|l|l|}
\hline Sport & $\begin{array}{l}\text { Number of } \\
\text { participants } \\
(\mathrm{n})\end{array}$ & $\begin{array}{l}\text { Median number of } \\
\text { hours per week } \\
\text { (range) }\end{array}$ & $\begin{array}{l}\text { Median number of } \\
\text { months per year } \\
\text { (range) }\end{array}$ \\
\hline 1. Alpine (downhill) skiing & 36 & $6(1,48)$ & $4.5(1,9)$ \\
\hline 2. Mountain biking & 26 & $3(1,10)$ & $4(1,12)$ \\
\hline 3. Running & 25 & $3(0.5,20)$ & $5(1,12)$ \\
\hline 4. Swimming & 25 & $3(1,7)$ & $4(1,12)$ \\
\hline 5. Hiking/ Scrambling & 23 & $3(1,16)$ & $4(1,10)$ \\
\hline 6. Soccer & 18 & $3(1,25)$ & $3(1,12)$ \\
\hline 7. Weight training & 17 & $2(1,10)$ & $8(2,12)$ \\
\hline 8. Road Cycling & 15 & $2(1,12)$ & $4(2,9)$ \\
\hline 9. Cross-country skiing & 15 & $2(1,10)$ & $3(1,9)$ \\
\hline 10. Traditional climbing & 14 & $4(1,8)$ & $6(1,12)$ \\
\hline
\end{tabular}

\subsection{Climbing Injury Incidence Rates and Incidence Proportions}

The outcome of interest, climbing injury, included any physical complaint, irrespective of any medical attention sought, or any time loss from activity. A total of 73 (63\%) climbers sustained at least one new climbing injury in the 12 months prior to completing the questionnaire, including those reported as "pains or discomforts." Thirtysix (31\%) participants reported multiple climbing injuries. The total number of climbing injuries incurred in the study sample was 142 , resulting in an injury incidence proportion (IP) of 122 injuries per 100 participants per year $(95 \%$ CI; 98, 147). The overall injury incidence rate (IR) was 4.44 injuries per 1000 participation hours in climbing $(95 \% \mathrm{CI}$; $3.74,5.23)$.

Examining the injury IPs and IRs for elite athletes and recreational climbers separately, a total of $41(82 \%)$ of the elite climbers sustained 84 total injuries [IP $=168$ $/ 100$ participants/year $(95 \% \mathrm{CI} ; 134,208)]$, as compared to $32(48 \%)$ of the recreational climbers who sustained 58 total injuries [IP $=88 / 100$ participants/year (95\% CI; 67, 
114)] in the 12 months prior to questionnaire completion. The IR for elite climbers was 4.27 per 1000 hours $(95 \% \mathrm{CI} ; 3.45,5.29)$, and for recreational climbers was 4.71 injuries per 1000 climbing hours $(95 \% \mathrm{CI} ; 3.64,6.09)$.

\section{Time loss injuries}

Overall, $109(77 \%)$ total injuries resulted in time loss from climbing of at least one day $[\mathrm{IP}=94 / 100$ participants/year $(95 \% \mathrm{CI} ; 72,116)$; IR $=1.81 / 1000$ hours $(95 \% \mathrm{CI}$; $1.38,2.34)]$. The median amount of time loss was 14 days (interquartile range; 7,61 ), including ongoing injuries where participants had not yet returned to full activity. It was a limitation of the questionnaire that time loss in days often had to be estimated depending on how the participant answered the question. If the participant answered in weeks, this number was multiplied by seven to obtain the number of days. If the participant answered in months, this number was multiplied by 30.4 to calculate days (365 days per year divided by 12 months per year). Several participants answered that there was "ongoing" time loss at the time of questionnaire completion, and in these cases, days of time loss from climbing was estimated by subtracting the month and year of injury from the month and year of survey completion (participants were not required to recall the specific day of the month an injury occurred). Figure 4.3 shows the proportions of injuries incurring time loss from climbing, categorized according to severity using groups defined by Fuller et al. (2006): Slight injury (no time loss), minimal (1-3 days), mild (4-7 days), moderate (8-28 days), and severe ( $>28$ days) ${ }^{62}$ 
Figure 4.3 Proportion of injuries incurring time loss from climbing in days

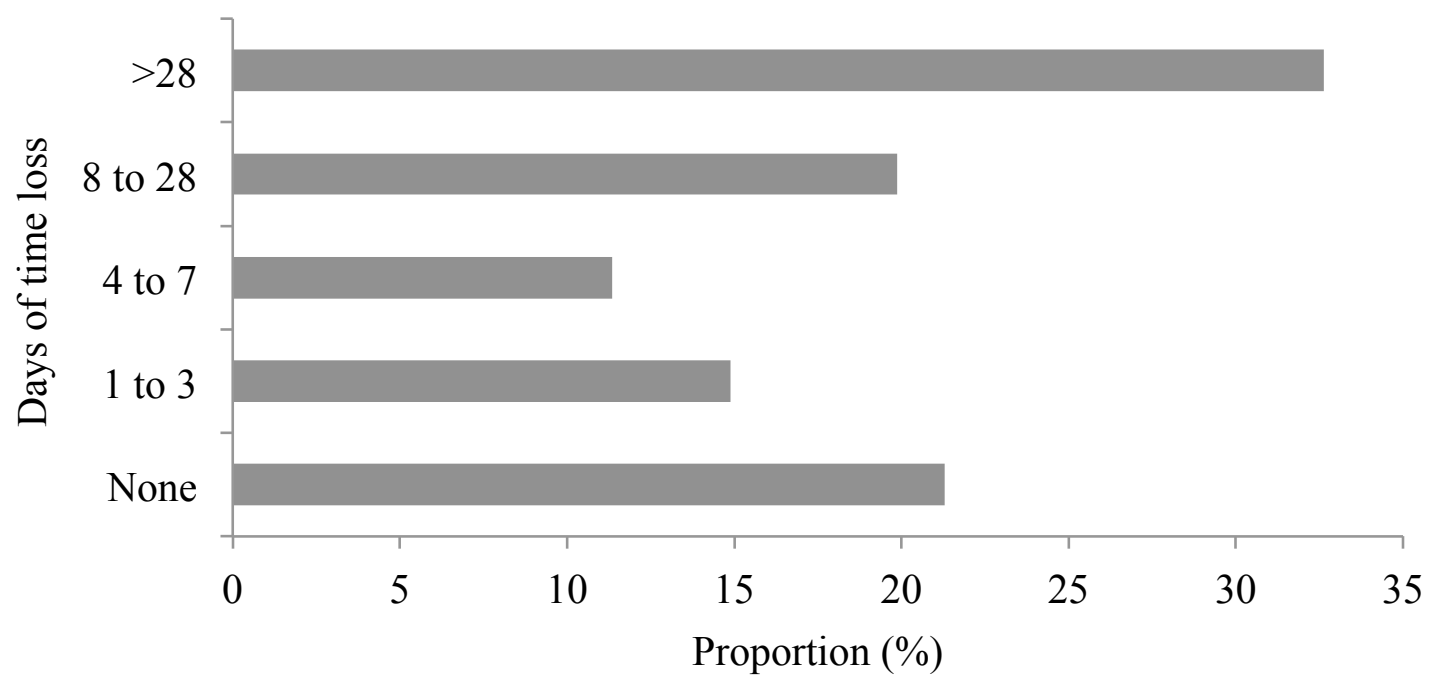

\section{Medically treated injuries}

Seventy-six (54\%) injured climbers reportedly received medical attention [IP = $66 / 100$ participants/year (95\% CI; 46, 85); IR =2.62/1000 hours (95\% CI; $2.09,3.25)]$. Medical attention included first aid, treatment by an emergency medical technician (EMT) or paramedic, physician, physiotherapist, chiropractor, athletic therapist, massage therapist, or "other". "Other" medical attention reported by participants included acupuncture, osteopathic manual therapy, and regular icing of the injury. Frequencies of medical practitioner visits for injuries are summarized in Table 4.5. Participants were allowed to select as many treatment sources as they wished for each injury. Physiotherapy was the most common type of medical treatment received by climbers. 
Table 4.5 Distribution of medical practitioner visits for all climbing injuries receiving medical attention

\begin{tabular}{|l|l|l|l|}
\hline Medical attention received & $\begin{array}{l}\text { Elite }(\mathrm{n}=77) \\
\text { Frequency }(\%)\end{array}$ & $\begin{array}{l}\text { Recreational }(\mathrm{n}=43) \\
\text { Frequency }(\%)\end{array}$ & $\begin{array}{l}\text { Total }(\mathrm{n}=120) \\
\text { Frequency }(\%)\end{array}$ \\
\hline Physiotherapist & $31(26)$ & $9(8)$ & $40(33)$ \\
\hline Chiropractor & $15(13)$ & $7(6)$ & $22(18)$ \\
\hline Physician & $9(8)$ & $9(8)$ & $18(15)$ \\
\hline Massage therapist & $8(7)$ & $6(5)$ & $14(12)$ \\
\hline First aid & $11(9)$ & $2(2)$ & $13(11)$ \\
\hline Athletic therapist & $1(1)$ & $8(7)$ & $9(8)$ \\
\hline Other & $2(2)$ & $2(2)$ & $4(3)$ \\
\hline EMT/Paramedic & $0(0)$ & $0(0)$ & $0(0)$ \\
\hline
\end{tabular}

\section{Injuries by climbing venue and by discipline}

Tables 4.6 and 4.7 describe the proportion of injuries sustained by climbing venue (i.e., indoor or outdoor), and by discipline (i.e., sport climbing or bouldering). Several participants indicated that with certain injuries, usually those described as having an insidious onset, the injury developed while climbing in both environments, and in both disciplines.

Table 4.6 Injury incidence proportion (IP) and incidence rate (IR) by venue

\begin{tabular}{|l|l|l|}
\hline Venue of sustained injury & $\begin{array}{l}\text { IP as injuries } / 100 \\
\text { participants /year } \\
(95 \% \text { Confidence } \\
\text { Interval) }\end{array}$ & $\begin{array}{l}\text { IR as injuries/1000 hrs. } \\
(95 \% \text { Confidence } \\
\text { Interval })\end{array}$ \\
\hline Indoor & $89(74,106)$ & $4.31(3.59,5.13)$ \\
\hline Outdoor & $6(2,11)$ & $2.94(1.27,5.79)$ \\
\hline Both indoor and outdoor & $6(2,11)$ & N/A \\
\hline Total & N/A & $4.44(3.74,5.23)$ \\
\hline
\end{tabular}


"Other discipline" reported by participants included strength training and conditioning for climbing, setting an indoor climbing route, and injuries originating elsewhere but aggravated by climbing.

Table 4.7 Injury incidence proportion (IP) by discipline

\begin{tabular}{|l|l|}
\hline Discipline during sustained injury & $\begin{array}{l}\text { IP as injuries } / 100 \\
\text { participants /year } \\
(95 \% \text { Confidence } \\
\text { Interval) }\end{array}$ \\
\hline Sport Climbing (\%) & $33(24,44)$ \\
\hline Bouldering (\%) & $58(46,72)$ \\
\hline Both sport and bouldering (\%) & $5(2,10)$ \\
\hline Other (conditioning, etc.) & $4(2,9)$ \\
\hline
\end{tabular}

\subsection{Injury Characteristics}

Participants were asked to classify their self-reported injuries by type and mechanism in addition to whether they received any medical attention or incurred time loss from climbing. Therefore, this does not include the self-reported "other pains or discomforts" described by participants, as they were not classified by injury type or mechanism. The predominant self-reported injury type was ligament sprain, followed by muscle or tendon strain. Injury types are summarized in Table 4.8. "Other" injury types were described as "disc bulge," hypermobility, and hyperextension. Twenty-two (26\%) injuries were re-injuries.

Those injuries classified by participants as "pains or discomforts" were described in an open answer format, and were described as low back pain, calcification of a previously strained muscle causing pain, general pain in a specific area during climbing, 
etc. As injury type and mechanism of injury was not collected for other "pains or discomforts," the tables below include only those 85 injuries reported as such by participants.

Table 4.8 Self-reported climbing injury by type

\begin{tabular}{|l|l|l|}
\hline Injury type & Frequency (\%) & $\begin{array}{l}\text { IR/1000 hrs. } \\
(95 \% \text { Confidence } \\
\text { Interval) }\end{array}$ \\
\hline Ligament sprain & $23(27)$ & $0.72(0.46,1.08)$ \\
\hline Muscle/tendon strain & $22(26)$ & $0.69(0.43,1.04)$ \\
\hline Tendonitis & $11(13)$ & $0.34(0.17,0.62)$ \\
\hline Joint swelling/inflammation & $7(8)$ & $0.22(0.09,0.45)$ \\
\hline Abrasion & $3(4)$ & $0.09(0.02,0.27)$ \\
\hline Concussion & $3(4)$ & $0.09(0.02,0.27)$ \\
\hline Cut/scrape/skin flapper & $3(4)$ & $0.09(0.02,0.27)$ \\
\hline Dislocation/subluxation & $3(4)$ & $0.09(0.02,0.27)$ \\
\hline Fracture & $3(4)$ & $0.09(0.02,0.27)$ \\
\hline Other & $3(4)$ & $0.09(0.02,0.27)$ \\
\hline Unspecified overuse injury & $2(2)$ & $0.06(0.01,0.23)$ \\
\hline Unspecified nerve injury & $2(2)$ & $0.06(0.01,0.23)$ \\
\hline Bruise & $0(0)$ & 0 \\
\hline Bleeding (i.e., nose bleed, etc.) & $0(0)$ & 0 \\
\hline Total & $85(100)$ & $2.66(2.12,3.29)$ \\
\hline
\end{tabular}


Figure 4.4 Self-reported climbing injury by type

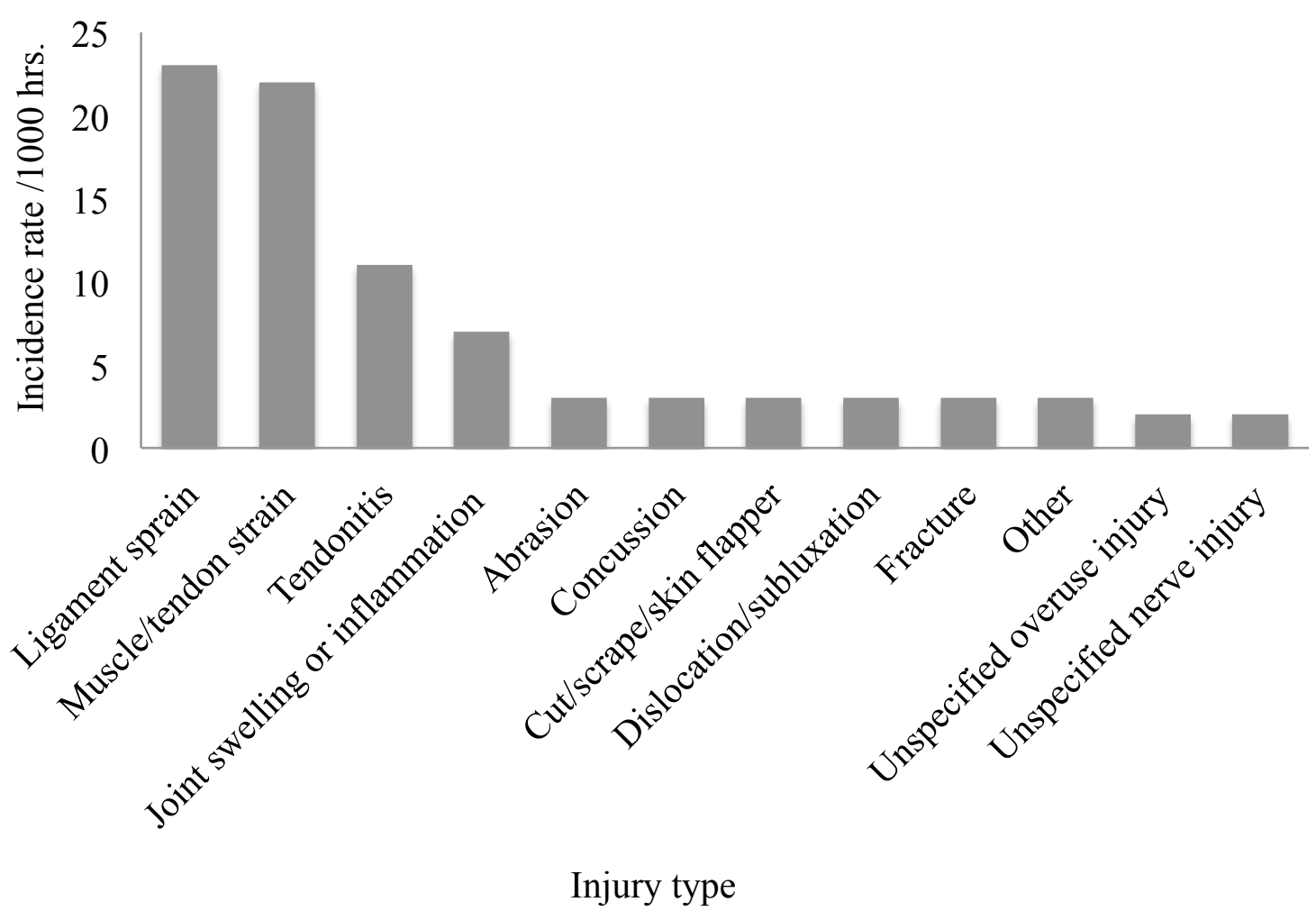

The most common mechanism of injury for the 85 self-reported injuries was repetitive overuse, followed by injuries resulting from falls, and those incurred during strenuous moves, being any demanding or difficult climbing move causing an injury. “Other" mechanisms included self-reported descriptions such as "incorrect use of muscles...bad posture." Table 4.9 lists the frequencies and incidence rates of selfreported mechanisms of injury. 
Table 4.9 Self-reported mechanism of climbing injury

\begin{tabular}{|l|l|l|}
\hline Mechanism of Injury & Frequency $(\%)$ & $\begin{array}{l}\text { IR/1000 hrs. } \\
(95 \% \text { Confidence } \\
\text { Interval })\end{array}$ \\
\hline Repetitive overuse & $36(42)$ & $1.13(0.79,1.56)$ \\
\hline Falling & $28(33)$ & $0.88(0.58,1.27)$ \\
\hline Strenuous move & $18(21)$ & $0.56(0.33,0.89)$ \\
\hline Other & $3(4)$ & $0.09(0.02,0.27)$ \\
\hline Total & $85(100)$ & $2.66(2.12,3.29)$ \\
\hline
\end{tabular}

The hands and fingers incurred the highest proportion of injuries $(21 \%)$, followed by shoulder (15\%), knee (9\%) and ankle (9\%) injuries. This included both self-reported injury and those reported as "pains or discomforts." Table 4.10 shows climbing injury by location.

Table 4.10 Climbing injury by anatomical location

\begin{tabular}{|l|l|l|}
\hline Injury location & Frequency $(\%)$ & $\begin{array}{l}\text { IR/1000 hrs. } \\
(95 \% \text { Confidence } \\
\text { Interval })\end{array}$ \\
\hline Hand/finger/thumb & $30(21)$ & $0.94(0.63,1.34)$ \\
\hline Shoulder & $22(15)$ & $0.69(0.43,1.04)$ \\
\hline Ankle & $13(9)$ & $0.41(0.22,0.69)$ \\
\hline Knee & $13(9)$ & $0.41(0.22,0.69)$ \\
\hline Wrist & $11(8)$ & $0.34(0.17,0.62)$ \\
\hline Lower back/pelvis/sacrum & $10(7)$ & $0.31(0.15,0.57)$ \\
\hline Elbow & $9(6)$ & $0.28(0.13,0.53)$ \\
\hline Neck/cervical spine & $5(4)$ & $0.16(0.051,0.36)$ \\
\hline Upper arm & $5(4)$ & $0.16(0.051,0.36)$ \\
\hline Foot/toe & $4(3)$ & $0.13(0.03,0.32)$ \\
\hline Lower leg/Achilles tendon & $4(3)$ & $0.13(0.03,0.32)$ \\
\hline Sternum/ribs/upper back & $4(3)$ & $0.13(0.03,0.32)$ \\
\hline Forearm & $3(2)$ & $0.09(0.02,0.27)$ \\
\hline Head/face & $3(2)$ & $0.09(0.02,0.27)$ \\
\hline Hip/groin & $3(2)$ & $0.09(0.02,0.27)$ \\
\hline Thigh/upper leg & $3(2)$ & $0.09(0.02,0.27)$ \\
\hline Abdomen & $0(0)$ & N/A \\
\hline Clavicle & $0(0)$ & N/A \\
\hline Other & $0(0)$ & N/A \\
\hline Total & $142(100)$ & $4.44(3.74,5.23)$ \\
\hline
\end{tabular}


Figure 4.5 illustrates the injury incidence rates for upper extremity, lower extremity, and other location by each self-reported mechanism of injury. Most repetitive overuse injuries involved the upper body, while most fall-related injuries involved the lower extremity.

\section{Figure 4.5 Climbing injury by mechanism of injury and anatomical location}

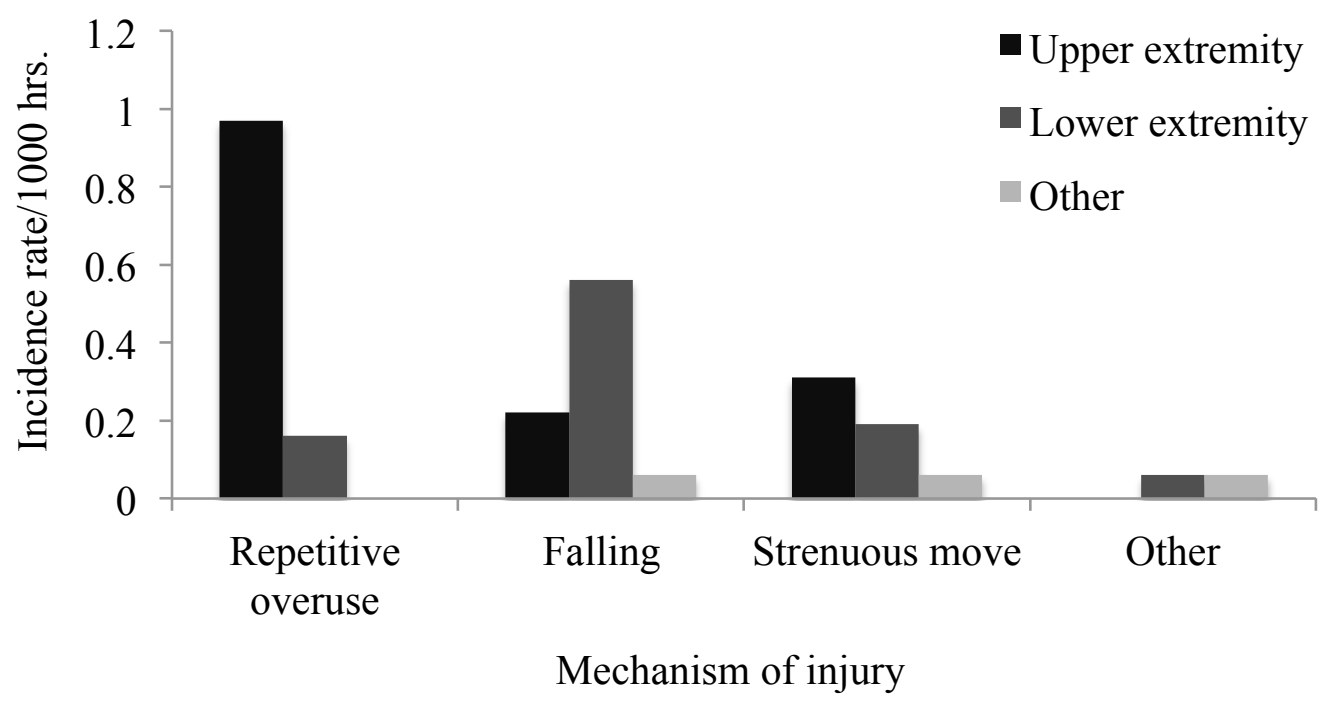

\subsection{Safety Practices and Injury Prevention}

Of the 116 children and adolescents who participated in this study, 112 (97\%) had previously taken a climbing course (including training on a team with a coach), and all 112 reported receiving some type of safety instruction during their course. Eighty-five climbers reported learning additional safety practices elsewhere. The frequencies of these sources of safety instruction are summarized in Table 4.11. Participants were able to choose as many sources of safety information as they believed were applicable. 
Table 4.11 Frequencies of reported sources of safety instruction

\begin{tabular}{|l|l|}
\hline Source of safety instruction & Frequency (\%) \\
\hline $\begin{array}{l}\text { Formal course instruction } \\
\text { (coaches, guides, other instructor) }\end{array}$ & $112(97)$ \\
\hline Other climber & $56(48)$ \\
\hline Parent & $21(18)$ \\
\hline Teacher (physical education, outdoor education) & $20(17)$ \\
\hline Internet & $8(7)$ \\
\hline Staff at a climbing gym (informal) & $4(3)$ \\
\hline Books/magazines & $4(3)$ \\
\hline Television & $1(1)$ \\
\hline
\end{tabular}

When asked about helmet use, 67 participants reported wearing a helmet during outdoor sport climbing, six during indoor sport climbing, 19 during outdoor bouldering, and four reported helmet use during indoor bouldering. However, the amount that these participants wore helmets varied. Climbers reported the percentage of outings during which they wore a helmet. The means of these percentages are summarized in Table 4.12. This does not include those participants who did not participate in each discipline and venue, or who did not wear helmets at all. The range for each of these four categories was $1 \%$ to $100 \%$, as there were participants for each that reported wearing a helmet only one percent of the time, and others that reported always wearing a helmet.

Table 4.12 Helmet use by proportion of outings for participants who wore helmets

\begin{tabular}{|l|l|}
\hline Climbing discipline and venue & $\begin{array}{l}\text { Mean proportion of outings in } \\
\text { which helmets were worn } \\
(95 \% \text { Confidence Interval })\end{array}$ \\
\hline Outdoor sport climbing $(\mathrm{n}=67)$ & $73 \%(57,92)$ \\
\hline Outdoor bouldering $(\mathrm{n}=19)$ & $72 \%(56,91)$ \\
\hline Indoor bouldering $(\mathrm{n}=4)$ & $65 \%(50,83)$ \\
\hline Indoor sport climbing $(\mathrm{n}=6)$ & $41 \%(29,56)$ \\
\hline
\end{tabular}


The use of warm-ups and cool-downs was also queried. All but two climbers reported warming up at the beginning of every climbing session $(98 \%)$. Fewer participants $(n=74,64 \%)$ reported cooling down regularly. When asked if they used other preventive measures to reduce injury, $51(44 \%)$ participants answered yes. With regards to preventive taping, $31(61 \%)$ of these climbers taped their fingers to prevent tendon injury, $17(33 \%)$ taped to prevent skin tears, $12(24 \%)$ taped wrists, three $(6 \%)$ taped shoulders, and two (4\%) taped ankles. Five (10\%) climbers reported using "other injury prevention measures." These included hip joint taping (due to previous injury), opposition exercises, "changing the way I grip holds," using crash mats (which is standard for bouldering), and one participant did not specify which preventive measures were used.

\subsection{Risk Factors}

\subsubsection{Univariate Analyses}

Preliminary univariate analyses demonstrate that the crude odds ratio (OR) consistently overestimates the OR adjusted for participation hours. Therefore, the latter was more appropriate to use for interpretation. Both the crude and the hours-adjusted ORs are reported in Table 4.13. Each potential risk factor was dichotomized into two exposure groups (Chapter 3). A clinical relevance of $20 \%$ difference in OR between exposure groups was used to determine which variables to include in the multivariate model. This number was chosen arbitrarily as a reasonable cut-off for clinical 
importance. As this was a preliminary assessment of possible risk factors, this relatively small percentage was chosen to capture as many variables as possible to examine in the multivariate model. Groups that demonstrated this difference were elite-level climbers, participants in the older age group (15-19-year-olds), those in the top $25^{\text {th }}$ percentile of height by age, those in the top $25^{\text {th }}$ percentile of weight by age, those who climbed at higher grades (5.11b-5.13c), those who had sustained at least one injury in a sport other than climbing during the previous year, those who wore helmets (any amount of time), those who used preventive taping (i.e., fingers, wrists, ankle, shoulder, skin), and finally those who consumed alcohol (any amount). Because too few participants reported smoking ( $\mathrm{n}=3)$, and all reported wearing seatbelts $(\mathrm{n}=116)$, these two variables could not be examined as risk factors in this analysis.

Risk factors for time loss injury were also examined for comparison purposes. Results from these univariate analyses yielded largely the same findings as for all climbing injuries, with the exception of height, weight, and alcohol consumption. The results are summarized in Table 4.13. 
Table 4.13 Crude and adjusted odds ratios from univariate models predicting climbing injury

\begin{tabular}{|c|c|c|c|c|c|c|}
\hline \multirow[b]{2}{*}{ Risk factors } & \multirow[b]{2}{*}{$\begin{array}{l}\text { Number } \\
\text { of } \\
\text { climbers }\end{array}$} & \multirow[b]{2}{*}{$\begin{array}{l}\text { Number } \\
\text { of } \\
\text { injuries }\end{array}$} & \multirow{2}{*}{$\begin{array}{l}\text { IR/1000 hrs. } \\
\quad(95 \% \\
\text { Confidence } \\
\text { Interval }[\mathrm{CI}])\end{array}$} & \multicolumn{2}{|c|}{ Climbing injury } & \multirow{2}{*}{$\begin{array}{l}\text { Time loss injury } \\
\text { OR adjusted for } \\
\text { climbing } \\
\text { participation hours } \\
\text { only } \\
(95 \% \mathrm{CI}) \\
\end{array}$} \\
\hline & & & & $\begin{array}{c}\text { Crude OR } \\
(95 \% \mathrm{CI})\end{array}$ & $\begin{array}{c}\text { OR adjusted for } \\
\text { climbing } \\
\text { participation hours } \\
\text { only }(95 \% \mathrm{CI})\end{array}$ & \\
\hline \multicolumn{7}{|l|}{ Climbing level } \\
\hline Recreational & 66 & 58 & $4.71(3.64,6.09)$ & 1 & 1 & 1 \\
\hline Elite & 50 & 84 & $4.27(3.45,5.29)$ & $4.84(2.03,11.53)^{*}$ & $2.43(0.88,6.72)$ & $2.43(0.96,6.12)$ \\
\hline \multicolumn{7}{|l|}{ Sex } \\
\hline Female & 60 & 84 & $5.56(4.49,6.88)$ & 1 & 1 & 1 \\
\hline Male & 56 & 58 & $3.44(2.66,4.45)$ & $1.30(0.61,2.77)$ & $0.97(0.42,2.23)$ & $0.81(0.37,1.77)$ \\
\hline \multicolumn{7}{|l|}{ Age group } \\
\hline $11-14$ years & 67 & 49 & $3.49(2.64,4.62)$ & 1 & 1 & 1 \\
\hline $15-19$ years & 49 & 93 & $5.18(4.22,6.34)$ & $6.97(2.74,17.72)^{*}$ & $4.45(1.65,11.99)^{*}$ & $5.39(2.20,13.22)^{*}$ \\
\hline \multicolumn{7}{|l|}{ Height } \\
\hline Lower $75 \%$ & 79 & 100 & $4.91(4.04,5.97)$ & 1 & 1 & 1 \\
\hline $\begin{array}{l}\text { Top } 25^{\text {th }} \text { percentile by } \\
\text { age group }\end{array}$ & 37 & 42 & $3.61(2.67,4.89)$ & $1.13(0.50,2.55)$ & $0.79(0.32,1.96)$ & $1.03(1.00,1.07)$ \\
\hline \multicolumn{7}{|l|}{ Weight } \\
\hline Lower $75 \%$ & 86 & 110 & $4.97(4.12,5.99)$ & 1 & 1 & 1 \\
\hline $\begin{array}{l}\text { Top } 25^{\text {th }} \text { percentile by } \\
\text { age group }\end{array}$ & 30 & 32 & $3.24(2.29,4.58)$ & $0.85(0.36,1.98)$ & $0.53(0.20,1.41)$ & $1.05(1.02,1.09)^{*}$ \\
\hline
\end{tabular}




\begin{tabular}{|c|c|c|c|c|c|c|}
\hline \multirow[b]{2}{*}{ Risk factors } & \multirow[b]{2}{*}{$\begin{array}{l}\text { Number } \\
\text { of } \\
\text { climbers }\end{array}$} & \multirow[b]{2}{*}{$\begin{array}{c}\text { Number } \\
\text { of } \\
\text { injuries }\end{array}$} & \multirow{2}{*}{$\begin{array}{c}\text { IR/1000 hrs. } \\
(95 \% \\
\text { Confidence } \\
\text { Interval }[\mathrm{CI}])\end{array}$} & \multicolumn{2}{|c|}{ Climbing injury } & \multirow{2}{*}{$\begin{array}{l}\text { Time loss injury } \\
\text { OR adjusted for } \\
\text { climbing } \\
\text { participation hours } \\
\text { only } \\
(95 \% \mathrm{CI})\end{array}$} \\
\hline & & & & $\begin{array}{c}\text { Crude OR } \\
(95 \% \mathrm{CI})\end{array}$ & $\begin{array}{l}\text { OR adjusted for } \\
\text { climbing } \\
\text { participation hours } \\
\text { only }(95 \% \mathrm{CI})\end{array}$ & \\
\hline \multicolumn{7}{|l|}{ SES } \\
\hline $\begin{array}{l}\text { Low-medium high } \\
\text { affluence } \\
\text { (0-7 on the Family } \\
\text { Affluence Scale [FAS]) }\end{array}$ & 44 & 59 & $4.76(3.69,6.14)$ & 1 & 1 & 1 \\
\hline $\begin{array}{l}\text { High affluence } \\
\text { (8-9 on the FAS) }\end{array}$ & 72 & 83 & $4.23(3.42,5.25)$ & $1.11(0.51,2.42)$ & $1.15(0.50,2.65)$ & $0.98(0.44,2.15)$ \\
\hline \multicolumn{7}{|c|}{ Sport climbing grade $(n=101 ;$ missing 15 values $)$} \\
\hline $\begin{array}{l}\text { Yosemite decimal } \\
\text { system (YDS): } \\
5.8-5.11 \mathrm{a} \\
\text { Metric: } 5.66-7.33\end{array}$ & 47 & 35 & $3.74(2.69,5.21)$ & 1 & 1 & 1 \\
\hline $\begin{array}{l}\text { YDS: } 5.11 b-5.13 c \\
\text { Metric: } 7.33-9.66\end{array}$ & 54 & 97 & $4.60(3.77,5.61)$ & $5.00(2.04,12.23)^{*}$ & $2.86(1.02,7.99)^{*}$ & $2.45(0.94,6.36)$ \\
\hline \multicolumn{7}{|l|}{ Participation in other sports } \\
\hline No & 27 & 35 & $5.39(3.87,7.50)$ & 1 & 1 & 1 \\
\hline Yes & 89 & 107 & $4.20(3.47,5.07)$ & $1.22(0.51,2.96)^{*}$ & $1.06(0.41,2.71)$ & $0.85(0.34,2.08)$ \\
\hline \multicolumn{7}{|c|}{ Injury sustained in other sports within the previous year } \\
\hline No & 47 & 70 & $3.47(2.70,4.45)$ & 1 & 1 & 1 \\
\hline Yes & 69 & 72 & $5.63(4.53,7.00)$ & $4.10(1.72,9.76)^{*}$ & $3.88(1.55,9.72)^{*}$ & $4.56(1.84,11.29)^{*}$ \\
\hline
\end{tabular}




\begin{tabular}{|c|c|c|c|c|c|c|}
\hline \multirow[b]{2}{*}{ Risk factors } & \multirow[b]{2}{*}{$\begin{array}{c}\text { Number } \\
\text { of } \\
\text { climbers }\end{array}$} & \multirow[b]{2}{*}{$\begin{array}{l}\text { Number } \\
\text { of } \\
\text { injuries }\end{array}$} & \multirow{2}{*}{$\begin{array}{c}\text { IR/1000 hrs. } \\
(95 \% \\
\text { Confidence } \\
\text { Interval }[\mathrm{CI}])\end{array}$} & \multicolumn{2}{|c|}{ Climbing injury } & \multirow{2}{*}{$\begin{array}{l}\text { Time loss injury } \\
\text { OR adjusted for } \\
\text { climbing } \\
\text { participation hours } \\
\text { only } \\
(95 \% \mathrm{CI})\end{array}$} \\
\hline & & & & $\begin{array}{c}\text { Crude OR } \\
(95 \% \mathrm{CI})\end{array}$ & $\begin{array}{l}\text { OR adjusted for } \\
\text { climbing } \\
\text { participation hours } \\
\text { only }(95 \% \mathrm{CI})\end{array}$ & \\
\hline \multicolumn{7}{|c|}{ Any climbing helmet use within the past year } \\
\hline No & 45 & 43 & $4.37(3.24,5.89)$ & 1 & 1 & 1 \\
\hline Yes & 71 & 99 & $4.47(3.67,5.44)$ & $3.68(1.66,8.15)^{*}$ & $2.61(1.10,6.24) *$ & $2.33(1.02,5.31)^{*}$ \\
\hline \multicolumn{7}{|c|}{ Use of taping as a preventive measure } \\
\hline No & 69 & 62 & $3.78(2.94,4.84)$ & 1 & 1 & 1 \\
\hline Yes & 47 & 80 & $5.14(4.13,6.40)$ & $4.10(1.72,9.76)^{*}$ & $3.24(1.30,8.06)^{*}$ & $1.52(0.69,3.39)$ \\
\hline \multicolumn{7}{|c|}{ Use of a cool-down after climbing } \\
\hline No & 42 & 65 & $4.91(3.85,6.26)$ & 1 & 1 & 1 \\
\hline Yes & 74 & 77 & $4.11(3.28,5.13)$ & $0.47(0.20,1.07)$ & $0.62(0.26,1.51)$ & $0.45(0.20,1.02)$ \\
\hline \multicolumn{7}{|c|}{$\begin{array}{l}\text { Other risk-taking behaviours: } \\
\text { Alcohol consumption }\end{array}$} \\
\hline No & 90 & 95 & $4.55(3.72,5.56)$ & 1 & 1 & 1 \\
\hline Yes & 26 & 47 & $4.23(3.18,5.63)$ & $3.07(1.06,8.87)^{*}$ & $1.30(0.39,4.32)$ & $1.06(0.38,2.98)$ \\
\hline Smokes tobacco & \multicolumn{6}{|c|}{ N/A - 113 participants reported that they did not smoke } \\
\hline Wears a seatbelt & \multicolumn{6}{|c|}{ N/A - All 116 participants reported that they wore seatbelts } \\
\hline Venue & \multicolumn{6}{|c|}{ N/A - Only 8 participants reported that they sustained an injury while outdoors } \\
\hline
\end{tabular}

*Statistically significant at $\mathrm{p}<0.05$ 


\subsubsection{Multivariate Logistic Regression Analysis}

It should be stated that this multivariate risk factor analysis was exploratory. The model for the multivariate analysis was derived using the relevant variables found in the univariate analyses, adjusting for participation hours. Height and weight demonstrated high collinearity based on a chi-square test; in general, as the height of participants increased, body weight also increased. It is logical to hypothesize that higher body weights may lead to increased injury in climbing, and therefore weight was included as risk factor, while height was omitted. The odds ratio calculated for height in the univariate model also closer to 1.00 , had wider $95 \%$ confidence intervals than weight, and was close to the clinically relevant cut-off.

Three significant findings can be noted from the multivariate logistic regression. Older age group, injury in a sport other than climbing, and taping were once again shown to be clinically significant predictors for injury, though helmet use was not. The odds of being injured when a climber was in the older age group (15-19 years old) were 11.30 times greater $(95 \% \mathrm{CI} ; 2.33,54.85)$ than the odds of being injured when a climber was in the younger age group (11-14 years). The wide confidence interval for this OR is due to the low number of climbers in the older age group in the combination of variables in the multivariate model. The odds of having a climbing injury were 6.46 times greater (95\% CI; 1.62, 25.68) for a participant who had sustained an injury from a sport other than climbing. Finally, the odds of having an injury for participants who used preventive taping were 5.09 times greater $(95 \% \mathrm{CI} ; 1.44,18.02)$ than the odds of having an injury for those who did not use tape. 
Neither age group nor sport climbing grade were found to modify the relationship between injury and climbing level. There was no evidence of confounding when examined for all co-variables in this model.

Table 4.14 Exploratory multivariate logistic regression predicting climbing injury

\begin{tabular}{|c|c|}
\hline Risk factors & $\begin{array}{c}\text { Adjusted OR } \\
\text { (95\% Confidence } \\
\text { Interval) } \\
\end{array}$ \\
\hline \multicolumn{2}{|l|}{ Climbing level } \\
\hline Recreational & 1 \\
\hline Elite & $2.19(0.56,8.50)$ \\
\hline \multicolumn{2}{|l|}{ Age group } \\
\hline $11-14$ years & 1 \\
\hline 15-19 years & $11.30(2.33,54.85)^{*}$ \\
\hline \multicolumn{2}{|l|}{ Weight } \\
\hline Lower $75 \%$ & 1 \\
\hline Top $25^{\text {th }}$ percentile by age group & $0.37(0.10,1.35)$ \\
\hline \multicolumn{2}{|c|}{ Sport climbing grade $(\mathrm{n}=101 ;$ missing 15 values $)$} \\
\hline $5.8-5.11 \mathrm{a}$ & 1 \\
\hline $5.11 \mathrm{~b}$ to $5.13 \mathrm{c}$ & $1.57(0.39,6.41)$ \\
\hline \multicolumn{2}{|c|}{ Injury sustained in other sports within the previous year } \\
\hline No & 1 \\
\hline Yes & $6.46(1.62,25.68)^{*}$ \\
\hline \multicolumn{2}{|c|}{ Any climbing helmet use within the previous year } \\
\hline No & 1 \\
\hline Yes & $1.27(0.36,4.47)$ \\
\hline \multicolumn{2}{|l|}{ Use of taping as a preventive measure } \\
\hline No & 1 \\
\hline Yes & $5.09(1.44,18.02)^{*}$ \\
\hline \multicolumn{2}{|l|}{ Use of a cool-down after climbing } \\
\hline No & 1 \\
\hline Yes & $1.09(0.29,4.08)$ \\
\hline \multicolumn{2}{|l|}{$\begin{array}{l}\text { Other risk-taking behaviours: } \\
\text { Alcohol consumption }\end{array}$} \\
\hline No & 1 \\
\hline Yes & $0.39(0.06,2.50)$ \\
\hline
\end{tabular}

$*$ Statistically significant at $\mathrm{p}<0.05$. 


\subsection{Other Sport Injury}

Forty-seven (53\%) of the 89 climbers who participated in sports other than sport climbing or bouldering reported sustaining at least one injury in these activities during the previous 12 months. Sixteen (18\%) participants reported multiple non-climbing injuries. The total number of such injuries was 68 , resulting in a cumulative IP of 76 injuries per 100 participants per year $(95 \% \mathrm{CI} ; 66,85)$ and an IR of 2.25 injuries per 1000 participation hours $(95 \% \mathrm{CI} ; 1.73,2.88)$. Four injuries were excluded from this calculation, as they were not sustained in sports for which participation hours were collected.

Fifty-six (82\%) of these non-climbing injuries resulted in time loss from sport, resulting in an overall "time loss" injury IP of 63 per 100 participants per year $(95 \% \mathrm{CI}$; 52,73 ) in sports other than sport climbing and bouldering. The mean amount of time loss was 14 days $(95 \% \mathrm{CI} ; 6,22)$ for these injuries.

Injuries requiring medical attention counted $46(68 \%)$ of the 68 non-climbing injuries. This resulted in an overall injury IP of 52 per 100 participants per year $(95 \% \mathrm{CI}$; 41,62 ) for non-climbing injuries. Medical practitioner visits for these injuries are summarized in Table 4.15 . 
Table 4.15. Distribution of medical practitioner visits for all non-climbing injuries receiving medical attention

\begin{tabular}{|l|l|l|l|}
\hline Medical attention received & $\begin{array}{l}\text { Elite }(\mathrm{n}=34) \\
\text { Frequency }(\%)\end{array}$ & $\begin{array}{l}\text { Recreational }(\mathrm{n}=33) \\
\text { Frequency }(\%)\end{array}$ & $\begin{array}{l}\text { Total }(\mathrm{n}=67) \\
\text { Frequency }(\%)\end{array}$ \\
\hline First aid & $8(12)$ & $8(12)$ & $16(24)$ \\
\hline Physiotherapist & $8(12)$ & $7(10)$ & $15(22)$ \\
\hline Physician & $6(9)$ & $7(10)$ & $13(19)$ \\
\hline Chiropractor & $4(6)$ & $4(6)$ & $8(12)$ \\
\hline Massage therapist & $2(3)$ & $3(4)$ & $5(7)$ \\
\hline Athletic therapist & $2(3)$ & $2(3)$ & $4(6)$ \\
\hline EMT/paramedic & $2(3)$ & $1(1)$ & $3(5)$ \\
\hline Other & $2(3)$ & $1(1)$ & $3(5)$ \\
\hline
\end{tabular}

In examining injury sustained in any sport, including sport climbing and bouldering as well as all other sports that these climbers participated in over the previous year, a total of $82(71 \%)$ participants were injured altogether, incurring a total of 210 injuries $[\mathrm{IP}=181 / 100$ participants/year $(95 \% \mathrm{CI} ; 157,207)]$. 


\section{CHAPTER FIVE: DISCUSSION}

This is the first study of its kind to examine incidence rates and details surrounding injury in youth rock climbers, in both elite and recreational levels of the sport. Additionally, prior to this study, there had been limited previous research regarding risk factors for climbing injury in this age group.

Findings from this cross-sectional study demonstrated a high climbing injury incidence rate (IR) of 4.44 injuries per 1000 climbing hours $(95 \%$ Confidence Interval [CI]; 3.74, 5.23) in young climbers. Sprains and strains were highlighted as the predominant injury type, and the primary mechanism of injury was repetitive overuse. The most commonly injured anatomical locations in this sample were found to be the hands and fingers, followed by the shoulders. Older age (15-19-year-olds), injury in a sport other than climbing, and preventive taping were shown to be significant risk factors for injury.

\subsection{Participant Characteristics and Participation}

Fifty elite athletes and 66 recreational climbers participated in this study. Previous studies have examined injury risk in elite level teams, though with small sample sizes. Classifying by the above inclusion criteria in the present study ensured that subjects were sorted correctly by climbing level. High-level competitive climbers who failed to achieve a place on the National Team, for example, were still assigned to the elite group based on 
competition experience rather than being excluded or included in the recreational category (Chapter 1).

Sport climbing and bouldering are highly male dominated in the elite level of the sport. This disparity is illustrated by the sample in the present study. The mean age of the elite group was also older, explaining greater mean heights and body weights found in this group, as well as their lower participation rates in school physical education classes. This also likely explains the higher grades at which this group climbed (i.e., skill level). A higher proportion of elite climbers in comparison to recreational climbers also reported climbing outdoors. This can be explained by the fact that these individuals would likely have had more experience and the skills needed to climb in this less controlled environment. Compared to recreational climbers who were more likely to be younger novices, the individuals in the elite group may have had more access to equally experienced partners and a more structured climbing community. Furthermore, the findings showed differences between elite and recreational level climbers in sport climbing and bouldering participation. Those who participated exclusively in bouldering were all recreational climbers. This is often the case with beginners, as bouldering does not require that the participant have a belay partner. Conversely, the youth in this study who participated only in sport climbing were exclusively elite level climbers. This may be explained by the fact that all Canadian regional and national youth competitions and all international youth competitions are in sport climbing, and not bouldering. Local youth competitions and open (adult) competitions in which children and adolescents can compete often involve bouldering, though the International Mountaineering and Climbing 
Federation (UIAA) Medical Commission has set the minimum age for international bouldering competition participation to 16 years of age.

There were low participation rates in outdoor climbing overall, especially in the recreational category. This may be due in part to the sampling methods, which took place only at indoor facilities, but can also be explained by several other factors. Perhaps the largest factor preventing children and adolescents from climbing outdoors is the challenge of accessibility. Outdoor climbing areas are often difficult to approach, and may be even more inaccessible for children who are not yet autonomous and rely on transportation from adults. For youth who have not yet taken skill or safety courses, and for those who do not have partners with whom to climb, it is more convenient and safe to climb at an indoor facility. Parents may also feel more comfortable and be more willing to leave their children at a supervised facility, especially one that is easily accessible.

Motivation to participate in indoor or outdoor climbing is also a factor to consider. Artificial facilities offer a safe and social environment in which to climb, while climbing outside may be intimidating or uninteresting for youth. Furthermore, seasons and weather dictate outdoor participation. Climbers seldom sport climb or boulder outdoors during the winter in Canada, and cold temperatures and precipitation often deter climbers during other months of the year. Indoor facilities are not affected by these factors and it is therefore unsurprising that indoor climbing participation is high.

Aside from sport climbing and bouldering, the results illustrate that mountain sports were the most popular among participants in this study. Alpine skiing $(n=36)$ and mountain biking ( $\mathrm{n}=26)$ were the most popular followed by running, swimming, and 
hiking or scrambling. Overall incidence proportions and rates for injury were highest for climbing injury when compared to these other sports.

Few participants in this study participated in any other disciplines of climbing, such as traditional climbing $(n=14)$, alpine climbing $(n=4)$ and ice climbing $(n=2)$. This provides evidence that bouldering and sport climbing are the disciplines that youth engage in the most. These three other disciplines are performed outdoors almost exclusively, further supporting the argument that accessibility is a key reason that many youth do not participate in outdoor climbing.

\subsection{Climbing Injury Incidence Rates and Incidence Proportions}

The definition of climbing injury used in this study was adapted from both the UIAA Medical Commission Injury Classification for Mountaineering and Climbing Sport, and from the consensus statement on injury definitions and data collection procedures in studies of football (soccer) injuries by Fuller et al. (2006). ${ }^{4462}$ As such, it is valid for climbing as well as comparable to studies that use similar definitions in research involving other sports. This definition is inclusive of "any physical complaint" comprising all "pains or discomforts," in order to maximize the capture of injury in this study.

The proportion of participants who incurred at least one injury in this study, including both injuries sustained while climbing and in other sports, was $71 \%$. This is comparable, though slightly higher, to the proportion found in a variety of sports examined in the study by Emery \& Tyreman (2009) involving 12- to 15-year-old junior 
high school students (60.9\%), and also to the study by Emery et al. (2006) involving 14to 19 -year-old high school students $[65.7 \%){ }^{54} 64$

Seventy-three (63\%) participants in this study reported sustaining at least one climbing injury in the previous year, and the cumulative incidence proportion (IP) was 122 injuries per 100 participants per year. The injury IP found in the present study is high, but similar to that found for adult sport climbers by Jones et al. (2008) of 137 injuries per 100 participants per year, and to that found for adult boulderers by Josephsen et al. (2007) of 127 injuries per 100 participants per year for indoor bouldering and 103 injuries per 100 participants per year for outdoor bouldering. ${ }^{26}{ }^{31}$ However, exposure to risk is critical in examining the risk of injury. This is confirmed by the results of the univariate analysis, which illustrate that exposure hours should be accounted for in the denominator. The climbing injury IR was 4.44 injuries per 1000 climbing hours. This rate is high and similar to the 4.2 injuries per 1000 climbing hours reported by Backe et al. (2008) in their cross-sectional study involving a population of recreational climbers, primarily adults, in Sweden. ${ }^{25}$ It is also similar to the injury IR reported in youth ice hockey of 4.13 injuries per 1000 participation hours, and slightly lower, though still similar, to that reported in youth soccer of 5.59 injuries per 1000 participation hours. ${ }^{34} 65$ It should be noted that the definition of "injury" used in this study is of broad scope and encompasses any general pain or discomfort experienced by participants. As stated previously, this served to maximize the capture of injury in this study. By also collecting additional information about rates of time loss injury and medically treated injury, this illustrates the injury burden of youth climbing in detail. The IR for medically treated injuries was 2.62 injuries per 1000 climbing hours. The definition of medically 
treated injury was wide-ranging as well, and encompassed any medical treatment received including first aid. It was also informative, therefore, to examine those injuries that incurred time loss of at least one day. The IR for time loss injury was 1.81 injuries per 1000 climbing hours. The median amount of time loss was 14 days per injury. The distribution of injuries by time loss in this study suggests greater time loss than previously reported in youth ice hockey and other sports. ${ }^{3454}$ This is likely due to the nature of these climbing injuries, a high proportion of which were ongoing chronic injuries as well as those likely traumatic injuries related to falls. There were several outliers for which a high number of time loss days were reported, explaining the distribution of injuries illustrated in Figure 4.3. It is also possible that there was an underreporting of minor injuries if climbers deemed these injuries as irrelevant. Underreporting could also be due to negative attitudes around injury, or related to recall bias, discussed in section 5.5.

In examining the types of medical treatment sought and the practitioners seen by young climbers, the results highlight the need to educate physiotherapists, chiropractors, and physicians in particular. By educating healthcare providers, awareness and knowledge around climbing-specific injuries in youth as well as their treatment methods will grow.

\subsection{Injury Characteristics}

According to the Injury and Illness Classification system (UIAA Medical Commission Score), injuries sustained in this study scored no higher than two, meaning 
that there was no major injury and they were not life threatening, though may have required prolonged treatment (Appendix A). Ligament sprains and muscle or tendon strains were the most commonly occurring injuries in these young climbers, followed by tendonitis. "Repetitive overuse" (i.e., any injury caused by repeated movements or stress and usually beginning with an insidious onset) was found to be the most commonly selfreported mechanism of injury, followed by fall-related injuries. It is a limitation that "repetitive overuse" was not defined on the questionnaire, and it is unknown to what extent there was consistent interpretation among participants as to the meaning of this term. The highest proportion of injuries overall occurred in the hands, fingers, and shoulders. Stratifying by mechanism of injury, repetitive overuse injuries occurred predominantly in the upper extremities. This is consistent with previous research involving adult climbers in which overuse injuries, sprains, and strains to the upper body were found to be the most common. ${ }^{61227-31}$ The high proportion of fall-related injuries $(32 \%)$ reported in the present study were mainly lower extremity injuries, and they accounted for $50 \%$ of the knee and ankle injuries reported. Neuhof et al. (2011) reported a similar proportion of $39.9 \%$ for fall injuries, and Josephsen et al. (2007) reported that $23 \%$ of injuries occurring outdoors and $50 \%$ of injuries occurring indoors resulted from falls. ${ }^{2627}$ By contrast, Jones et al. (2008) reported that only $10 \%$ of injuries sustained by climbers in their study resulted from falls. ${ }^{12}$ This difference may be attributed to the definition of injury used by these authors, which was "requiring either medical attention or withdrawal from participation for one day or more." However, the way in which the data was collected in their questionnaire may have been highly influential in leading participants to report only serious acute injuries. The question "How many times in the 
last 12 months have you injured yourself as the result of a climbing fall?" was followed immediately by, "If you did injure yourself in this way, indicate the number of times each body part was affected: lower limb fracture, upper limb fracture, serious cuts, concussion, other (please specify)." 12 Because of this, participants in the study by Jones et al. (2008) may have under-reported fall injuries.

\subsection{Risk Factors and Injury Prevention}

Examination of the crude and exposure hours-adjusted odds ratios (ORs) estimated in the preliminary univariate analysis (Table 4.13) supports evidence that the risk of injury increases with participation hours in sport. ${ }^{54}$ The results of the multivariate logistic regression demonstrate that older age group (15-19-year-olds), reporting a previous injury in a sport other than sport climbing and bouldering, and preventive taping are risk factors for injury in rock climbing for youth in this study.

One previous study has examined age as a risk factor in youth climbers. Schlegel et al. (2002) found no significant association between age and injury in 29 elite youth climbers between the ages of 10 to 17 years. ${ }^{8}$ The results of the present study are conflicting. Findings show that the odds of injury for individuals in the older age group (15-19 years) are 11.30 times higher than for individuals in the younger age group (11-

14 years). This result is consistent with that of studies evaluating age in a variety of other sports. Emery (2003) reviewed 46 studies involving risk factors for injury in child and adolescent sport and concluded that the risk of injury increases with increasing age, and 
that adolescents older than 13 years were at a higher risk than younger children. ${ }^{66}$ Further examination of age is warranted in future studies to confirm this finding.

Injury in sports other than climbing has not been previously examined as a risk factor for injury in climbing. Those who sustained injury in a sport other than sport climbing or bouldering were at a greater risk of climbing injury in this study. The temporal association between other sport injury and climbing injury remains unclear in the context of this cross-sectional design. However, previous literature regarding sport injury demonstrates that previous injury is a predictor for subsequent injury. ${ }^{546466}$ This will be a key risk factor to consider in future prospective study designs in order to establish a temporal sequence and to examine why this relationship may exist. It is uncertain at present whether this finding may be related to physiological factors, the amount of exposure time to sport in general, risk behaviours, or other variables.

Preventive taping was used by a large proportion of participants $(41 \%)$, and is often used as an injury prevention measure by climbers. However, in this study, taping was found to be a predictor for climbing injury. This finding is contrary to what Josephsen et al. (2007) reported in examining taping of the fingers and wrists in adults participating in bouldering. Wrist taping, though not finger taping, was found to be significantly associated with a decreased rate of injury. ${ }^{26}$ Findings in the present study may be due to the fact that climbers who have sustained previous injuries (or are presently injured) use taping as a preventive measure for re-injury. Unfortunately, participants were not required to report their reasons for using preventive taping, and in a cross-sectional study design a temporal relationship could not be established. These results could also be explained by risk compensation, previously studied in several sports 
including protective equipment in skiing and snowboarding. ${ }^{67}$ This is a phenomenon in which introduced safety measures may actually result in "negative unintended consequences." ${ }^{67}$ In the context of youth climbing, it is possible that individuals who tape may engage in more aggressive or riskier climbing behaviour than they otherwise would have. Further research is needed to prospectively examine this relationship.

Several studies suggest that male climbers are at a higher risk of injury than females, though literature on this subject is highly conflicting. ${ }^{25} 303252$ In this study, no significant difference in injury risk was found for males compared to females, consistent with other studies examining climbing injury and cross-sectional studies investigating general sport injury in youth. ${ }^{12} 262736515464$ This study was not powered to examine differences in the types, mechanisms, or severity of climbing injury by sex, but this should be examined in the future.

Due to the low variability in the Family Affluence Scale II (FAS II) scores in this study sample, the groups created to examine socioeconomic status (SES) both encompassed scores in the "high affluence" category of the FAS II scale, and may not have shown meaningful differences for this reason. This overall high SES may be explained by the baseline cost associated with participating in climbing. This includes fees, equipment, access to facilities, and traveling to competitions. Previous research regarding SES as a risk factor for injury has been conflicting. ${ }^{37} 68$

Risk-taking behaviours such as alcohol consumption, smoking tobacco, and seatbelt non-use have not been examined previously in young climbers specifically, though Pickett et al. (2002) found these factors to be associated with an increased risk of sport injury in a general youth sample. ${ }^{37}$ These authors describe several different socio- 
behavioural models involving "risk behaviours" to explain injury gradients in adolescents, distinct from socioeconomic status as a risk factor. Smoking tobacco, alcohol consumption, and seatbelt non-use were used as proxy measures for evaluating these risk-taking tendencies leading to injury. ${ }^{37}$ Conversely, Gerdes et al. (2006) examined "climbing under the influence of illicit substances" as a direct risk factor, and found this to be significantly associated with injury $(\mathrm{p}=0.008) .{ }^{53}$ There was not enough variability in responses in the present study to examine smoking or seatbelt non-use as risk factors in this analysis, as all participants reported wearing seatbelts in vehicles, and only three reported that they had smoked tobacco during the previous year. Alcohol consumption appeared to be associated with a greater risk of injury, though this association was not statistically significant. This will be an area to examine further in the future, as risk-taking behaviours may be modifiable and therefore targeted in future injury prevention measures.

Previous injury has been found to be a risk factor for further sport injury in adolescents. ${ }^{6466}$ Only $26 \%$ of injuries incurred in this study were reported to be reinjuries, a lower percentage than was found by other authors. ${ }^{64}$ However, the main mechanism of injury in the present study was repetitive overuse, and participants may not have known how to properly differentiate re-injuries from ongoing chronic injuries. Consequently, previous injury merits further investigation as a risk factor for injury in youth rock climbing.

When asked about safety, $97 \%$ of participants reported having received instruction in this area during a course or youth program. This high proportion of education is encouraging, though the quality of this instruction is unknown and may have 
been different for each subject. Participants were also not asked to list what course was taken, and which skills or safety practices were learned. The results suggest that outside of these courses young climbers learn predominantly from peers and authority figures, and little from published or online sources. In order to maximize safety education and implement future prevention strategies for youth climbers, the focus should be on educating parents, coaches, teachers, and climbing gym instructors, as well as those organizations and gyms that offer courses, as they will be the best modes of disseminating knowledge to this population. Online and published materials will possibly be more important for adults, as the results here suggest that youth glean little information from these resources.

There has been no previous literature involving helmet use in rock climbing. The results of the multivariate analyses suggest that helmet use does not significantly change the risk of injury in youth climbers. Unlike sports in which head injuries are the most common, such as in hockey, football, and snowboarding, the rate of head injuries in climbing appears to be low, comprising only three of the total 142 injuries $(2 \%) \cdot{ }^{54}$ It is unknown whether helmets were worn during these injuries, as helmet use and injury were queried separately. Further research is certainly warranted, particularly regarding outdoor climbing, where additional factors such as overhead rock fall are present. Outdoor climbing as a risk factor could not be examined in this analysis due to the low number of outdoor injuries and also warrants investigation.

A high number of participants (98\%) reported warming up prior to climbing, suggesting that it is standard practice among young climbers. As such, it was not possible to examine this variable as a potential risk factor in this study. A lower percentage (64\%) 
reported cooling down after climbing. Performing a cool-down routine was not shown to be either protective or predictive of injury in this study. However, both warming-up and cooling-down merit further study as they are modifiable variables and may contribute to prevention strategies developed in the future. It will be important to define the details and length of each in subsequent research.

Although this multivariate analysis was exploratory and underpowered to reach conclusive results, it did introduce potentially clinically significant findings that can inform future studies. Low body mass index (BMI), venue, and specific discipline will be risk factors to further examine as they could not be analyzed within the scope of this study.

\subsection{Limitations}

Cross-sectional studies are subject to limitations inherent in their design. Temporality is perhaps the largest limiting factor to consider, as it is not always possible to establish temporal relationships between all risk factors and climbing injuries. Furthermore, it may be difficult to differentiate between re-injuries and new injuries.

Selection bias is possible as the study sample was recruited from climbing facilities and was carried out partially by convenience sampling. Injured climbers, especially those in the recreational group who may have been less motivated to climb or train, may not have frequented the indoor climbing gyms due to their injury. This would have caused an underestimation of the incidence and severity of injury, which may have differed between recreational and elite climbers. This difficulty was known at the outset 
of the study and an attempt was made to contact climbers not present at the gyms by having gym managers send out a mass email to participants in their programs. Only five out of the ten facilities agreed to do this as the remainder either did not keep contact information for youth participants on file or else declined due to privacy concerns.

Self-report designs are subject to potential limitations including self-diagnosis. Responses were subjective and not all subjects had been diagnosed by a medical practitioner. To mediate this problem, both anatomical location and mechanism of injury were recorded on the questionnaire, to provide objective ways of categorizing injuries. There was also the potential for bias related to the recall in this study. Harel et al. (1994) examined recall bias in children and adolescents for recall periods from one to 12 months, and found that reported injury IPs declined significantly in this time period. The authors also noted that minor injuries were underestimated and that injuries incurring time loss from school or time in bed, as well as those requiring medical attention were more easily remembered. ${ }^{69}$ This bias may have been present as the recall period in this study encompassed a full 12 months. It may therefore have led to under-reporting of minor injuries and thus a comparative overrepresentation of more memorable traumatic injuries. This may explain the high proportion of medically treated and time loss injuries. However, given that the largest proportion of injuries in this study were non-acute overuse injuries, the effect of recall bias is unclear. It should also be noted that, for many of the younger climbers in this study, parents may have helped complete the questionnaire, possibly improving recall for these participants. Thus the incidence proportion would have been inflated for the younger group, resulting in an 
underestimation of the effect of older age in the risk factor analysis. However, given the calculated OR and wide confidence intervals, this bias is unlikely or minimal.

The original target sample size of 206, estimated to detect a clinically important difference in injury incidence proportion of $20 \%$ between elite and recreational groups, was not achieved as too few climbers consented to be part of the study. Based on an anticipated compliance rate of $70 \%$, it was estimated that at least 268 climbers were to be approached to ensure a sample size large enough to reach the desired study power. Although a total of 285 climbers were invited to participate, only 126 returned completed consent forms. Of these, 116 subsequently returned either an on-line or a hard-copy questionnaire, resulting in a participation rate of approximately 41\%. Emery et al. (2006) reported that compliance rates for their cross-sectional study were as low as $41 \%$ for schools that required signed parental consent forms. ${ }^{54}$ This may have also been the reason for low compliance in this study. However, given that the effect size found was much larger than expected ( $80 \%$ difference based on elite and recreational IPs), a statistically significant and clinically relevant difference was found. This study was not powered for a multivariate analysis and thus these analyses were exploratory. A larger sample size would have enabled further comparisons and analyses. However, the sample size calculated in the present study was a conservative estimate. Prior to this study, there had been no studies examining the injury incidence rate in young elite climbers on which to properly base this calculation. Therefore, $30 \%$ was used as an estimate of the IP for recreational climbers based on the survey by Backe et al. (2008) involving a general adult climbing population in Sweden. ${ }^{25}$ To detect a clinically important difference of $20 \%$, $50 \%$ was chosen as the IP for elite climbers as previous literature suggested that elite 
athletes had a higher proportion of injury than recreational climbers. ${ }^{6}{ }^{12}$ A continuity correction was also used to calculate a more conservative estimate of sample size. Sample size calculations can be found in Appendix C.

Potential clustering effects lie in the fact that different gyms may be of different sizes, and possess different coaches, wall angles, training facilities, and ratios of sport climbing to bouldering. Thus the similarities between climbers within one gym may be greater than between climbers from different gyms. As such, the precision of effect estimates (ORs) found here may be overestimated. There were only 10 facilities from which participants were recruited and therefore 10 possible clusters. This low number of climbing facilities limited our ability to control for cluster, but it is likely that the effect of cluster would be small or non-existent as climbers often frequent more than one single gym. Furthermore, four of these gyms included only five participants or less.

The generalizability of this study must also be considered. This study included subjects sampled from indoor facilities only and the results are therefore not necessarily relevant to youth that participate in climbing primarily or exclusively outdoors. Indoor and outdoor climbing may have many of the same risk factors, but outdoor climbing has additional elements such as rock-fall, uneven terrain, weather, and a lack of safety regulations. It is unclear whether incidence rates and results would be different than those found in the present study. However, it is likely that the number of youth participants in outdoor climbing is low compared to indoor as there are many factors, not the least of which are accessibility and cold seasons, that would cause the number of youth that climb exclusively outdoors to be very low or non-existent. Furthermore, by including both 
indoor and outdoor injuries and participation rates in this study, we have decreased the severity of this problem.

The generalizability outside of Canada is also a question to consider. Equipment is relatively standard worldwide, though climbing routines may vary. The culture and attitudes associated with climbing and climbing injury have never been studied and it is unknown whether these factors may affect injury itself or whether they differ between countries.

Finally, there were limits to the amount of information that could be collected on the questionnaire. In order to limit its length to a maximum of 15 minutes, certain omissions had to be made. Additionally, to facilitate data entry and analysis as well as to maintain a reasonable length, most questions were close-ended, eliminating the possibility of participants adding details, explanations, or additional comments. In order to create the best possible tool for the purposes and within the limits of the present study, the questionnaire was face validated through interviews with 20 relevant experts, including researchers, climbers, parents, coaches, physicians, physiotherapists, one occupational therapist and one athletic therapist.

\subsection{Strengths}

This is the first study of its kind to examine the burden of climbing injury in a relatively large sample of youth rock climbers, involving youth that climb at both the elite and recreational level. Previous research has primarily focused on injuries sustained

in traditional mountaineering and alpine climbing in adult participants. ${ }^{1-5}$ More recent 
studies involving youth have predominantly examined finger injury and radiographic changes in small groups of elite climbers, located primarily in Germany, or focus on growth and development or anthropometrics. ${ }^{78} 10333940$ Though the sample size originally calculated was not met, a high proportion (84\%) of the competitive climbers approached were recruited for this study. As all competitive teams in Alberta were approached to participate, the results are highly generalizable to this population.

This study serves to deepen the epidemiological knowledge of sport climbing and bouldering injury in youth, and creates a base that will inform future research in the field. 


\section{CHAPTER SIX: CONCLUSIONS}

\subsection{Summary of Findings}

This is the first study of its kind to examine injury incidence rates, mechanisms of injury, and risk factors for injury in youth climbers. One-hundred and sixteen individuals participated in this study, 50 of whom were elite climbers, and 66 recreational. Overall, $63 \%$ of climbers sustained at least one new injury in the previous 12 months, while $31 \%$ reported multiple climbing injuries. The overall climbing injury incidence rate (IR) was high at 4.44 injuries/1000 climbing hours [95\% Confidence Interval (CI); 3.74, 5.23]. The IR for medical attention injuries was 2.63 injuries per climbing 1000 hours $(95 \% \mathrm{CI}$; $2.09,3.25)$, and for time loss injuries was 1.81 injuries per 1000 hours (95\% CI; 1.38 , 2.34). Recreational and elite climbers were not significantly different in injury incidence rates, at 4.71 injuries per 1000 climbing hours $(95 \% \mathrm{CI} ; 3.64,6.09)$ and 4.27 per 1000 hours $(95 \% \mathrm{CI} ; 3.45,5.29)$, respectively.

Hand, finger and shoulder ligament sprains and muscle or tendon strains are highlighted in this study as the most common injuries. Tendonitis is also common. Repetitive overuse was found to be the primary mechanism of injury followed by fallrelated injuries. These results are consistent with previous research involving adult climbers in which overuse injuries to the upper body were found to be the most common. The proportion of fall-related injuries found was also similar to previous adult climbing studies. 
The majority of participants in this study (97\%) reported that they received climbing safety instruction in a course or as part of team training. Seventy-three percent of climbers also reported learning additional safety practices elsewhere.

The results of this study indicate that adolescents aged 15 to 19 years are at a greater risk of injury in sport climbing and bouldering than younger adolescents (11-14year-olds). Youth who have been injured in a sport other than climbing and those who use preventive taping are also at a greater risk of injury. Although preliminary univariate analyses suggested a clinically meaningful association between body weight and climbing injury, as well as helmet use and injury, these factors were not statistically significant in a multivariate model adjusting for all other potential risk factors. This may have been related to study power. The present study also illustrates the need to adjust for exposure time when evaluating incidence and risk. Other factors that were not found to be significant risk factors for injury include climbing level, sex, weight, socioeconomic status (SES), sport climbing grade, participation in sports other than sport climbing and bouldering, climbing helmet use, the use of a cool-down, and alcohol consumption.

\subsection{Public Health Implications}

Climbing is becoming increasingly popular as both a recreational and a competitive sport in Canada. As such, understanding the healthcare burden presented by this sport is essential. This study is the first to examine injury incidence rates, mechanisms, and risk factors for injury in a population of young climbers of varying abilities. The findings indicate that the incidence rates of injury in 11- to 19-year-old 
climbers are high, and that chronic overuse injuries as well as fall-related injuries are common. This may increase the long-term burden on the healthcare system. Further injury research is undoubtedly warranted, and as the knowledge in this area continues to deepen, injury prevention measures can begin to be developed to reduce the depletion of healthcare resources. Translating and disseminating knowledge about the main types, mechanisms, and risk factors for injury to parents, coaches, and climbers will be also important to help reduce injury incidence through awareness.

\subsection{Recommendations for future research}

Climbing injury research will benefit from future prospective cohort studies to establish temporal relationships in examining risk factors. Further examination of the risk factors examined in this analysis, as well as additional modifiable risk factors including risk taking behaviours, safety courses, body mass index (BMI), climbing volume, and prevention strategies is necessary. Watts et al. (2003) reported that young, competitive sport climbers tend to have a lower estimated body fat percentage than non-climbers. ${ }^{40}$ It will be necessary to establish BMI cut-offs for underweight children in order to examine this variable as a risk factor for injury in youth. Furthermore, deeper examination of body weight and helmet use is necessary in order to confirm that these variables are not risk

factors for injury. In the present study, the nature of the questionnaire and the information captured did not allow any discussion around attitudes and beliefs toward injury, prevention, or training. Therefore, this may be an additional topic to examine in future studies as research continues toward implementing possible interventions. 
As research in this field develops, a focus on knowledge translation including climbing community stakeholders is imperative to develop, implement, and validate effective injury prevention strategies. Targeting prevention measures for upper body repetitive overuse injuries as well as fall-related injuries will have the greatest impact. Youth programs through climbing facilities will be an important venue by which to introduce these measures. As sport climbing and bouldering gain more youth participants and as research develops for this sport, it may be useful to develop a long-term athlete development (LTAD) plan. Thus, coaches and climbing instructors can learn safe, ageappropriate activities and drills in order to promote healthy activity for youth within the sport of climbing. ${ }^{70}$ 


\section{REFERENCES}

1. Bannister P, Foster P. Upper limb injuries associated with rock climbing. British Journal of Sports Medicine 1986;20(2):55-55.

2. Bowie WS, Hunt TK, Allen HA. Rock-climbing injuries in Yosemite National Park. WJM: Western Journal of Medicine 1988;149(2):172-77.

3. Addiss DG, Baker SP. Mountaineering and rock-climbing injuries in US national parks. Annals of Emergency Medicine 1989;18(9):975-9.

4. Schussman LC, Lutz LJ. Mountaineering and rock climbing accidents: a descriptive study. Summit 1983;29(3):6-9.

5. Paige TE, Fiore DC, Houston JD. Injury in traditional and sport rock climbing. Wilderness Environ Med 1998;9(1):2-7.

6. Rohrbough JT, Mudge MK, Schilling RC. Overuse injuries in the elite rock climber. Medicine and Science in Sports and Exercise 2000;32(8):1369-72.

7. Hochholzer T, Schoffl VR. Epiphyseal fractures of the finger middle joints in young sport climbers. Wilderness Environ Med 2005;16(3):139-42.

8. Schlegel C, Buechler U, Kriemler S. Finger injuries of young elite rock climbers. Schweizerische Zeitschrift fuer Sportmedizin \& Sporttraumatologie 2002;50(1):710.

9. Schöffl V, Hochholzer T, Karrer A, Winter S, Imhoff A. Finger problems in adolescent top level climbers: A comparison of the German Junior National Team with recreational climbers. Deutsche Zeitschrift fuer Sportmedizin 2003;54(11):317-22. 
10. Schöffl V, Hochholzer T, Imhoff A. Radiographic changes in the hands and fingers of young, high-level climbers. American Journal of Sports Medicine 2004;32(7):1688-94.

11. Chell J, Stevens K, Preston B, Davis TRC. Bilateral fractures of the middle phalanx of the middle finger in an adolescent climber. American Journal of Sports Medicine 1999;27(6):817-19.

12. Jones G, Asghar A, Llewellyn DJ. The epidemiology of rock-climbing injuries. British Journal of Sports Medicine 2008;42(9):773-78.

13. Nelson NG, McKenzie LB. Rock climbing injuries treated in emergency departments in the U.S., 1990-2007. American Journal of Preventive Medicine 2009;37(3):195-200.

14. History. International Mountaineering and Climbing Federation (UIAA).

15. UIAA. UIAA Council 14 May 2005 Agenda item 8.3: Research on mountaineering as an Olympic sport 1896-1948: Note for information., 2005.

16. Competition Climbing History International Federation of Sport Climbing (IFSC).

17. van der Putten EP, Snijders CJ. Shoe design for prevention of injuries in sport climbing. Applied Ergonomics 2001;32(4):379-87.

18. Schöffl VR, Küpper T. Injuries at the 2005 World Championships in Rock Climbing. Wilderness and Environmental Medicine 2006;17(3):187-90.

19. Thornhill G. The World's First Artificial Climbing Wall-The Schurman Rock Seattle - 1938-1940.

20. 2012 Outdoor Recreation Participation Report. Boulder, CO: The Outdoor Foundation, 2012. 
21. Canadian hard outdoor adventure enthusiasts : a special analysis of the Travel Activities and Motivation Survey (TAMS). Ottawa, ON: Research Resolutions \& Consulting Ltd, Canadian Tourism Commission (CTC), 2003.

22. Special Report on Youth: The Next Generation of Outdoor Champions. Boulder, CO: The Outdoor Foundation, 2010.

23. Standards. International Mountaineering and Climbing Federation (UIAA).

24. Limb D. Injuries on British climbing walls. Br J Sports Med 1995;29(3):168-70.

25. Backe S, Ericson L, Timpka T, Janson S. Rock climbing injury rates and associated risk factors in a general climbing population. British Journal of Sports Medicine 2008;42(6):508-09.

26. Josephsen G, Shinneman S, Tamayo-Sarver J, Josephsen K, Boulware D, Hunt M, et al. Injuries in bouldering: A prospective study. Wilderness and Environmental Medicine 2007;18(4):271-80.

27. Neuhof A, Hennig FF, Schöffl I, Schöffl V. Injury Risk Evaluation in Sport Climbing. International Journal of Sports Medicine 2011;32(10):794-800.

28. Schöffl V, Hochholzer T, Winkelmann HP, Strecker W. Pulley injuries in rock climbers. Wilderness Environ Med 2003;14(2):94-100.

29. Shea KG, Shea OF, Meals RA. Manual demands and consequences of rock climbing. J Hand Surg Am 1992;17(2):200-5.

30. Wright DM, Royle TJ, Marshall T. Indoor rock climbing: who gets injured? British Journal of Sports Medicine 2001;35(3):181-85.

31. Logan AJ, Makwana N, Mason G, Dias J. Acute hand and wrist injuries in experienced rock climbers. British Journal of Sports Medicine 2004;38(5):545-48. 
32. Carmeli E, Shuruk S, Sheklow SL, Masharawi Y. Incidence of hand injuries in wall climbers: a comparison between adolescent adults and young adults. Biology of Sport 2002;19(4):283-94.

33. Schöffl VR, Hochholzer T, Imhoff AB, Schöffl I. Radiographic adaptations to the stress of high-level rock climbing in junior athletes: a 5-year longitudinal study of the German Junior National Team and a group of recreational climbers. American Journal of Sports Medicine 2007;35(1):86-92.

34. Emery CA, Meeuwisse WH. Injury Rates, Risk Factors, and Mechanisms of Injury in Minor Hockey. The American Journal of Sports Medicine 2006;34(12):1960-68.

35. Bijur PE, Trumble A, Harel Y, Overpeck MD, Jones D, Scheidt PC. Sports and recreation injuries in US children and adolescents. Archives of pediatrics \& adolescent medicine 1995;149(9):1009-16.

36. Rose MS, Emery CA, Meeuwisse WH. Sociodemographic Predictors of Sport Injury in Adolescents. Medicine \& Science in Sports \& Exercise 2008;40(3):444-50 10.1249/MSS.0b013e31815ce61a.

37. Pickett W, Garner MJ, Boyce WF, King MA. Gradients in risk for youth injury associated with multiple-risk behaviours: a study of 11,329 Canadian adolescents. Social Science \& Medicine 2002;55(6):1055-68.

38. Balás J, Strejcová B, Maly T, Malá L, Martin AJ. Changes in upper body strength and body composition after 8 weeks indoor climbing in youth. Isokinetics \& Exercise Science 2009;17(3):173-79. 
39. Schöffl I, Schöffl V, Dötsch J, Dörr HG, Jüngert J. Correlations Between High Level Sport-Climbing and the Development of Adolescents. Pediatric Exercise Science 2011;23(4):477-86.

40. Watts PB, Joubert LM, Lish AK, Mast JD, Wilkins B. Anthropometry of young competitive sport rock climbers. British Journal of Sports Medicine $2003 ; 37(5): 420-24$.

41. Tomczak RL, Wilshire WM, Lane JW, Jones DC. Injury patterns in rock climbers. Journal of Osteopathic Sports Medicine 1989;3(2):11-16.

42. Schöffl I, Einwag F, Strecker W, Hennig F, Schöffl V. Impact of Taping After Finger Flexor Tendon Pulley Ruptures in Rock Climbers. Journal of Applied Biomechanics 2007;23(1):52-62.

43. Humphries D. Injury Rates in Rock Climbers. Journal of Wilderness Medicine $1993 ; 4: 281-85$.

44. Schöffl V, Morrison A, Hefti U, Ullrich S, Küpper T. The UIAA Medical Commission Injury Classification for Mountaineering and Climbing Sports. Wilderness \& Environmental Medicine (Allen Press Publishing Services Inc.) 2011;22(1):46-51.

45. Outdoor Recreation Participation Report 2012. In: Foundation TO, editor, 2012.

46. Rating Systems. In: Eng R, Van Pelt J, editors. Mountaineering: the freedom of the hills. 8 ed. Seattle, WA: The Mountaineers Books, 2010.

47. Meeuwisse WH. Predictability of sport injuries: what is the epidemiological evidence? Sports Medicine 1991(12):8-15. 
48. Downs SH, Black N. The feasibility of creating a checklist for the assessment of the methodological quality of randomised and non-randomised studies of health care interventions. Journal of Epidemiological Community Health 1998(52):377-84.

49. Shahram A, Farzad A, Reza R. A study on the prevalence of muscular-skeleton injuries of rock climbers. Facta Universitatis: Series Physical Education \& Sport 2007;5(1):1-7.

50. Logan AJ, Mason G, Dias J, Makwana N. Can rock climbing lead to Dupuytren's disease? Br J Sports Med 2005;39(9):639-44.

51. Hasler RM, Bach P, Brodmann M, Heim D, Spycher J, Schotzau A, et al. A pilot case-control study of behavioral aspects and risk factors in Swiss climbers. European journal of emergency medicine : official journal of the European Society for Emergency Medicine 2012;19(2):73-6.

52. Pieber K, Angelmaier L, Csapo R, Herceg M. Acute injuries and overuse syndromes in sport climbing and bouldering in Austria: a descriptive epidemiological study. Wiener Klinische Wochenschrift 2012;124(11-12):357-62.

53. Gerdes EM, Hafner JW, Aldag JC. Injury patterns and safety practices of rock climbers. Journal of Trauma 2006;61(6):1517-25.

54. Emery CA, Meeuwisse WH, McAllister JR. Survey of Sport Participation and Sport Injury in Calgary and Area High Schools. Clinical Journal of Sport Medicine 2006;16(1):20-26.

55. Faigenbaum AD, Myer GD. Resistance training and pediatric health. Revista Kronos 2011;10(1):31-38. 
56. Canadian Physical Activity, Fitness and Lifestyle Approach Manual. 3rd ed. Ottawa, ON.: Canadian Society for Exercise Physiology, 2003.

57. Emery CA, Meeuwisse WH. The effectiveness of a neuromuscular prevention strategy to reduce injuries in youth soccer: a cluster-randomised controlled trial. Br J Sports Med 2010;44(8):555-62.

58. Rooks MD, Johnston RB, III, Ensor CD, McIntosh B, James S. Injury patterns in recreational rock climbers. American Journal of Sports Medicine 1995;23(6):68385.

59. Williams JM, Currie CE, Wright P, Elton RA, Beattie TF. Socioeconomic status and adolescent injuries. Social Science \& Medicine 1997;44(12):1881-91.

60. Boyce W, Torsheim T, Currie C, Zambon A. The Family Affluence Scale as a Measure of National Wealth: Validation of an Adolescent Self-Report Measure. Social Indicators Research 2006;78(3):473-87.

61. Boyce W, Dallago L, Currie C, Roberts C, Morgan A, Smith R, et al. Socioeconomic inequality. Young people's health in context. Health Behaviour in School-aged Children study: international report from the 2001;2002.

62. Fuller CW, Ekstrand J, Junge A, Andersen TE, Bahr R, Dvorak J, et al. Consensus statement on injury definitions and data collection procedures in studies of football (soccer) injuries. Br J Sports Med 2006;40(3):193-201.

63. Cole TJ, Bellizzi MC, Flegal KM, Dietz WH. Establishing a standard definition for child overweight and obesity worldwide: international survey. British Medical Journal 2000;320:1-6. 
64. Emery CA, Tyreman H. Sport participation, sport injury, risk factors and sport safety practices in Calgary and area junior high schools. Paediatrics \& Child Health 2009;14(7):439-44.

65. Emery CA, Meeuwisse WH, Hartmann SE. Evaluation of Risk Factors for Injury in Adolescent Soccer: Implementation and Validation of an Injury Surveillance System. The American Journal of Sports Medicine 2005;33(12):1882-91.

66. Emery CA. Risk factors for injury in child and adolescent sport: a systematic review of the literature. Clin J Sport Med 2003;13:256-68.

67. Hagel B, Meeuwisse WH. Risk Compensation: A "Side Effect” of Sport Injury Prevention? Clinical Journal of Sport Medicine 2004;14(4):193-96.

68. King MA, Pickett W, King AJC. Injury in Canadian youth: A secondary analysis of the 1993-94 health behaviour in school-aged children survey. Canadian Journal of Public Health 1998;89(6):397-401.

69. Harel Y, Overpeck MD, Jones DH, Scheidt PC, Bijur PE, Trumble AC, et al. The Effects of Recall on Estimating Annual Nonfatal Injury Rates for Children and Adolescents. American Journal of Public Health 1994;84(4):599-605.

70. Learn About Canadian Sport For Life: LTAD Stages: Canadian Sport Centre, 2011. 71. Casagrande JP, M.; Smith, P. An Improved Approximate Formula for Calculating Sample Sizes for Comparing Two Binomial Distributions. Biometrics 1978;34(3):483-86. 


\section{APPENDIX A: UIAA MEDICAL COMMISSION INJURY CLASSIFICATION FOR MOUNTAINEERING AND CLIMBING SPORTS}




\section{Main groupings and categories for classifying injury location ${ }^{62}$}

\begin{tabular}{|l|l|l|}
\hline Main Grouping & Category & $\begin{array}{l}\text { Equivalent OSICS } \\
\text { Body Area Character }\end{array}$ \\
\hline Head and neck & Head/Face & $\mathrm{H}$ \\
& Neck/cervical spine & $\mathrm{N}$ \\
\hline Upper limbs & Shoulder/clavicle & $\mathrm{S}$ \\
& Upper arm & $\mathrm{U}$ \\
& Elbow & $\mathrm{E}$ \\
& Forearm & $\mathrm{R}$ \\
& Wrist & $\mathrm{W}$ \\
& Hand/finger/thumb & $\mathrm{P}$ \\
\hline Trunk & Sternum/ribs/upper back & $\mathrm{C}, \mathrm{D}$ \\
& Abdomen & $\mathrm{O}$ \\
& Lower back/pelvis/sacrum & $\mathrm{B}, \mathrm{L}$ \\
\hline Lower limbs & Hip/groin & $\mathrm{G}$ \\
& Thigh & $\mathrm{T}$ \\
& Knee & $\mathrm{K}$ \\
& Lower leg/Achilles tendon & $\mathrm{Q}, \mathrm{A}$ \\
& Ankle & $\mathrm{A}$ \\
& Foot/toe & $\mathrm{F}$ \\
\hline
\end{tabular}

\section{Injury and Illness Classification (IIC) - UIAA MedCom Score}

$0 \quad$ No injury or illness

1 Slight injury or illness, no medical intervention necessary, self-therapy (e.g. bruises, contusions, strains)

2 Middle severe injury or illness, not life threatening, prolonged conservative or surgical therapy, outpatient therapy, doctors attendance within a short time frame (days), injury related work absence, heals without permanent damage (e.g. undisplaced fractures, tendon ruptures, pulley ruptures, dislocations)

3 Major injury or illness, not life threatening, residential hospital therapy, surgical intervention necessary, immediate doctors attendance necessary, injury related work absence, heals with or without permanent damage e.g. dislocated joint, fractures, vertebral fractures, cerebral injuries

4 Acute mortal danger, polytrauma, immediate prehospital doctors or experienced trauma paramedics attendance if possible, acute surgical intervention, outcome alive, permanent damage

5 Acute mortal danger, polytrauma, immediate prehospital doctors or experienced trauma paramedics attendance if possible, acute surgical intervention, outcome dead

6 Immediate death 
APPENDIX B: UIAA MEDICAL COMMISSION COMPARISON OF THE RECOMMENDED CLIMBING GRADE METRIC SCALE FOR SCIENTIFIC STUDIES TO THE UIAA, FRENCH, AND AMERICAN GRADES 


\begin{tabular}{|c|c|c|c|}
\hline $\begin{array}{l}\text { Metric } \\
\text { scale }\end{array}$ & UIAA & $\begin{array}{c}\text { French } \\
\text { (Fr.) }\end{array}$ & $\begin{array}{l}\text { US-American } \\
\text { (YDS) }\end{array}$ \\
\hline 5.66 & 6- & $5 b / c$ & 5.8 \\
\hline 6 & 6 & $5 c / 6 a$ & 5.9 \\
\hline 6.33 & $6+$ & $6 a / 6 a+$ & $5.10 a$ \\
\hline 6.66 & 7- & $6 a+/ b$ & $5.10 \mathrm{~b} / \mathrm{c}$ \\
\hline 7 & 7 & $6 b / b+$ & $5.10 \mathrm{~d}$ \\
\hline 7.33 & $7+$ & $6 b+/ 6 c$ & $5.11 \mathrm{a} / \mathrm{b}$ \\
\hline 7.66 & 8- & $6 c+$ & $5.11 \mathrm{c}$ \\
\hline 8 & 8 & $7 a$ & $5.11 \mathrm{c} / \mathrm{d}$ \\
\hline 8.33 & $8+$ & $7 a+/ 7 b$ & $5.12 \mathrm{a} / \mathrm{b}$ \\
\hline 8.66 & 9- & $7 \mathrm{~b} / 7 \mathrm{~b}+$ & $5.12 \mathrm{~b} / \mathrm{c}$ \\
\hline 9 & 9 & $7 \mathrm{c} / 7 \mathrm{c}^{+}$ & $5.12 d$ \\
\hline 9.33 & $9+$ & $7 c+/ 8 a$ & $5.13 a$ \\
\hline 9.66 & $10-$ & $8 a / 8 a+$ & $5.13 \mathrm{~b} / \mathrm{c}$ \\
\hline 10 & 10 & $8 b$ & $5.13 d$ \\
\hline 10.33 & $10+$ & $8 b+/ 8 c$ & $5.14 \mathrm{a} / \mathrm{b}$ \\
\hline 10.66 & 11- & $8 c / 8 c+$ & $5.14 \mathrm{~b} / \mathrm{c}$ \\
\hline 11 & 11 & $9 a$ & $5.14 d$ \\
\hline 11.33 & $11+$ & $9 a+$ & $5.15 a$ \\
\hline 11.66 & $12-$ & $9 b$ & $5.15 b$ \\
\hline
\end{tabular}


APPENDIX C - SAMPLE SIZE CALCULATIONS 
$\alpha=0.05=$ acceptable type I error (two-tailed) $\rightarrow Z_{1-\alpha / 2}=Z_{0.975}=1.960$

$\beta=0.20=$ acceptable type II error for a study powered at $80 \%(1-\beta) \rightarrow Z_{1-\beta}=Z_{0.80}=$ 0.842

$p_{1}=0.50=50 \%$ incidence of injury will be used for the elite group. There have been no studies examining the incidence proportion of injury in young elite climbers, but some research suggests a higher proportion of injury in elite climbers than for recreational climbers. ${ }^{68}$ Jones et al. (2008) found that half (50\%) of the climbers they surveyed had sustained an injury in the previous 12 months, and although elite and recreational climbers were not differentiated in this study, it was found that the odds of injury was higher in subjects that climbed at higher grades. ${ }^{12}$ A conservative estimate of 0.50 will therefore be used to detect a clinically important difference of $20 \%$ between groups.

$q_{1}=1-p_{1}=1-0.50=0.50$

$p_{2}=0.30=30 \%$ (106 of 355) of climbers sustained an injury based on a survey of a general climbing population in Sweden. ${ }^{25}$ These can be assumed to be recreational climbers.

$$
\begin{aligned}
& q_{2}=1-p_{2}=1-0.30=0.70 \\
& \bar{p}=\left(\mathrm{p}_{1}+\mathrm{p}_{2}\right) \div 2=(0.50+0.29) \div 2=0.40 \\
& \bar{q}=1-\bar{p}=1-0.40=0.60 \\
& \Delta_{p A}^{2}=\mathrm{p}_{1}-\mathrm{p}_{2}=0.50-0.30=0.20
\end{aligned}
$$

The number of climbers required per group is calculated by: ${ }^{71}$

$$
n=\frac{A\left[1+\sqrt{1+\frac{4\left(p_{1}-p_{2}\right)}{A}}\right]^{2}}{4\left(p_{1}-p_{2}\right)^{2}} \text { where } A=\left[z_{1-\frac{\alpha}{2}} \sqrt{2 \overline{p q}}+z_{1-\beta} \sqrt{p_{1} q_{1}+p_{2} q_{2}}\right]^{2}
$$




$$
A=[1.960 \sqrt{2(0.40 * 0.60)}+0.842 \sqrt{(0.50 * 0.50)+(0.30 * 0.70)}]^{2}=3.72
$$

$n=\frac{3.72\left[1+\sqrt{\left.1+\frac{4(0.50-0.30)}{3.72}\right]^{2}}\right.}{4(0.50-0.30)^{2}}=102.76=103$ subjects per group

The total sample size would then be 206 climbers. This number has been verified using STATA 12.0.This calculation incorporates a continuity correction that results in a more conservative estimate. ${ }^{71}$

The survey study by Emery et al. (2006) on injuries in Calgary and area high schools reported an overall compliance of $71.5 \%$. To be conservative, the following estimate of the minimum number of subjects that we aimed to recruit is based on $70 \%$ compliance.

$206+30 \% * 206=267.8 \rightarrow 268$

Therefore, approximately 268 climbers needed to be approached to ensure a sample size large enough to reach the desired study power, based on $70 \%$ participation. However, although a total of 285 climbers were invited to participate, only 126 returned completed consent forms. Of these, 116 subsequently returned either an on-line or a hardcopy questionnaire, resulting in a participation rate of approximately $41 \%$. 
APPENDIX D: PARENTAL CONSENT FORM 


\title{
PARENTAL CONSENT FORM TITLE: Youth Rock Climbing Injury Study
}

SPONSOR: Sport Injury Prevention Centre, Roger Jackson Sport Medicine Centre, University of Calgary

\author{
INVESTIGATORS: \\ PRINCIPAL INVESTIGATOR: DR. CAROLYN EMERY, UNIVERSITY OF CALGARY \\ CO-INVESTIGATORS (UNIVERSITY OF CALGARY): NANI WOOLLINGS, DR. CARLY MCKAY, \\ DR. JIAN KANG, DR. WILLEM MEEUWISSE
}

This consent form is only part of the process of informed consent. It should give you the basic idea of what the research is about and what your participation will involve. For further details about this study, or to have your questions addressed please contact us. Please take the time to read this carefully and to understand any accompanying information. If you choose to participate, please keep your copy of this form and return the study copy (signed and witnessed) to the research coordinator.

\section{BACKGROUND}

Participation in rock climbing has grown in global popularity in recent years. In February 2010, the International Federation of Sport Climbing (IFSC) was officially recognized by the International Olympic Committee $(\mathrm{IOC})$ as a part of the Olympic Family, and is pursuing the addition of climbing as an Olympic sport for the 2020 Summer Games. Although there has been some research describing sport climbing injuries in adults, few studies have examined injury rates and risk factors for injury in youth sport climbers and boulderers. Some of today's youth rock climbing participants will aspire to one day represent this sport in the Olympics. The expected increase in participation will inevitably result in a greater number of injuries and in time loss from activity. This will increase the public health burden of climbing injuries and healthcare providers will require familiarity with climbing injuries in order to recognize and manage these injuries specific to a pediatric population. This study will examine the incidence of injury, injury types, and their mechanisms in young sport climbers and boulderers. Potential risk factors for injuries will also be examined. By increasing knowledge about climbing injury types and risk factors, injury in this sport may become more predictable and prevention strategies developed and evaluated accordingly in the future. 


\section{WHAT IS THE PURPOSE OF THE STUDY?}

The purpose of this study is to examine the burden of injury in 11 to 19 year-old recreational and elite sport climbers and boulderers. The objectives are to examine the incidence rates, types of climbing injuries, and to identify potential risk factors for climbing injury in youth.

\section{WHAT WOULD MY CHILD HAVE TO DO?}

We will be recruiting 206 young climbers in Alberta from several different climbing facilities. Climbers agreeing to participate in this study will be asked to complete an anonymous questionnaire (approximately 10 minutes will be required to complete it). The questionnaire examines the climber's previous one year of sport participation and sport injuries.

\section{DOES MY CHILD HAVE TO PARTICIPATE?}

No, your child does not have to participate.

WILL THERE BE FINANCIAL COMPENSATION, OR WILL THERE BE COSTS FOR THE PARTICIPANT? There will be no financial compensation to the child or costs to the child as a participant in this study.

\section{WILL MY CHILD'S RECORDS BE KEPT PRIVATE?}

All of the information collected from the questionnaire will be anonymous and will remain strictly confidential. Only the investigators responsible for this study, the research assistants who will be administering the questionnaire, the statistician who will analyze the data and the University of Calgary, Conjoint Health Research Ethics Board will have access to this information. Confidentiality will be protected by using a study identification number in the database. Any results of the study, which are reported, will in no way identify study subjects.

\section{SIGNATURES}

Your signature on this form indicates that you have understood to your satisfaction the information regarding your child's participation in the research project and agree to their participation as a subject. In no way does this waive your legal rights nor release the investigators, or involved institutions from their legal and professional responsibilities. You are free to withdraw your child from the study at any time. If you have further questions concerning matters related to this research, please contact:

$$
\text { Dr. Carolyn Emery (403) 220-4608 }
$$

or

Nani Woollings (403) 210-8961

If you have any questions concerning your rights as a possible participant in this research, please contact The Chair of the Conjoint Health Research Ethics Board at the Office of Medical Bioethics, at 403-220-7990. 


\section{CONSENT FOR YOUTH ROCK CLIMBING INJURY STUDY}

Email address:

PARENT/GUARDIAN'S NAME (PRINTED)

CHILD'S NAME (PRINTED)

INVESTIGATOR/DELEGATE'S NAME

(PRINTED)
Phone number:

SIGNATURE AND DATE

SIGNATURE AND DATE

SIGNATURE AND DATE

SIGNATURE AND DATE

\begin{tabular}{l} 
SIGNATURE AND DATE \\
\hline SIGNATURE AND DATE
\end{tabular}

The investigator or a member of the research team will, as appropriate, explain to your child the research and his or her involvement. They will seek your child's ongoing cooperation throughout the study.

The University of Calgary Conjoint Health Research Ethics Board has approved this research study.

\section{PLEASE SIGN THIS PAGE AND RETURN THE FULL DOCUMENT TO THE RESEARCH COORDINATOR. *KEEP THE OTHER COPY FOR YOUR RECORDS*}


APPENDIX E: CHILD ASSENT FORM (UNDER 18-YEAR-OLDS) 
Room 3300D, Sport Medicine Centre University of Calgary

\title{
CHILD ASSENT FORM \\ TITLE: Youth Rock Climbing Injury Study
}

SPONSOR: Sport Injury Prevention Centre, Roger Jackson Sport Medicine Centre, University of Calgary

\author{
INVESTIGATORS: \\ PRINCIPAL INVESTIGATOR: DR. CAROLYN EMERY, UNIVERSITY OF CALGARY \\ CO-INVESTIGATORS (UNIVERSITY OF CALGARY): NANI WOOLLINGS, DR. CARLY MCKAY, \\ DR. JIAN KANG, DR. WILLEM MEEUWISSE
}

This consent form is only part of the process of informed consent. It should give you the basic idea of what the research is about and what your participation will involve. For further details about this study, or to have your questions addressed please contact us. Please take the time to read this carefully and to understand all attached information. If you choose to participate, please keep your copy of this form and return the study copy (signed) to the research coordinator.

\section{BACKGROUND}

Participation in rock climbing has grown in global popularity in recent years. In February 2010, the International Federation of Sport Climbing (IFSC) was officially recognized by the International Olympic Committee (IOC) as a part of the Olympic Family, and is pushing for the addition of climbing as an Olympic sport for the 2020 Summer Games. Although there has been some research about sport climbing injuries in adults, few studies about injury rates and risk factors for injury in youth sport climbers and boulderers have been done. Some of today's youth rock climbing participants will be hoping to one day represent this sport in the Olympics. The expected increase in participation will certainly result in a greater number of injuries and in time loss from activity. Professionals, such as doctors, who treat climbing injuries should be able to recognize and manage these injuries. By increasing what we know about climbing injury types and risk factors, injury in this sport may become more predictable and we can begin to prevent these injuries in the future.

\section{WHAT IS THE PURPOSE OF THE STUDY?}

The purpose of this study is to learn about the impact of injury in 11 to 19 year-old recreational and competitive sport climbers and boulderers. Incidence rates, types of climbing injuries, and potential risk factors for climbing injury in youth will be studied. 


\section{WHAT WOULD I HAVE TO DO?}

We will be recruiting 206 young climbers in Alberta from several different climbing gyms. Climbers agreeing to take part in this study will be asked to fill out an anonymous questionnaire (about 10 minutes will be required to complete it). The questionnaire asks about your last one year of sport participation and sport injuries.

\section{DO I HAVE TO PARTICIPATE?}

No, you do not have to participate.

\section{WILL I BE PAID FOR BEING IN THE STUDY, OR WILL I HAVE TO PAY FOR ANYTHING?}

You will not be paid for being in the study, and you will not have to pay to participate.

\section{WILL MY RECORDS BE KEPT PRIVATE?}

The questionnaire will not require any names, and all of the information collected will remain private. Only the investigators responsible for this study, the research assistants who will be giving the questionnaire, the statistician who will analyze the data and the University of Calgary, Conjoint Health Research Ethics Board will have access to this information. Using only a study identification number in the database will protect privacy. The reported results of the study will not identify you in any way.

\section{SIGNATURES}

Your signature on this form means that you have understood the information about taking part in the research project and agree to be a subject. This does not waive your legal rights nor release the investigators, or involved institutions from their legal and professional responsibilities. You are free to leave the study at any time. If you have more questions related to this research, please contact:

$$
\text { Dr. Carolyn Emery (403) 220-4608 }
$$

\section{or}

Nani Woollings (403) 210-8961

If you have any questions about your rights as a possible participant in this research, please contact The Chair of the Conjoint Health Research Ethics Board, University of Calgary, at 403-220-7990. 
ASSENT FOR YOUTH ROCK CLIMBING INJURY STUDY

CHILD'S NAME (PRINTED)

INVESTIGATOR/DELEGATE'S NAME

(PRINTED)
SIGNATURE AND DATE

SIGNATURE AND DATE

The University of Calgary Conjoint Health Research Ethics Board has approved this research study.

\section{PLEASE SIGN THIS PAGE AND KEEP ONE COPY FOR YOUR RECORDS}


APPENDIX F: ADULT CONSENT FORM (18- \& 19-YEAR-OLDS) 


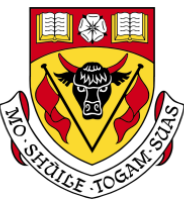

UNIVERSITY OF
Sport Injury Prevention

Research Centre

$\overline{\text { UNIVERSITY OF CALGARY }}$

Room 3300D, Sport Medicine Centre University of Calgary 2500 University Dr NW Calgary, AB T2N 1N4

\title{
CONSENT FORM (18 \& 19 YEAR-OLDS) TITLE: Youth Rock Climbing Injury Study
}

SPONSOR: Sport Injury Prevention Centre, Roger Jackson Sport Medicine Centre, University of Calgary

\author{
INVESTIGATORS: \\ PRINCIPAL INVESTIGATOR: DR. CAROLYN EMERY, UNIVERSITY OF CALGARY \\ CO-INVESTIGATORS (UNIVERSITY OF CALGARY): NANI WOOLLINGS, DR. CARLY MCKAY, \\ DR. JIAN KANG, DR. WILLEM MEEUWISSE
}

This consent form is only part of the process of informed consent. It should give you the basic idea of what the research is about and what your participation will involve. For further details about this study, or to have your questions addressed please contact us. Please take the time to read this carefully and to understand any accompanying information. If you choose to participate, please keep your copy of this form and return the study copy (signed and witnessed) to the research coordinator.

\section{BACKGROUND}

Participation in rock climbing has grown in global popularity in recent years. In February 2010, the International Federation of Sport Climbing (IFSC) was officially recognized by the International Olympic Committee (IOC) as a part of the Olympic Family, and is pursuing the addition of climbing as an Olympic sport for the 2020 Summer Games. Although there has been some research describing sport climbing injuries in adults, few studies have examined injury rates and risk factors for injury in youth sport climbers and boulderers. Some of today's youth rock climbing participants will aspire to one day represent this sport in the Olympics. The expected increase in participation will inevitably result in a greater number of injuries and in time loss from activity. This will increase the public health burden of climbing injuries and healthcare providers will require familiarity with climbing injuries in order to recognize and manage these injuries specific to a pediatric population. This study will examine the incidence of injury, injury types, and their mechanisms in young sport climbers and boulderers. Potential risk factors for injuries will also be examined. By increasing knowledge about climbing injury types and risk factors, injury in this sport may become more predictable and prevention strategies developed and evaluated accordingly in the future. 


\section{WHAT IS THE PURPOSE OF THE STUDY?}

The purpose of this study is to examine the burden of injury in 11 to 19 year-old recreational and elite sport climbers and boulderers. The objectives are to examine the incidence rates, types of climbing injuries, and to identify potential risk factors for climbing injury in youth.

\section{WHAT WOULD I HAVE TO DO?}

We will be recruiting 206 young climbers in Alberta from several different climbing facilities. Climbers agreeing to participate in this study will be asked to complete an anonymous questionnaire (approximately 10 minutes will be required to complete it). The questionnaire examines the climber's previous one year of sport participation and sport injuries.

\section{DO I HAVE TO PARTICIPATE?}

No, you do not have to participate.

\section{WILL THERE BE FINANCIAL COMPENSATION, OR WILL THERE BE COSTS FOR ME?}

There will be no financial compensation to you or costs to you as a participant in this study.

\section{WILL MY RECORDS BE KEPT PRIVATE?}

All of the information collected from the questionnaire will be anonymous and will remain strictly confidential. Only the investigators responsible for this study, the research assistants who will be administering the questionnaire, the statistician who will analyze the data and the University of Calgary, Conjoint Health Research Ethics Board will have access to this information. Confidentiality will be protected by using a study identification number in the database. Any results of the study, which are reported, will in no way identify study subjects.

\section{SIGNATURES}

Your signature on this form indicates that you have understood to your satisfaction the information regarding your participation in the research project and agree to participate as a subject. In no way does this waive your legal rights nor release the investigators, or involved institutions from their legal and professional responsibilities. You are free to withdraw from the study at any time. If you have further questions concerning matters related to this research, please contact:

$$
\text { Dr. Carolyn Emery (403) 220-4608 }
$$

or

Nani Woollings (403) 210-8961

If you have any questions concerning your rights as a possible participant in this research, please contact The Chair of the Conjoint Health Research Ethics Board at the Office of Medical Bioethics, at 403-220-7990. 


\section{CONSENT FOR YOUTH ROCK CLIMBING INJURY STUDY}

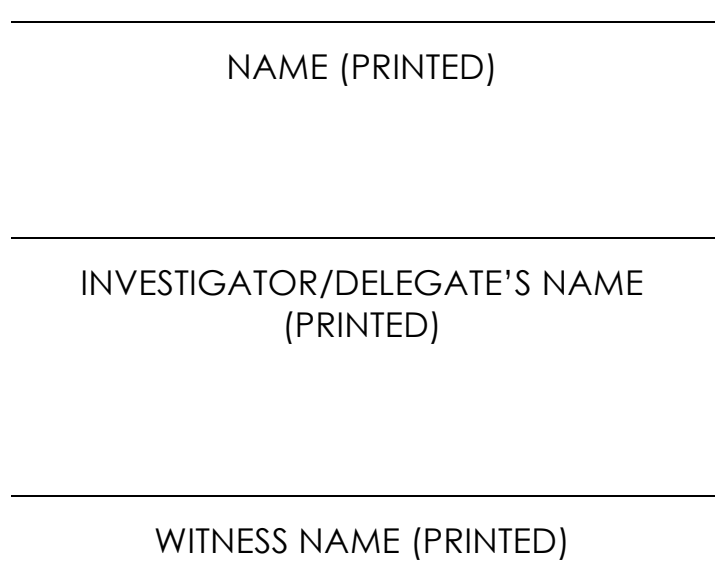

WITNESS NAME (PRINTED)
SIGNATURE AND DATE

SIGNATURE AND DATE

SIGNATURE AND DATE

The investigator or a member of the research team will, as appropriate, explain to you the research and your involvement. They will seek your ongoing cooperation throughout the study.

The University of Calgary Conjoint Health Research Ethics Board has approved this research study.

\section{PLEASE SIGN THIS PAGE AND RETURN THE FULL DOCUMENT TO THE RESEARCH COORDINATOR. *KEEP THE OTHER COPY FOR YOUR RECORDS*}


APPENDIX G: STUDY QUESTIONNAIRE 


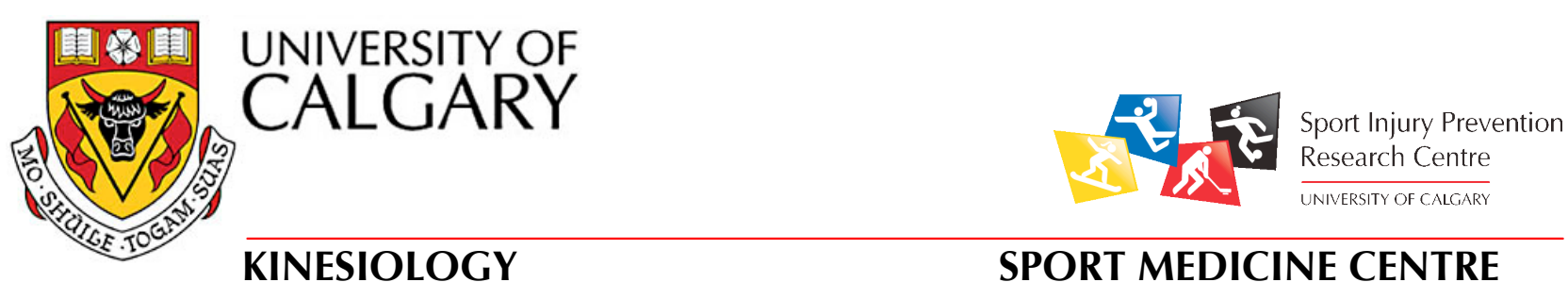

October 2012

You are being invited to complete an online survey by Dr. Carolyn Emery, from the Sport Injury Prevention Research Centre at the University of Calgary.

We would like to find out about injury in youth climbers. This information will help us to make climbing injuries more predictable in the future, so that we can eventually begin to prevent them.

Completing this survey is voluntary, and will only take 10-15 minutes of your time. All responses are anonymous (we do not need your name). Choosing to respond or not to respond will have no consequences to you.

If you have questions or concerns before filling out the survey, or if you would like to provide feedback after completing it, please contact the research coordinator Nani Woollings at 403-210-8961 or kylwooll@ucalgary.ca.

Thank you for your time, and for your support of our research.

Sincerely,

Carolyn Emery, PhD

Associate Professor

Faculty of Kinesiology

Community Health Sciences and Pediatrics

Faculty of Medicine

Phone: 403-220-4608 (w)

Email: caemery@ucalgary.ca 


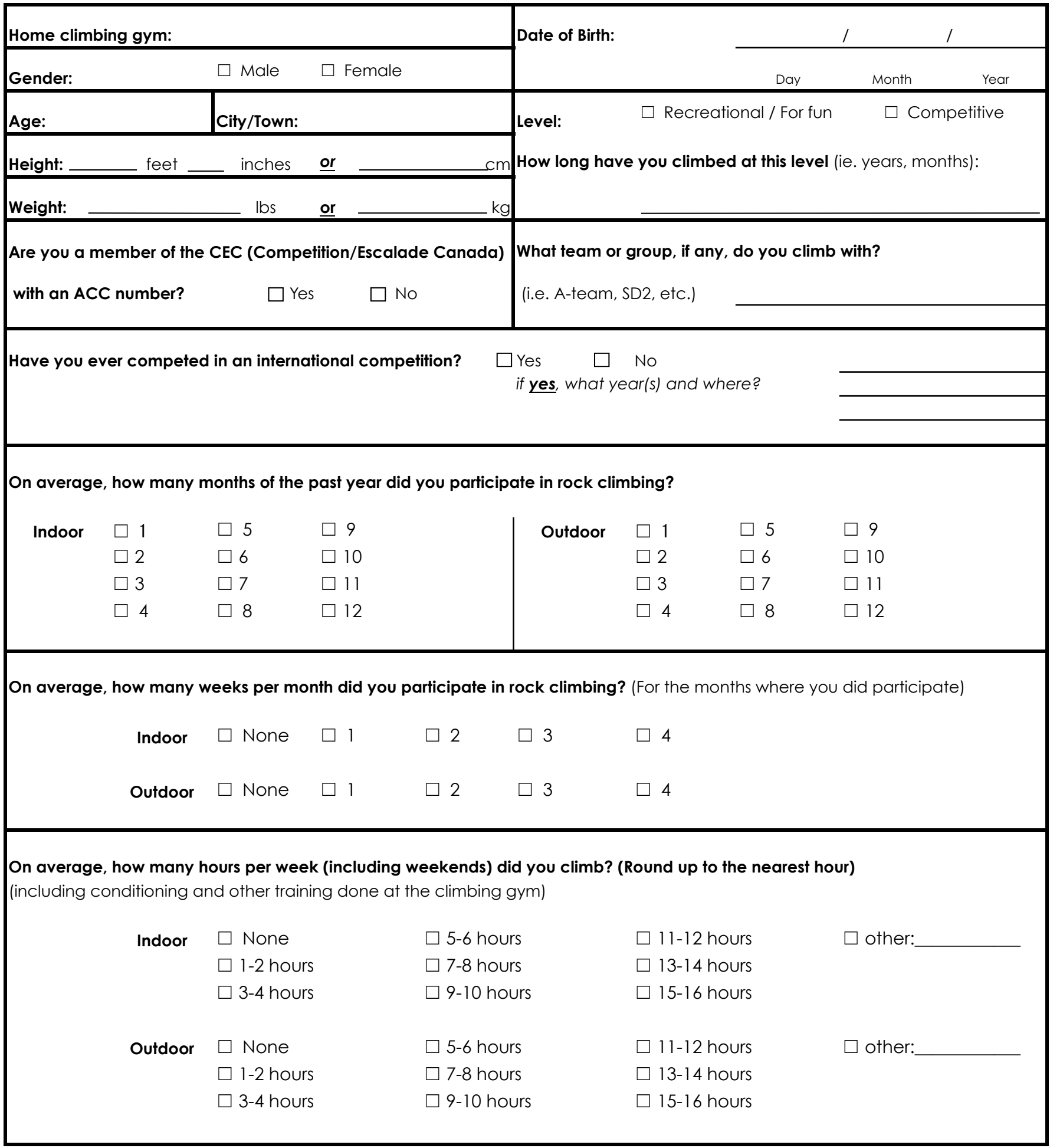




On average, how long does one climbing session last for you?
\[ \begin{aligned} \text { Indoor } & \square \text { less than 1 hour } & \square \text { 5-6 hours } \\ & \square \text { 1-2 hours } & \square \text { 7-8 hours } \\ & \square \text { 3-4 hours } & \square \text { other: } \\ & & \\ \text { Outdoor } & \square \text { less than 1 hour } & \square \text { 5-6 hours } \\ & \square \text { 1-2 hours } & \square \text { 7-8 hours } \\ & \square \text { 3-4 hours } & \square \text { other: }\end{aligned} \]

What is the hardest red-point grade that you have sport climbed (hardest grade on any route, without falls)?

(You may have a coach or parent help You with this question. Please list only ONE grade.)

Write N/A if you don't sport climb, or 'not familiar' if you are not familiar with sport climbing grades.

What is the hardest red-point grade that you have bouldered (hardest grade on any problem, without falls)?

(You may have a coach or parent help You with this question. Please list only ONE grade.)

Write N/A if you don't boulder, or 'not familiar' if you are not familiar with bouldering grades.

Please list other gyms and outdoor locations that you climb at regularly.

\section{INJURY AND MEDICAL HISTORY:}

In the past year (12 months), have you had an injury while climbing?

(This includes training and conditioning for climbing and bouldering, belaying, and approaches to, or descents from climbs.)
$\square$ Yes
$\square$ No
if yes, please list:

\begin{tabular}{|c|c|c|c|c|c|c|c|}
\hline Injury Date & Injury Type & Climbing Type & Venue & Body Part & Climbing time loss & Treatment (if any) & How were you injured? \\
\hline ie. (month, year) & sprain, bruise, etc. & $\begin{array}{l}\text { bouldering, } \\
\text { sport, etc. }\end{array}$ & indoor/outdoor & $\begin{array}{l}\text { pulley tendon, } \\
\text { shoulder, etc. }\end{array}$ & $\begin{array}{l}1 \text { day, } 3 \text { weeks, } \\
\text { none, etc }\end{array}$ & $\begin{array}{c}\text { none, first aid, Dr., chiropractor, } \\
\text { physio, massage, other }\end{array}$ & $\begin{array}{l}\text { fall, repetitive overuse, } \\
\text { strenuous move, etc }\end{array}$ \\
\hline \multicolumn{8}{|l|}{1} \\
\hline \multicolumn{8}{|l|}{2} \\
\hline \multicolumn{8}{|c|}{3} \\
\hline \multicolumn{8}{|l|}{4} \\
\hline \multicolumn{8}{|l|}{5} \\
\hline \multicolumn{8}{|c|}{6} \\
\hline \multicolumn{8}{|c|}{7} \\
\hline \multicolumn{8}{|c|}{8} \\
\hline \multicolumn{8}{|l|}{9} \\
\hline 10 & & & & & & & \\
\hline
\end{tabular}

Were any of these injuries re-injuries?
$\square$ Yes
$\square \quad$ No
if yes, please list which (\#'s): 
In the past year (12 months), have you had any pain, discomfort, or physical problems during climbing that you did not list above?

Yes $\square$ No

if yes, please list and describe:

\begin{tabular}{|c|c|c|c|c|c|c|}
\hline Date & Climbing Type & Venue & Body Part & Climb time los: & Treatment (if any) & Please describe \\
\hline ie. (month, year) & $\begin{array}{l}\text { bouldering, } \\
\text { sport, etc. }\end{array}$ & indoor/outdoor & $\begin{array}{l}\text { pulley tendon, } \\
\text { shoulder, etc. }\end{array}$ & $\begin{array}{c}1 \text { day, } 3 \text { weeks, } \\
\text { none, etc }\end{array}$ & $\begin{array}{c}\text { none, first aid, Dr., chiropractor, } \\
\text { physio, massage, other }\end{array}$ & \\
\hline 1 & & & & & & \\
\hline 2 & & & & & & \\
\hline 3 & & & & & & \\
\hline 4 & & & & & & \\
\hline 5 & & & & & & \\
\hline
\end{tabular}

In the past year (12 months), how many months, weeks and hours per week (on average) did you participate in a school PE class?

number of months

number of weeks

hours per week

Based on the past year (12 months), did you participate in any sports on a weekly basis (NOT including PE class or climbing)?

$\square$ Yes $\square$ No

If yes, please estimate the average number of hours per week you participated in each sport:

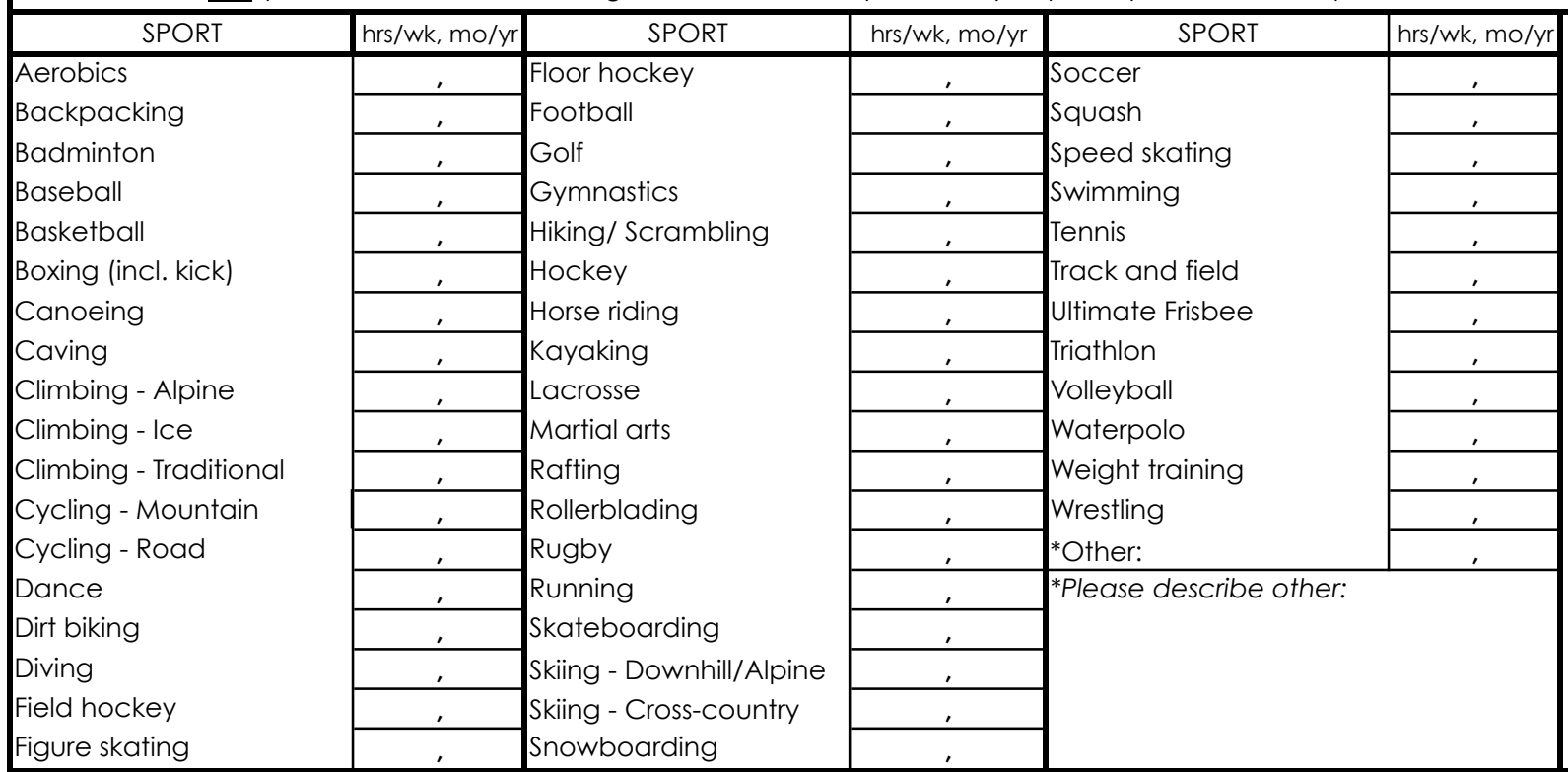

In the past year (12 months), have you had an injury while participating in a sport other than climbing?

$\square$ Yes $\square$ No

\begin{tabular}{|l|c|c|c|c|c|}
\hline \multicolumn{1}{|c|}{ Injury Date } & Injury Type & Sport & Body Part & Sport time loss & Treatment (if any) \\
\hline ie. (month, year) & sprain, bruise, fracture, etc. & $\begin{array}{c}\text { Basketball, } \\
\text { sking, etc. }\end{array}$ & $\begin{array}{c}\text { Head, nose, } \\
\text { lower leg, etc. }\end{array}$ & $\begin{array}{c}\text { 1 day, 3 weeks, } \\
\text { none, etc }\end{array}$ & $\begin{array}{c}\text { none, first aid, Dr., chiropractor, } \\
\text { physio, massage, other }\end{array}$ \\
\hline 1 & & & & & \\
\hline 2 & & & & & \\
\hline 3 & & & & & \\
\hline 5 & & & & & \\
\hline 6 & & & & & \\
\hline
\end{tabular}




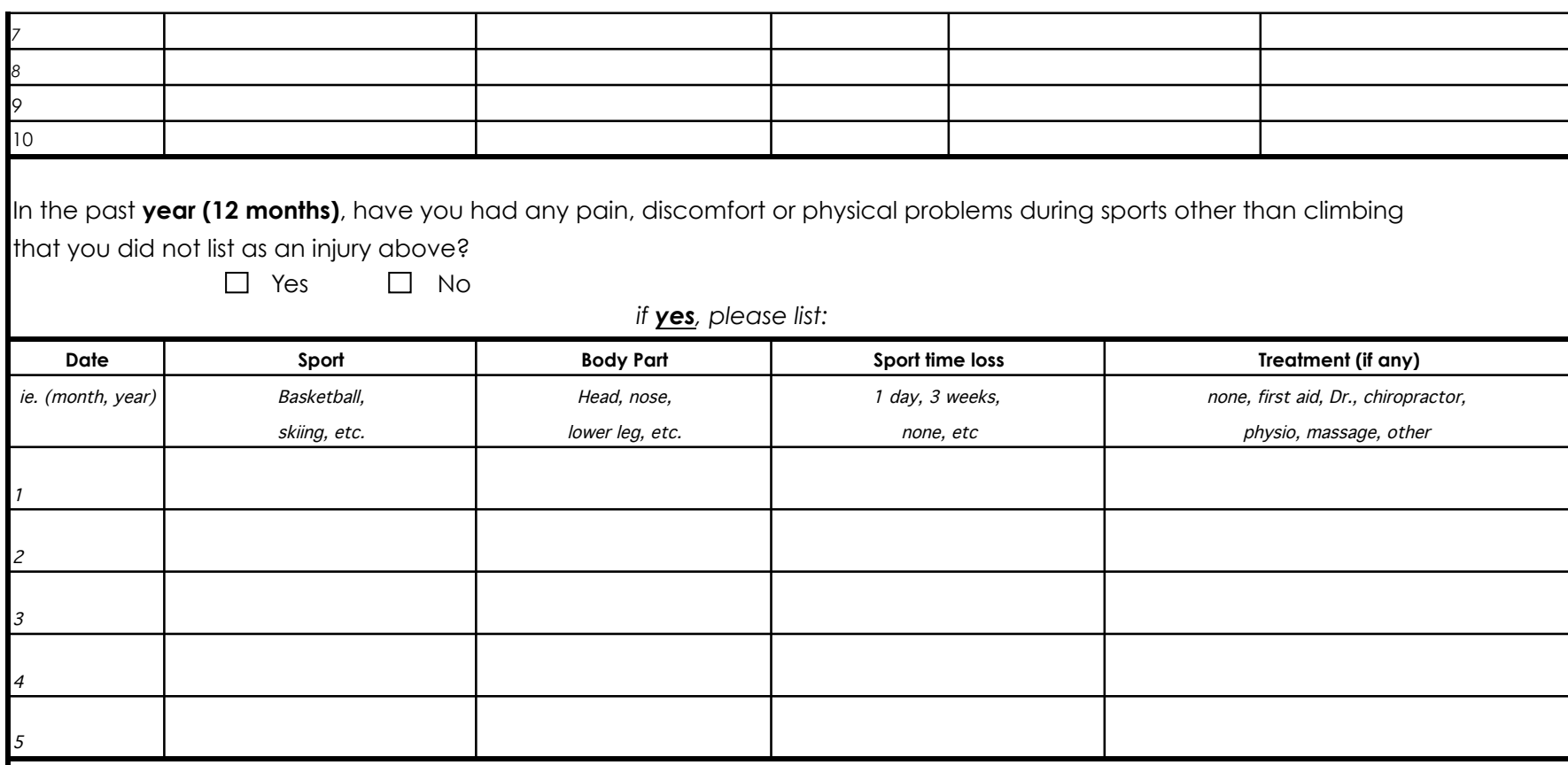

\section{SAFETY AND INJURY PREVENTION:}

Please mark (on the line) how often you wear a helmet. (What percentage of the time?) For each type of climbing below:

$\begin{array}{llcccc}\text { Indoor Sport Climbing } & \text { Never } & 25 \% & 50 \% & 75 \% & \text { Always } \\ \text { Outdoor Sport Climbing } & \text { Never } & 25 \% & 50 \% & 75 \% & 75 \% \\ \text { Indoor Bouldering } & \text { Never } & 25 \% & 50 \% & \text { Always } \\ \text { Outdoor Bouldering } & \text { Never } & 25 \% & 50 \% & 75 \% \text { Always }\end{array}$

Have you ever taken a formal climbing course (including junior team training)?

$$
\square \text { Yes } \square \text { No }
$$

If yes, did the course include safety instruction?
$\square$ Yes
$\square$ No

Have you learned safety practices from elsewhere?

$$
\square \text { Yes } \square \text { No }
$$

If yes, where from? (choose as many as you like)
$\square$ Other climber
$\square$ Internet
PE or outdoor ed. teacher
$\square$ Parent
Television
$\square$ Other (describe):

Do you use preventative measures for reducing injury (i.e. taping fingers to prevent tendon pulley injuries)?

- Note: This does not include helmet or harness/climbing equipment use.
$\square$ Yes
$\square \quad$ No

If yes, what? (choose as many as you like)
$\square$ Finger tendon taping
Ankle taping
Skin taping
$\square$ Wrist taping
$\square$ Shoulder taping
$\square$ Other (describe): 
In the last 12 months, did you usually warm up before climbing?

That is, did you do at least 5 minutes of gentle exercise or easy climbing before beginning more difficult climbing skills?

$\square$ Yes $\square$ No

In the last 12 months, did you usually cool down after climbing?

That is, after you finished climbing or training, did you slow down gradually / finish with gentle, easy climbing?

$$
\square \text { Yes } \square \text { No }
$$

\section{DEMOGRAPHICS AND BEHAVIOUR:}

How many computers does your family own?

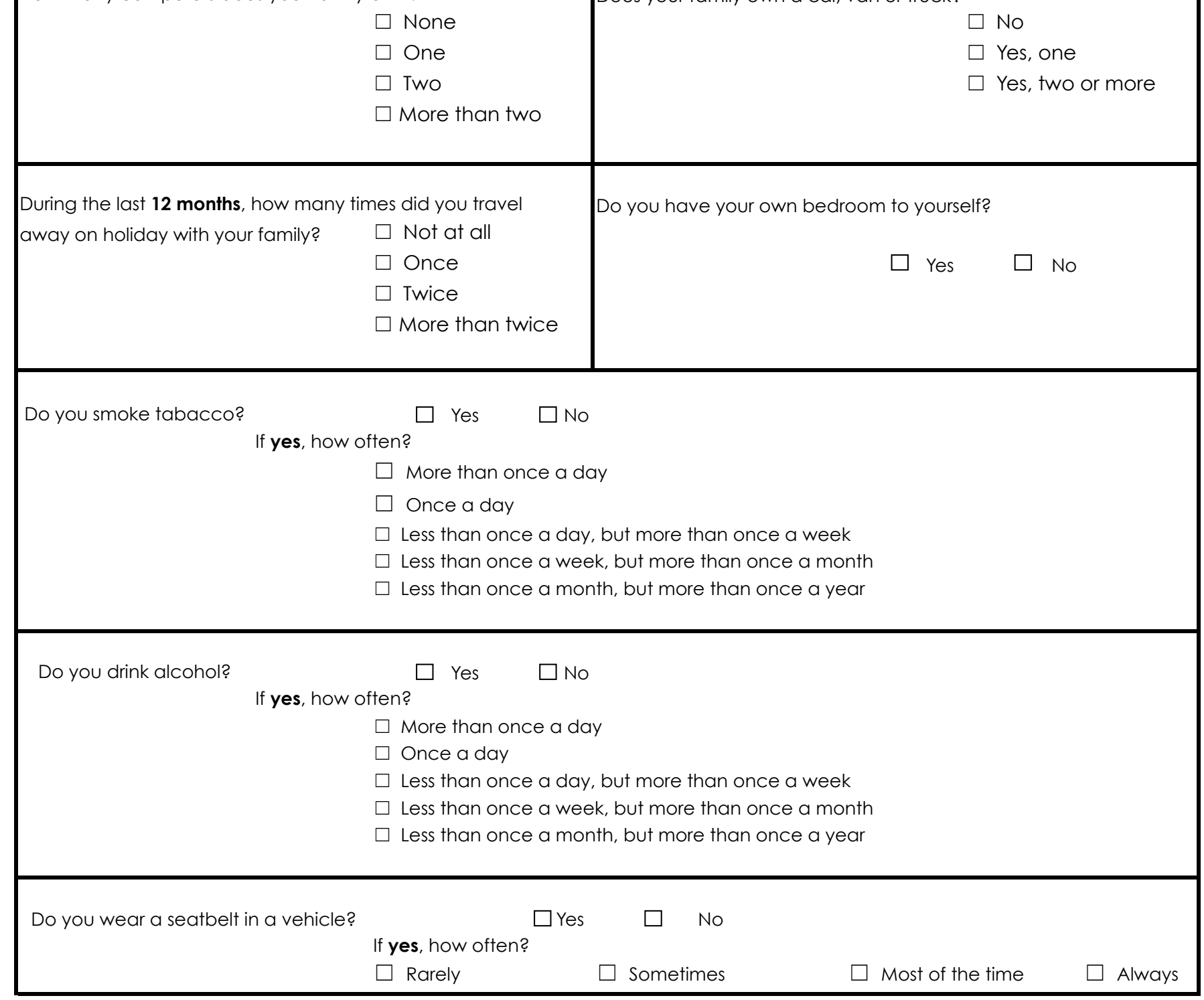

Does your family own a car, van or truck? 